University of Louisville

ThinkIR: The University of Louisville's Institutional Repository

$12-2012$

\title{
Second year college experiences that affect persistence and attrition for first generation and continuing generation students at small, private institutions.
}

Angela Brown Taylor

University of Louisville

Follow this and additional works at: https://ir.library.louisville.edu/etd

\section{Recommended Citation}

Taylor, Angela Brown, "Second year college experiences that affect persistence and attrition for first generation and continuing generation students at small, private institutions." (2012). Electronic Theses and Dissertations. Paper 1420.

https://doi.org/10.18297/etd/1420

This Doctoral Dissertation is brought to you for free and open access by ThinkIR: The University of Louisville's Institutional Repository. It has been accepted for inclusion in Electronic Theses and Dissertations by an authorized administrator of ThinkIR: The University of Louisville's Institutional Repository. This title appears here courtesy of the author, who has retained all other copyrights. For more information, please contact thinkir@louisville.edu. 
SECOND YEAR COLLEGE EXPERIENCES THAT AFFECT PERSISTENCE AND ATTRITION FOR FIRST GENERATION AND CONTINUING GENERATION STUDENTS AT SMALL. PRIVATE INSTITUTIONS

By

Angela Brown Taylor

B.A., Georgetown College, 2003

M.Ed., University of Louisville, 2006

A Dissertation Submitted to the Faculty of the

College of Education and Human Development of the University of Louisville In Partial Fulfillment of the Requirements

For the Degree of

Doctor of Philosophy

College of Education and Human Development

University of Louisville

Louisville, KY

December 2012 
Copyright 2012 by Angela Brown Taylor

All rights reserved 


\section{SECOND YEAR COLLEGE EXPERIENCES THAT AFFECT PERSISTENCE AND ATTRITION FOR FIRST GENERATION AND CONTINUING GENERATION STUDENTS AT SMALL, PRIVATE INSTITUTIONS}

\section{By}

Angela Brown Taylor

B.A., Georgetown College, 2003

M.Ed., University of Louisville, 2006

A Dissertation Approved on

November 8, 2012

By the following Dissertation Committee:

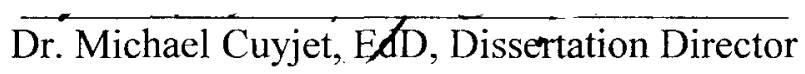

Dn Amy Hirschy, $\mathrm{hb}$

Br. Joseph Petrosko, PhD

Dr. Bridgette Pregliasc $\varnothing, \overline{\mathrm{EdD}}$ 


\section{DEDICATION}

This dissertation is dedicated to my family—my husband, Steve Taylor, for encouraging me to follow my dreams; my parents, Danny and Debby Brown, for having confidence in me, and my son, Spencer George Taylor, for reminding me why I get up in the morning every day. 


\section{ACKNOWLEDGEMENTS}

I would like to thank my dissertation director, Dr. Michael Cuyjet, for guidance, support, and patience. I would also like to thank my other committee members, Dr. Amy Hirschy, Dr. Bridgette Pregliasco, and Dr. Joseph Petrosko, for their commitment to my success. My husband of 7+ years has always supported me in my work and my education-the support during the writing of this dissertation was no different. Much thanks to him for his understanding and love. Many thanks are expressed to my parents, Danny and Debby Brown, for their belief in me. I also would like to thank my sisters and their families-Valerie and Jerry Penders; Melanie, Chris and Hazel French; and Emily May Brown-your support and encouragement has meant a lot to me. Finally, I want to thank my son, Spencer George Taylor, your smiles, laughs, and coos motivated me to finish my degree. 


\section{ABSTRACT \\ SECOND YEAR COLLEGE EXPERIENCES}

Angela Brown Taylor

November 8, 2012

The persistence and attrition of second year college students is a growing concern of colleges and universities as second year college students face some of the greatest challenges (Gahagan \& Hunter, 2006; Lemons \& Richmond, 1987; Morgan \& Davis, 1981; Wilder, 1993). This study examined the factors that predict second year student persistence for students who have enrolled at private institutions in the state of Kentucky. This study reviewed those pre-entry variables that predict persistence beyond the second year. Students were surveyed (during the end of) their fourth semester in college. Spady's (1970b) model of student dropout and Tinto's (1975) model of student departure served as the theoretical foundation for this study.

The participants in this study consisted of full-time, second year students who were completing their fourth semester of academic work. This research was a quantitative predictive study that used data collected by administering the Sophomore Experiences Survey via the Internet. This predictive study examined the relationship between predictor variables including pre-college characteristics, scores on the Thriving Quotient in the Sophomore Experiences Survey, and campus experiences and perceptions and the criterion variables of the student's intent to re-enroll after their fourth semester of their 
second year and intent to graduate from college. Hierarchical logistic regression was used to measure the predictive nature and magnitude of the relationship between the variables in the first five research questions. The sixth and seventh research questions constituted a comparative study. Cross tabulations and chi-square statistics were used to address each of these questions. 


\section{TABLE OF CONTENTS}

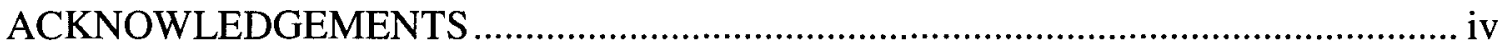

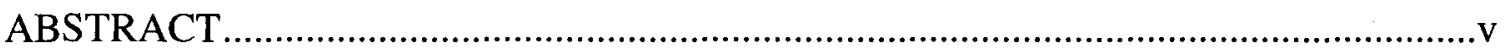

LIST OF TABLES

\section{CHAPTER}

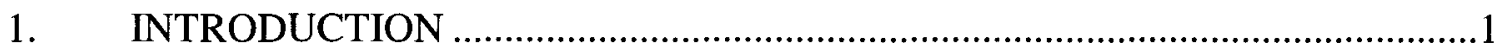

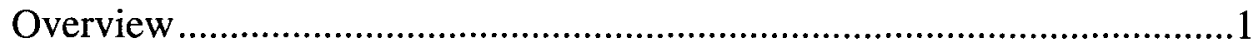

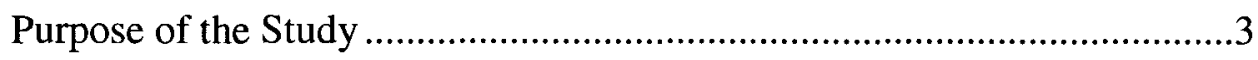

Problem Statement ..................................................................................

Rationale

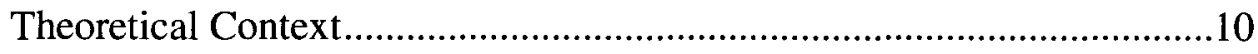

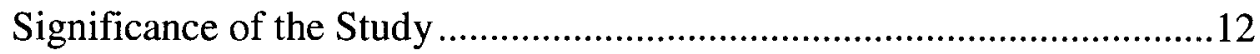

Research Questions and Hypotheses .....................................................14

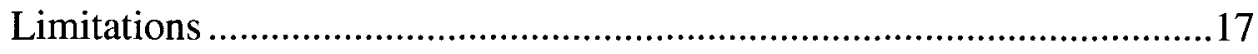

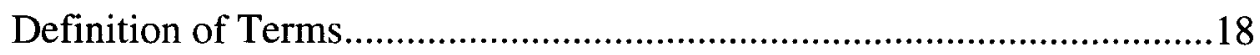

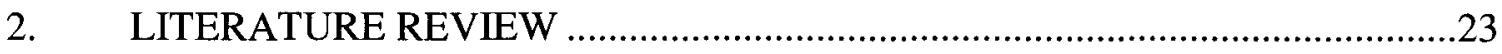

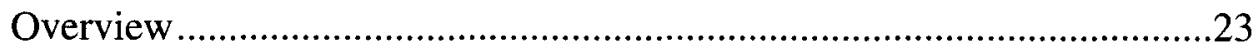

Spady's Model of Student Dropout ..........................................................24

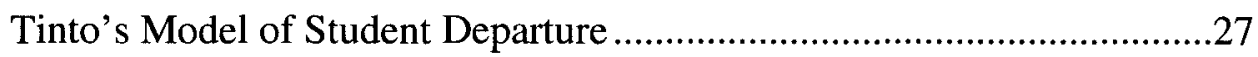

Schreiner's Understanding of Student Thriving ........................................31 
Spady's, Tinto's and Schreiner's Impact on the Conceptual

Model of this Study

College Student Persistence and Attrition .....................................................35

Factors that Impact College Student Attrition ............................................38

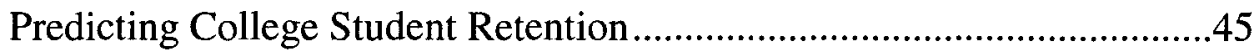

First Generation College Students ............................................................4

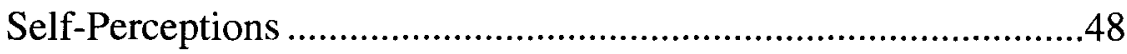

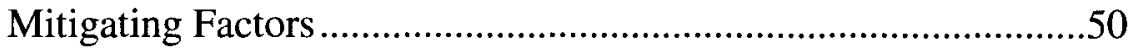

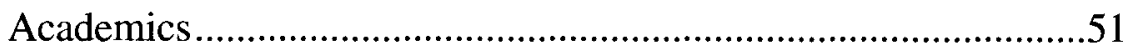

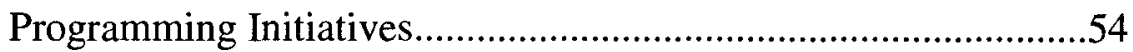

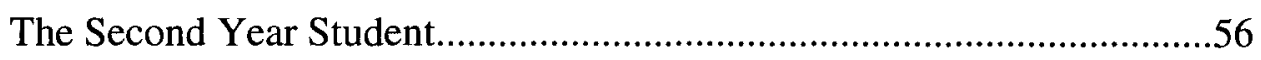

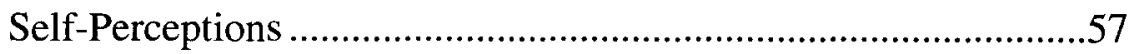

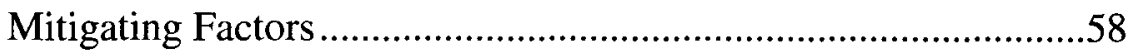

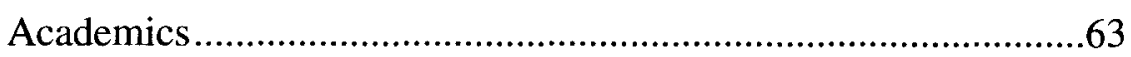

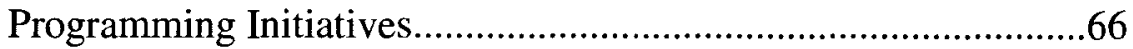

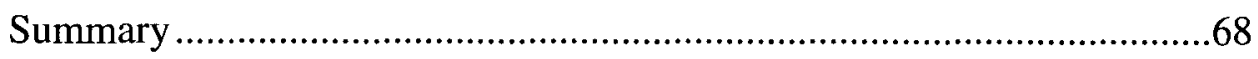

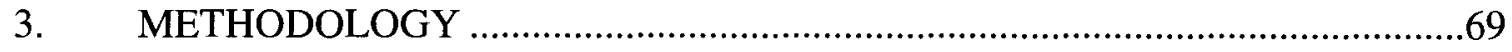

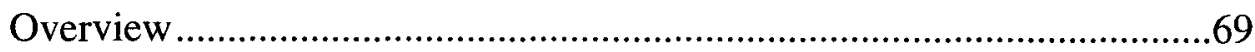

Population and Sample .........................................................................69

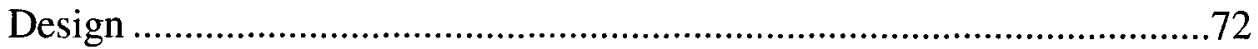

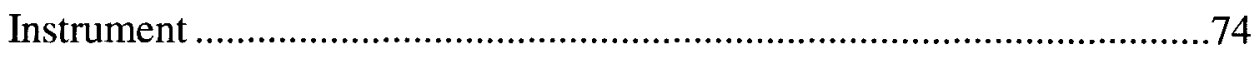

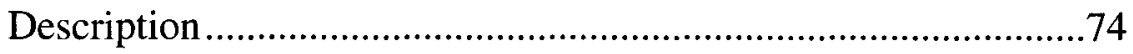

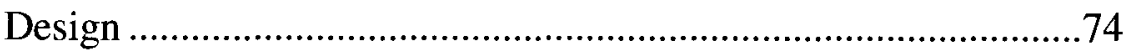


Sophomore Experiences Survey Thriving Quotient

Validity and Reliability...........................................................

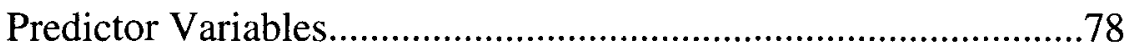

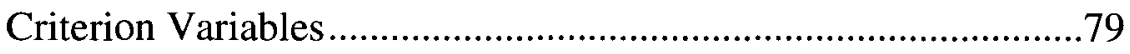

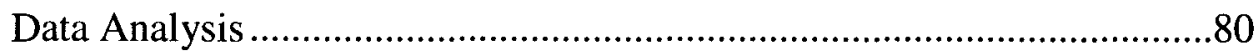

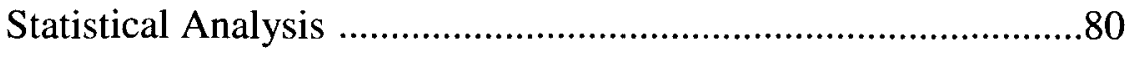

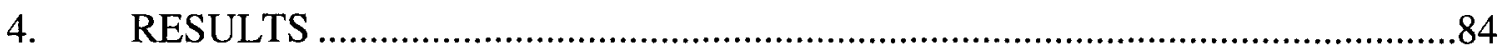

Descriptive Statistics on Survey Variables .................................................84

Scales Used in the Study and Their Reliability .........................................99

Statistical Analyses Addressing Research Questions One to Seven.........101

Summary of Statistical Analyses Addressing Research Questions ..........121

One to Seven

5. DISCUSSION, IMPLICATIONS, AND LIMITATIONS ………………..........125

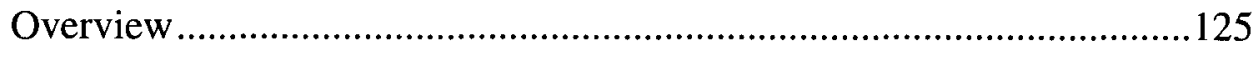

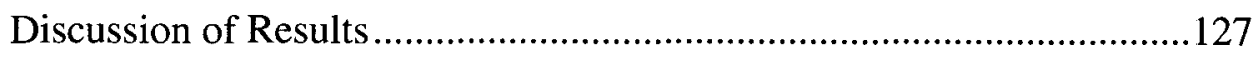

Demographic and Background Data...........................................127

The Thriving Quotient ...............................................................130

Experiences and Perceptions.....................................................132

First Generation and Continuing Generation Second Year .........134

College Students

Implications and Recommendations for Practitioners .............................138

Second Year College Student Attrition..........................................138

Second Year College Student Advising.......................................139

Partnering with Career Centers .....................................................140 
Examination and Assessment of Existing Campus Programs .....140

Recommendations for Future Research .........................................141

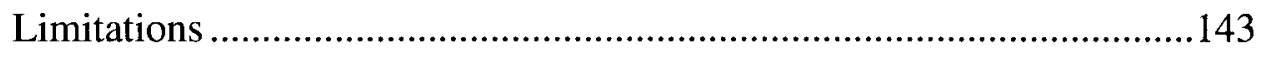

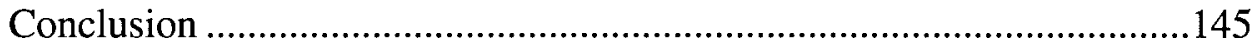

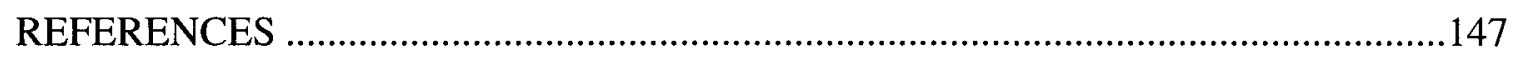

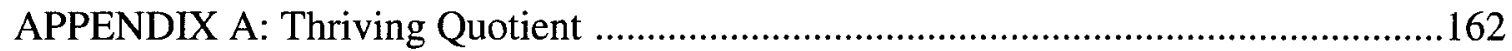

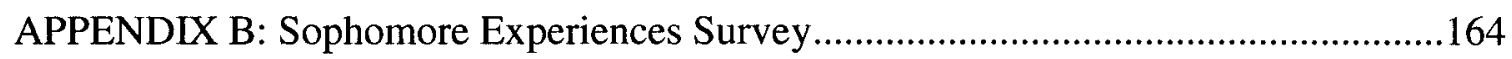

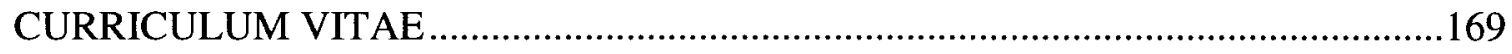




\section{LIST OF TABLES}

TABLE

PAGE

1 Comparison of the Four Institutions Studied in this Dissertation...............................70

2. Reliability Estimates for Five-Factor Model in the Sophomore Experiences ..............78 Survey

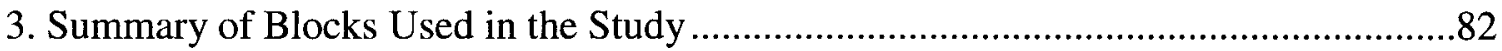

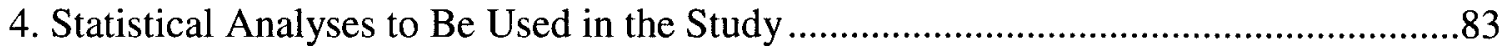

5. Frequency Distributions for Sex, Age, and Ethnic Group .....................................87

6. Frequency Distributions for Enrollment Status and College ....................................88

7. Descriptive Statistics for Number of College Credits Student Earned .......................89 (Including this Semester) and Number of Credits Student is Taking this Semester

8. Frequency Distribution for Responses to the Item "What is the Level of ...................91 Education for Your Parent Who has the Highest Level of Education?"

9. Frequency Distribution for Responses to Item Asking the Highest Level of .92 Education to Which the Student Aspires

10. Frequency Distributions for Responses to Items on Grades the First Year . .93 of College and Grades in the Second Year of College

11. Frequency Distributions for Responses to Items On How Many Hours .94 per Week the Student Worked In An Off-Campus Job Or An On-Campus Job 
12. Frequency Distribution for Responses to Item Asking

"How Sure Are You of Your College Major?”

13. Frequency Distributions for Responses to Items Asking .96

"Compared to Your First Year of College, This Year Has Been:" And "Compared to The Courses You Took In Your First Year of College, The Courses This Year Have Been."

14. Frequency Distributions for Responses to Items

“I Intend to Re-enroll Next Year At the Institution I Am Currently Attending" And "I Intend To Graduate From College And Obtain My Bachelor's Degree"

15. Frequency Distributions for Responses to Items "How Many Courses .98 Have You Dropped or Withdrawn From Since Beginning College at Your Current Institution?” And “In How Many Courses Have You Received a Grade Below C Since Beginning College at Your Current Institution?”

16. Cronbach's Alpha Internal Consistency Reliability Coefficients for the 101

Four Scales Measuring Attitudes and Experiences of Second Year College

Students

17. Descriptive Statistics for the Four Scales Measuring 101 Attitudes and Experiences of Second Year College Students

18. Frequency Distributions for Intent to Re-enroll and Intent to Graduate.

19. Statistically Significant Demographic Predictor Variables of Intent to. 106 Re-Enroll: OLS and Logistic Regression

20. Statistically Significant Demographic Predictor Variables of. 107 Intent to Graduate: OLS and Logistic Regression 
21. Results of Adding Thriving Scale Average to Regression Models

Containing Demographic Variables Predicting Intent to Re-enroll and Intent to

Graduate

22. Results of Campus Experience and Perception Variables Predicting.

Intent to Re-enroll: Controlling For Demographic Variables And Thriving

Coefficient

23. Results of Campus Experience and Perception Variables Predicting. .112 Intent to Graduate: Controlling For Demographic Variables And Thriving Coefficient

24. Statistically Significant Predictors of Intent to Re-enroll for First 114 Generation and Continuing Generation Students: Ordinary Least Squares Regression

25. Statistically Significant Predictors of Intent to Re-enroll First Generation 115 and Continuing Generation Students: Logistic Regression

26. Statistically Significant Predictors of Intent to Graduate for First

Generation and Continuing Generation Students: Ordinary Least Squares

Regression

27. Statistically Significant Predictors of Intent to Graduate for First

Generation and Continuing Generation Students: Logistic Regression

28. Cross-tabulation of Intent to Re-enroll with First-Generation in

College Status

29. Cross-tabulation of Intent to Graduate with First-Generation in

College Status 
30. Research Questions, Analyses, and Key Results Pertaining to Variables

Associated with the Intention to Re-enroll in College and the Intention to

Graduate 


\section{CHAPTER I}

\section{INTRODUCTION}

\section{Overview}

Research reveals that the second year is a time in which many students face some of their greatest challenges in college (Gahagan \& Hunter, 2006; Lemons \& Richmond, 1987; Morgan \& Davis, 1981; Wilder, 1993). Freedman (1956) was the first to reveal that second year students were the least satisfied students during their collegiate years. In 1976, Margolis described the second year as a period of identity crisis involving a student's academic, social, and personal life. Later in 1982, Furr and Gannaway found that the second year experience for some college students was a "...period of confusion and uncertainty" that led to dissatisfaction (p. 340). Lemons and Richmond (1987), through the lens of Chickering, determined that challenges during some students' second year existed as they "...struggle[d] with achieving competence, desiring autonomy, establishing identity, and developing purpose" all of which are vectors in Chickering's model of student development (p. 18). Lemons and Richmond (1987) suggested that student affairs professionals must reach out to students to help them learn how to cope and adjust with developmental changes during the second year.

The Consortium for Student Retention Data Exchange (2003) revealed that nearly $81 \%$ of first-year students at 440 institutions returned to college for their second year but 
of those returners, only 70.7\% of those students returned for a third year (as cited in Lipka, 2006). These persistence concerns of college students must lead researchers to understand the factors that lead to attrition for second year students. For second year students, "financial hardships, academic concerns, and questions about their future goals and aspirations can become daunting issues" (Gahagan \& Hunter, 2006, p. 17). Lipka's (2006) data suggested that second year student attrition rates must be understood with hopes of creating cultural change that can lead to increased persistence rates for these students. Issues such as academic challenges and difficulties with determining future plans lead some second year students to dissatisfaction in college. These issues must be analyzed as they are of "...critical importance to the learning, retention, and success of sophomore" students (Gahagan \& Hunter, 2006, p. 17).

Gahagan and Hunter (2006) recommended educational reform in our colleges and universities in hopes of assisting second year students with their challenges. Some of these recommendations included committees devoted to understanding a specific institution's second year student population, intentionally seeking out second year students through developing initiatives created for them, assessing second year students' needs, and advocating for the success of second year students. Gahagan and Hunter (2006) encourage ...responsible campus decision makers...[to] seriously consider the needs, characteristics, behavior patterns, and academic experiences of second year students. Our campuses will be better places and our students will be better served and more successful if we do (p. 49). 
Understanding second year college student attrition including the factors that influence the attrition of second year students is vital for researchers and practitioners. "Historically [second year] students have been overlooked, both on college campuses and in higher education literature, [yet] there has long been an awareness that many students struggled during their second year in college" (Tobolowsky \& Cox, 2007, p. xi). Without addressing the needs of these students, they may feel isolated and could drop out (Hunter, Tobolowsky, \& Gardner, 2010). The primary reason for addressing the needs and issues for second year students is the concern for retention. Retention of college students is critical as revenue rises as students are retained and graduated from institutions of higher education (Hunter, Tobolowsky, \& Gardner, 2010). Retention is also important for college and universities as their primary role is to educate students leading to personal development of the student and economic growth of the surrounding community and beyond.

Purpose of the Study

This study attempted to explain the experiences of second year students with specific understanding of those students that are first generation and how they differ from continuing generation students. This study also attempted to outline factors that contribute to second year student attrition. Using the Sophomore Experiences Survey (SES), factors were identified as they impact attrition of second year students at four four-year, private, institutions in the state of Kentucky. Demographic variables in the SES instrument served as specific variables of interest in this study. Using questions from the SES which were developed from the engaged learning index, mindset items, academic self-efficacy items, adult hope scale items, meaning in life questionnaire items, 
faculty interaction frequency questions, and satisfaction levels questions, this study looked at factorial differences (if any) between first generation second year students and second year students that are not first generation.

It is important to study first generation college students as one study found after controlling for all other variables, first generation, low income college students across all institutional types were four times more likely to drop out of college after their first year as compared to continuing generation college students (Engle \& Tinto 2008). Researchers suggest that first generation college students and their precollegiate factors must be considered as well as other factors that impact persistence through college (Jehangir, 2010a). Since the second year in college has been found to be challenging for many students, it becomes apparent that first generation college students (with their pre-existing challenges) may struggle more during their second year (Gahagan \& Hunter, 2006; Lemons \& Richmond, 1987; Morgan \& Davis, 1981; Wilder, 1993).

First generation students are defined "as a student whose parents [neither of which] have [any] postsecondary education" (U.S. Department of Education, 1998, p. 1). Continuing generation college students are any students with at least one parent who has attended some college. Students with parents with some college experience and those with at least one parent with a baccalaureate degree have enough social capital needed for assistance to navigate the transition to college and the college environment (Purswell, Yazedjian, \& Toews, 2008).

\section{Problem Statement}

As institutions become more challenged to retain students during the struggling economic times, it is imperative that colleges and universities understand the disconnect 
students perceive between themselves and the institution they are attending. Understanding this disconnect allows universities and colleges the opportunity to develop initiatives to meet the needs of an ever-changing student population. Research reveals that the sophomore year is a time in which many students face some of their greatest challenges in college (Gahagan \& Hunter, 2006; Lemons \& Richmond, 1987; Morgan \& Davis, 1981; Wilder, 1993). While much research has been done to develop and enhance first-year initiatives, a lack of retention efforts and attention have been done during the second year (Graunke \& Woosley, 2005; Karp \& Logue, 2002; Wilder, 1993). Gahagan and Hunter (2006) call for an extension of first-year initiatives into the second year. Initiatives can be the creation of second year traditions that lead second year students to a stronger commitment to the college or university (Gahagan \& Hunter, 2006).

Schaller (2005) found that students in their second year felt alone and isolated. These students felt overwhelmed with plans for their future and unsure as to their fit in the career world. Many of the students Schaller (2005) studied felt as though they were operating in periods of crisis both in relationships and academics. The stress and the worry in these students' lives were impacting their academic success. With such problems occurring on colleges and universities throughout the nation, it is clear that more research on the second year student is critical. Understanding these students will only benefit colleges and universities as they work to retain and educate students.

\section{Rationale}

The purpose of this dissertation research was to understand the experiences of second year students at private institutions in Kentucky. Specially, this dissertation research examined the differences in second year students' experiences for those students 
that were first generation and those that were not first generation students. Factors may vary between first generation college students and continuing generation college students because of differences in academic preparation, parental support, ability to adjust to the campus environment, the ease of socialization, and cultural capital for each group of students (Jehangir, 2010a). Thayer (2000) suggested that first generation college students are less likely to persistent through graduation. Some of these students, unlike their counterparts, come to college with greater academic risks as they are less prepared for the college experience as it relates to reading, math, and critical thinking skills (Pascarella et al., 1996). Pascarella et al. (1996) determined that first generation college students have decreased critical thinking skills as compared to continuing generation college students.

Pascarella et al. (1996) also discovered that many first generation college students as compared to continuing generation college students will make significant improvements in their critical thinking and math skills during their first year (as compared to continuing generation college students) however their reading comprehension scores will still significantly fall behind those of continuing generation college students. This same research suggests that first generation college students will need to spend more time studying as compared to continuing generation college students in order to improve their reading comprehension scores. Pike and Kuh (2005) found that first generation college students as compared to continuing generation college students found the college environment to be less welcoming and supportive. Pike and Kuh (2005) suggested that a first generation college student's difficulty with socialization and adjustment in the college environment may be the result of a lack of role models with 
knowledge of the college experiences. While their parents may want to assist with these issues, they may not know how to support their students.

Socialization challenges exist for first generation college students as many of these students have found to be less likely to form friendships on campus and join student clubs and organizations (Billson \& Terry, 1982; Richardson \& Skinner, 1992; Terenzini et al., 1994; Terenzini et al., 1996). Pascarella et al. (2004) have conducted research studies on the social and cultural capital gained through attending college. These researchers determined that those students engaged outside of the classroom had higher critical thinking skills, aspiration for degree attainment, and a better sense of control of their environment. Yet, first generation college students were found to be less engaged outside of the classroom. Pascarella et al. (2004) revealed that while first generation college students were less likely to be engaged outside of the classroom, those that were engaged, acquired greater benefits from those experiences as compared to their continuing generation counterparts. Using the information gathered from this survey, one will be able to suggest programming initiatives at private colleges in the state of Kentucky that could have an impact on the experiences of second year students. With limited research on second year students, much of which has been performed on a few number of students through case study procedures, more data must be collected in this area. Collection and analysis of data will allow for a better understanding of factors that impact second year college students. More data will also provide greater knowledge of specific pre-entry variables, such as the parental educational level, and their impact on second year college students. With such results in 
hand, practitioners and scholars can work together in developing programs and initiatives for second year students.

Retention must be of grave concern for all practitioners and scholars at institutions in higher education especially private institutions that rely on the tuition from students to operate. According to Tinto (1993), the number of students who enroll in higher education and then withdraw is greater than the number of students who enroll in higher education and stay. Tinto's (1993) discovery is alarming as private institutions need students for financial support as well as the opportunity to educate students and without students education cannot occur. This discovery calls institutions to develop programs and initiatives that appeal to all students.

Beyond financial concerns for institutions, second year college students at the four private institutions in this study are part of the 36,000 students from Association of Independent Kentucky College and Universities (AIKCU). Seventy-four percent of all undergraduate students in AIKCU are Kentucky residents (Association of Independent Kentucky College and Universities, 2012). In 2001, Kentucky's employment gains were less than normal for the state and were not at par with the national employment growth trends. The median income for Kentucky residents was only higher than 12 other states in the country. The median income from Kentucky residents directly correlates with the low rate of educational attainment for residents in the state. Forty-seven percent of Kentucky college students complete a bachelor's degree within six years ("Kentucky Employment," 2005). Only $22 \%$ of Kentucky residents have a bachelor's degree ("Measuring Up," 2012). Educational attainment is a reason for economic growth and social well-being in the state ("Kentucky Employment," 2005). In 2011, 4,431 bachelor degrees were given to 
students from AIKCU schools. The target goal for Kentucky is to award 5,600 bachelor degrees in a given year (Association of Independent Kentucky College and Universities, 2012). Reaching this target goal certainly will impact the economic growth of the state.

For AIKCU schools, the six year graduation rate in 2011 was $50 \%$ (Association of Independent Kentucky College and Universities, 2012). In 2004, the six year graduation rate for all private, nonprofit institutions was 65\% ("The Condition of Education," 2012). It is clear that AIKCU schools still have a ways to go in their graduation rates. Since the four institutions selected for this study are members of the AIKCU the data provided from the study will help the institutions learn how they can impact their six-year graduation rates in hopes of reaching the national average.

Most students at private institutions in Kentucky attend college full time. According to the Kentucky Council of Postsecondary Education, of the 28,282 students in 2010 at private institutions, 23,906 of those students attend college full-time (Kentucky Council on Postsecondary Education, 2011). In 2010, Metro Louisville, Kentucky started the $55 \mathrm{~K}$ Degrees initiatives to increase the number of adults in the area that had completed a four year degree because the $27.9 \%$ of residents who had completed a four year degree was roughly the national average but far below peer cities ("UofL Sustainability," n.d.). Understanding second year students and their experiences can only ensure institutions a better knowledge of their student population and how to help them persist with their education. 


\section{Theoretical Context}

William G. Spady's (1970b) model of student dropout and Vincent Tinto's (1975) model of student departure provide the theoretical framework for this study. Spady (1970b) believed that "...no one theoretical model can hope to account for most (let alone all) of the variance in dropout rates..." of college students (p. 64). Yet, Spady (1970b) suggested that without a social connection to the institution students are more likely to dropout. Spady (1970b) proposed that individuals interact with their college environment which is influenced by expectations and demands of others (e.g., faculty, courses, and administrators). A successful interaction provides students an opportunity to fully acclimate into the academic and social realms of the college community (Spady, 1970b). However, if the student finds that the rewards (e.g. grades, friendships) of such acclimation are not sufficient he/she may withdraw from the institution. Spady's (1970b) theory suggests that without such rewards, connections, and integration into the community withdrawing is a possibility for a student.

The term social integration for Spady (1970b) was developed from enhancing the research of Durkheim (1897/1951) on suicide theory. Durkheim (1897/1951) purposed that individuals commit suicide because of their lack of social integration and social regulation within society. Durkheim (1897/1951) suggested that individuals with low normative congruence and low friendship support from society were more likely to commit suicide. Spady (1970b) modeled his theory after Durkheim's (1951) postulate proposing students who dropout have little to no connection with their community, have been unable to develop friendships with other students, and have values that are inconsistent with the norm of the college community. Durkheim's (1951) research 
attempted to understand the variation in suicide rates (Pope, 1976). Durkheim (1897/1951) argued that while most psychologists believed suicide to be an individual act, it was rather influenced by society. Durkheim (1897/1951) believed that suicide rates revealed a glimpse into a country's social body and reflected the social dissatisfaction of that country (Pope, 1976). Durkheim (1897/1951) proposed that if one studied suicide one could better understand the social dissatisfaction of a country and hopefully recommend suitable actions to change the society. While Spady's (1970b) model of student dropout does not have anything to do with suicide it does have much to do with social integration. Durkheim's (1951) work influenced Spady's (1970b) model because of the work on social integration; the concept of suicide was just Durkheim's (1951) method of understanding the impact of social integration on an individual.

Following Spady's (1970b) model of student dropout using some similar tenets from the theory, Tinto's (1975) developed the theory of student integration which relies heavily on the college student's assimilation into college life. Tinto (1975) suggested that student attrition is caused by unsuccessful social and academic integration into the institutional culture. Tinto (1988) argued that a student's transition into the college environment can be very difficult. These difficulties may lead a student to feel stressed and experience a sense of loss. Persistence through college may pose a challenge for students as the emotions they experience may be too much for them. Depending on an individual's ability to cope with the changing environment and emotions that he or she is experiencing will help determine whether he or she is able to successfully assimilate into the college life. Many students seek out assistance during their challenging times in order to integrate successfully into the institutional culture (Tinto, 1988). 
Braxton's (2000) review of Tinto's (1975) model of student departure suggested that internal motivation is an important student entry characteristic for successfully staying in college. This motivation allows for the student an opportunity to integrate both socially and academically in the collegiate environment. Tinto (1975) found that the student's integration into the social and academic environment in college life directly correlated with the student's persistence throughout college.

Tinto's (1982) research revealed that a student's informal and formal interactions in the college community can impact dropout decisions. Since all students enter college with different attributes, skills, abilities, commitments, and value orientations, it is important that these individual characteristics are taken into consideration when members of a college community interact with individual students. If institutions want to change dropout rates, individual characteristics of each student must be considered in order to help each student assimilate both academically and socially into the college environment. Students may leave college because of the demands that are placed on them in higher education and Tinto (1982) recommended that institutions make an effort to change their environment to meet the needs of individual students. Expanded descriptions of the theoretical context of this study are described in Chapter II.

Significance of the Study

Scholars and practitioners need to be concerned about the challenges that second year students face during collegiate life as their class often receives the "least [amount of] attention" (Schreiner \& Pattengale, 2000, p. v). If practitioners and scholars do not purposefully focus on second year students, an unacceptable number of these students will experience challenges during their collegiate years that may increase their likelihood 
of dropping out of college (Schreiner \& Pattengale, 2000). Gahagan and Hunter's (2006) call for action among practitioners and scholars is to focus their efforts on second year college student research. Without "...focused and sustained examination[s] of the second year student experience" colleges and universities will continue to struggle to retain second year students (Gahagan \& Hunter, 2006, p. 22). Working in partnership with each other, this "unexplored frontier" of the second year student can be successfully understood (Gahagan \& Hunter, 2006, p. 22).

Other research on higher education students (Barry, 2009; Horn, 1998; Nunez \& Guccaro-Alamin, 1998; Riehl, 1994; Stieha, 2010) has revealed that first generation students experience college somewhat differently than students whose parents have had a college experience. Longwell-Grice \& Longwell-Grice (2008) followed the lives of four first generation, working class, Caucasian male college students in an attempt to learn about their opinions of faculty support at colleges and universities. They learned that "first generation college students undergo enormous transformations as they negotiate the difficult transition into the culture of academia" (Longwell-Grice \& Longwell-Grice, 2008, p. 407). Longwell-Grice \& Longwell-Grice (2008) also noted that their “...interviews showed young men struggling to negotiate both family and institutional expectations and past and future academic success" (p. 416). These students need mentors to guide them through their collegiate experience and successful retention programs to keep them connected to the institution. (Longwell-Grice \& Longwell-Grice, 2008). Part of this study will examine whether or not the variable of first generation exacerbates the impact of the second year experience. 
The intersection of second year college students and first generation college students is significant because these populations of students struggle greatly during their collegiate years. Research shows that the second year can be one of the most difficult times in students' lives (Gahagan \& Hunter, 2006; Lemons \& Richmond, 1987; Morgan \& Davis, 1981; Wilder, 1993). Gahagan and Hunter (2006) learned through their research that financial hardships play an instrumental role in the attrition of second year students. This increased concern for how to pay for college lead many second year students to worry about their education. First generation college students also have similar struggles. Since many of these students come from low income families, paying for college poses a big challenge for them (Terenzini et al., 1996). Many second year college students also have a great deal of self-doubt especially when it relates to choosing a major (Schaller, 2005). Similarly, first generation college students have difficulty making choices because of the pressures they experience from family voices trying to guide their way (London, 1989).

\section{Research Questions and Hypotheses}

The research questions and hypotheses that were used for this study are listed below:

Research Question 1. What pre-college characteristics contribute to the intent to re-enroll and intent to graduate of second year college students?

Research Hypothesis 1. There is a significant predictive relationship between college grades and major certainty and the dependent variables, intent to re-enroll and intent to graduate, of second year students at private institutions in Kentucky as measured by the Sophomore Experiences Survey. 
Research Question 2. Does the Thriving Quotient contribute to the intent to re-enroll and intent to graduate of second year college students?

Research Hypothesis 2. There is a significant predictive relationship between the Thriving Quotient and the dependent variables, intent to re-enroll and intent to graduate, of second year students at private institutions in Kentucky as measured by the Sophomore Experiences Survey

Research Question 3. What campus experiences and perceptions contribute to the intent to re-enroll and intent to graduate of second year college students?

Research Hypothesis 3 . There is a significant predictive relationship among campus involvement, student-faculty interaction, and student satisfaction and the dependent variables, intent to re-enroll and intent to graduate, of second year students at private institutions in Kentucky as measured by the Sophomore Experiences Survey.

Research Question 4. What are the significant predictor variables that distinguish between first generation and continuing generation second-year college students in their intent to re-enroll at private institutions in Kentucky?

Research Hypothesis 4. Significant predictor variables that distinguish between first generation and continuing generation second year college students in their intent to reenroll at private institutions in Kentucky as measured by the Sophomore Experiences Survey include hours worked off campus, campus involvement, and student-faculty interaction. 
Research Question 5. What are the significant predictor variables that distinguish between first generation and continuing generation second-year college students in their intent to graduate at private institutions in Kentucky?

Research Hypothesis 5. Significant predictor variables that distinguish between first generation and continuing generation second year college students in their intent to graduate at private institutions in Kentucky as measured by the Sophomore Experiences Survey include hours worked off campus, campus involvement, and student-faculty interaction.

Research Question 6. Are first generation second year college students less likely to intend to re-enroll for the following semester of college as compared to continuing generation college students?

Research Hypothesis 6. First generation college students are less likely to intend to reenroll for the following semester of college as measured by the response to the question "I intend to re-enroll next year at the institution I am currently attending" as measured by the Sophomore Experiences Survey.

Research Question 7. Are first generation second year college students less likely to intend to graduate from college as compared to second year continuing generation college students?

Research Hypothesis 7. First generation college students are less likely to intend to graduate from college as compared to continuing generation college students as measured by the response to the question "I intend to graduate from college and obtain a bachelor's degree" as measured by the Sophomore Experiences Survey. 


\section{Limitations}

As with any research study, there are limitations. This study was hard to generalize as it will be conducted at only four, private institutions. Therefore, these data will inform about the experiences at those four private institutions, which may or may not be similar to experiences of students at other private schools or other types of institutions (public, for-profit, community colleges,). This study did not use an existing data set, as it relied on the responses of current second year students in their fourth semester of course work. Self-reported data posed a limitation for this study. Dillman (2007) suggests that "one of the difficulties with many self-administered surveys is that respondents answer questions quite rapidly, spending as little time as possible deciding what answer to choose" (pp. 66-67). Since participation in the survey was completely voluntarily it can be assumed that a specific subset of students will respond to the survey questions. This specific subset of students may be motivated to respond because of reasons related to the social exchange theory.

Dilliman (2007) explains survey responses serve as an example of the social exchange theory. Social exchange theory suggests that actions of individuals are motivated by the return these individual actions will have from others. This subset of students may have characteristics that vary from the "type" of student that will not respond. Respondents of surveys generally respond because of rewards, costs, and trust. Rewards are what the individual expects to get from participating. Costs are what the individuals give up for participating. Trust, for a respondent, is expecting that the rewards will outweigh the costs in the end. Respondents of this survey had to be willing to give up some time to complete the survey. These students had to have trust in the survey hoping 
that the time they spend resulted in rewards. For these students, that reward may have been a change in their institution's response to second year students. Acknowledging this limitation is important for this study. Also, students in self-reported students have a tendency to want to give desirable responses. Dillman (2007) research shows that even the most ordinary questions often display socially desirable responses.

\section{Definition of Terms}

\section{Attrition}

Attrition can be defined as "... anyone leaving a college at which [the student] is enrolled" (Spady, 1970b, p. 665). While several other definitions exist for attrition, for purposes of this paper, this definition was used. A limitation of this definition for attition is that the definition does not account for students who transfer to another institution or for students who dropout but then return after some period of time (Spady, 1970). Understanding student attrition will be particularly important in the data analysis portion of the research. Understanding which students leave college and their responses to the survey on the second year experience can guide future decisions on programming initiatives.

\section{Continuing Generation College Students}

For the purposes of this dissertation, a continuing-generation student was defined as any student with at least one parent who has attended some college. While Pike and Kuh (2005) suggested that a continuing generation college student is student with at least one parent that has earned a baccalaureate degree, research shows that students with parents who have some attended some college better understand the college experience than those who have not. Purswell, Yazedjian, and Toews (2008) studied students with 
parents who had no college experience, some college experience, and students with at least one parent who earned a baccalaureate degree. These researchers learned that parental support was predictive of the academic behavior of students with parents with some college experience as well as students with at least one parent with a baccalaureate degree. Therefore, students with parents with some college experience and those with at least one parent with a baccalaureate degree had enough social capital needed for assistance to navigate the transition to college and the college environment (Purswell, Yazedjian, \& Toews, 2008). Understanding this research, it is sufficient to classify a continuing generation college students as any student with at least one parent who has attended some college.

\section{Dropout}

Dropouts are defined as students who leave an institution and do not return (Tinto, 1975). Student dropout behavior can be explained "at given levels of educational goal commitment. It is the individual's institutional commitment that most directly relates to variation in dropout behavior" (Tinto, 1975, p. 110).

\section{First Generation College Students}

The term first generation has several meanings. The United States Department of Education defines first generation students “... as a student whose parents [neither of which] have [any] postsecondary education" (U.S. Department of Education, 1998, p. 1). In some cases,... “first generation students are defined as students whose parents [neither of which] earned a bachelor's degree" (U.S. Department of Education, 1998, p. 1). For the purposes of this dissertation, first generation students were defined as any student "as 
a student whose parents [neither of which] have [any] postsecondary education" (U.S. Department of Education, 1998, p. 1).

\section{Matriculation}

Matriculation is defined as "successfully moving from one level of education to another, such as completing a high school diploma or GED and matriculating to a college, or completing a two-year degree and matriculating to a university to work on a four-year degree" (Kentucky Council on Postsecondary Education, 2010, n. p.)

\section{Persistence and Persisters}

Those students who continue enrollment as they fulfill requirements for their bachelor's degree are called persisters (Jones \& Dennison, 1972). The Kentucky Council on Postsecondary Education defines persistence as "continued enrollment of students as they work toward completing a credential" $(2012$, n. p.) This study was specifically interested in those students were enrolled during their fourth semester of their second academic year in college.

\section{Second Year Students}

Second year students, as defined most recently by a taskforce at the University of South Carolina are any "first-time, full-time students who have persisted into their second year of academic work" (Gahagan \& Hunter, 2006, p. 18). For purposes of this study, second year students were completing their fourth semester of academic work (as the survey was administered in April of their fourth semester).

\section{Retention}

Retention is "the proportion of first-time postsecondary students who enter a public Kentucky institution in a given fall semester and return to any Kentucky institution 
the following fall semester" (Kentucky Council on Postsecondary Education, 2012, n. p.) For purposes of this dissertation, private institutions rather than public institutions were analyzed.

Social Capital

Social capital is defined by the relationships that an individual has with others and how that individual gains access to resources through those relationships (Coleman, 1988).

Sophomores

Generally, the term "sophomores" is interchangeable with the team "second year" at traditional, four year institutions (Gardner, 2000; Schaller, 2005). However, for purposes of this dissertation, the term "second year" was used as sophomores are characterized by accumulating a specific number of hours at a given institution. Since research for this dissertation was collected at various private, four year institutions, the term "second year" was more appropriately used to define the students that were studied. Stopout

Stopouts are students "who, after leaving college, re-enter at a later time to complete their degree" (Tinto, 1993, pp. 25-26).

This introduction provides a framework for this study. Understanding the purpose of the study, problem statement, rationale, theoretical context, significance, research questions, limitations and definitions provided the reader with a solid overview of why this study was performed. Having reviewed those items, a critical look at the literature in the areas of retention, first generation college students, and second year college students 
was important in understanding the research that came before this study was performed. Such research did impact the methodology and data analysis procedures.

\section{Thriving}

The term thriving was developed from the psychology literature by Keyes and Haidt (2003). Keys and Haidt (2003) used the term flourishing to explain midlife adults who were actively engaged with others. The foundation of flourishing adults is emotional energy and optimistic functioning. These adults have healthy relationships, are hopeful for the future, dynamic in their work, and find importance in their lives. Schreiner's (2010a) added the elements of academic success and goal orientation to Keyes and Haidt (2003) concept of flourishing and called the new concept thriving. Schreiner (2012) believes that thriving students are able to successfully experience transitions in their lives. These transitions lead to personal development. Students experience thriving in various areas of college life: academics, intrapersonal development, and interpersonal development. 


\section{CHAPTER II}

\section{LITERATURE REVIEW}

\section{Overview}

This literature review outlines the retention and attrition concerns for college students with specific emphasis on the second year student and students that are first generation. Retention is essential to the survival of colleges and universities across the United States. With particular focus on second year students, practitioners and scholars can help prevent these students from experiencing attrition during their second year. Academic and faculty involvement are important for all students and particularly for second year students who are struggling to decide on their future careers (Schaller, 2005).

This chapter will begin with a discussion of two theories: Spady's model of student dropout and Tinto's model of student departure. These two theories play an important role in understanding student attrition and the theoretical framework of this study. Following a review of theories, Schreiner's (2010a) understanding of student thriving will be outlined. Then, the literature review will analyze articles related to college student attrition with specific emphasis on factors that have been shown to impact college student attrition and how educators can predict college student attrition. Since an understanding of first generation college students is important to this literature review, an extensive presentation of pertinent literature about first generation college students will 
be included. Second year students are an additional focus of this dissertation and knowledge of these students' self-perceptions, experiences, academic abilities, and programming initiatives designed for them will be reviewed. This dissertation intends to expand on the knowledge gathered from the reviewed literature in an effort to decrease the gap of information that still exists on second year students. To begin, it is essential to look at the theories of Spady (1970b) and Tinto (1975), as they have guided much of the research noted in this review and how the social and academic integration for all college students has impacted their persistence to graduation.

\section{Spady's Model of Student Dropout}

William G. Spady (1970b) believes that "...no one theoretical model can hope to account for most (let alone all) of the variance in dropout rates..." of college students (p. 64). Yet, in Spady's (1970b) review of research on attrition rates in higher education, he attempts to develop and explain his theory of college student drop out. One of the foundational components of his theory stems from Durkheim's (1951) work on suicide theory, which suggests that disconnecting from one's social system occurs after a lack of assimilation within such social systems. Durkheim (1897/1951) disagreed that suicide was an act solely psychological but rather an act related to society. Durkheim (1897/1951) believed that with, a lack of social integration and social regulation, social isolation was created for the individual. Social integration relates to how connected an individual is to others in society while social regulation is defined as the amount of control society has on the individual (Durkheim, 1951).

Durkheim (1897/1951) believed that if an individual had a greater sense of his/her meaning in life he/she was less likely to commit suicide. But, if that individual developed 
a weak sense of his/her meaning in life then suicide was of great risk (Pope, 1976).

Isolation developed in an individual as he/she becomes less integrated into society.

Durkheim (1897/1951) proposed that a more integrated a society had greater control over the behavior of its members, therefore guarding them from suicide. However, as an individual became less integrated within society he/she developed his/her own behaviors and beliefs resulting in a greater risk of suicide (Pope, 1976). Durkheim (1897/1951) had an impact on Spady's (1970b) theory of student attrition. While Spady's (1970b) theory does not include suicide, the theory does suggest that students who do not feel a social connection to the institution are more likely to drop out. This concept is very similar to Durkheim's (1951) understanding of integration as integration is critical for individuals in society in order to decrease the likelihood of suicide from occurring.

Spady's (1970b) theory of student dropout states that students who do not feel a social connection to their institution and do not share similar values with other students at their institution are more likely to drop out. Spady's (1970b) model relies on two critical variables: social and academic rewards as well as a student's sense of integration. Social rewards are those rewards related to the society or college community. Examples of social rewards include social status or extracurricular rewards such as those rewards that come with participation in athletics, involvement in campus organizations or clubs, living on campus, or part-time campus work (Spady, 1970a). Academic rewards are those that are associated with high test scores, achievement, and grade point average (Spady, 1970a). These variables play an important role in a student's satisfaction in college life (Spady, 1970b). Through review of attrition studies and dropout concerns, Spady (1970b), when constructing his model of student attrition, hoped to create a "...a 
reasonable synthesis of some of the more consistent findings on college attrition... and a worthwhile conceptual framework for guiding future research" (p. 79).

This synthesis that Spady (1970b) described is the combination of five independent variables: normative congruence, friendship support, grades, intellectual development, and social integration. The first four variables, as Spady (1970b) suggested, have an influence on social integration for a student. This interaction between the first four variables and social integration influences attrition. Additionally, Spady (1970b) argued that social integration has an indirect link to dropping out because of two crucial variables that come from integration: satisfaction with the college experience and commitment to the social system. In understanding Spady's (1970b) synthesis of findings, his model has become a framework that impacts future research. This framework is outlined in Figure 1.

Researchers have tested Spady's (1970b) model of student dropout. Eggens, Van der Werf, and Bosker (2008) learned that the greater the number of social networks a student had the more likely that he or she would attain a college degree. Through the lens of Spady (1970b) as well as other retention theorists, Eggens, Van der Werf, and Bosker (2008) also learned that personal networks for students, similar to the construct, friendship support, helped students deal with stress and challenges during their collegiate years. Zeitlin-Ophir, Melitz, Miller, Podoshin, and Mesh (2004) learned that background and personnel characteristics of nursing students impacted the students' academic performance and integration. These researchers also discovered that positive social relationships through friendship support lead to greater academic integration. Lastly, the 
researchers learned that satisfaction with the institutions facilities increased the likelihood of positive academic integration (Zeitlin-Ophir, Melitz, Miller, Podoshin, \& Mesh, 2004). DesJardins, Ahlburg, and McCall (2002) found that when a student had good grades he/she had a higher likelihood of successfully progressing through college and attaining a degree. For these researchers, academic performance did have a direct relationship with a student's dropout decision.

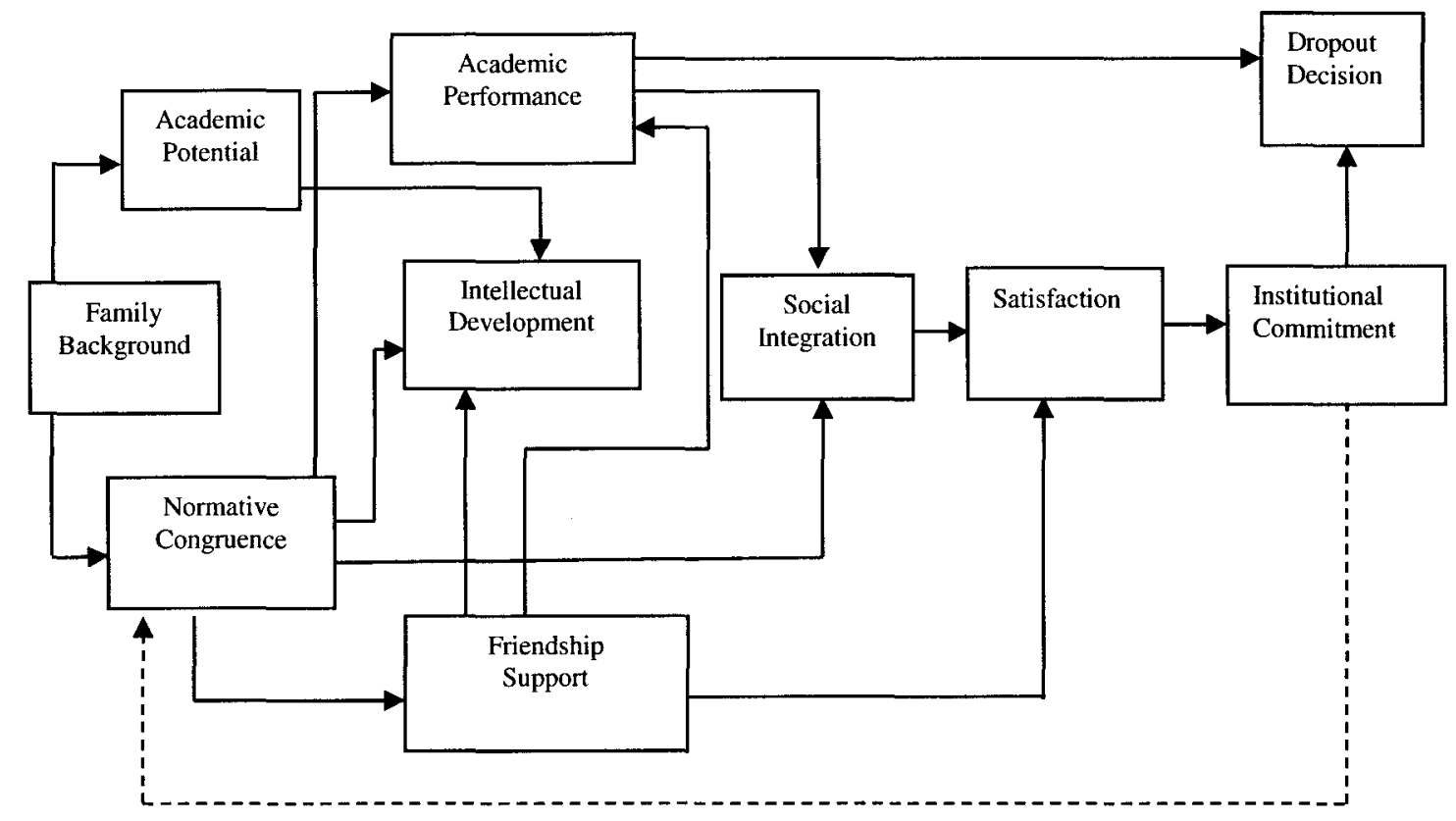

Figure 1: Spady's Model of Dropout

Tinto's Model of Student Departure

Like Spady's (1970b) theory of student dropout, Tinto's (1975) theory of student departure relies heavily on the college student's assimilation into college life. Tinto (1975) suggested that student attrition is caused by unsuccessful social and/or academic integration into the institutional culture (Tinto, 1975). Braxton's (2000) review of Tinto's (1975) model of student departure suggested that internal motivation is an important student entry characteristic for successfully staying in college. This motivation allows for 
the student the opportunity to integrate both socially and academically in the collegiate environment. The student's integration into the social and academic environment in college life then becomes directly correlated with the student's persistence throughout college (Tinto, 1975). According to Tinto (1975), the most important characteristics for students and their persistence throughout college include family characteristics, individual characteristics, educational experiences before college, and the student's future educational expectations. Tinto's (1975) model is displayed in Figure 2.

In 1999, Tinto spoke to the members of the National Academic Advising Association (NACADA) and in his speech he shared significant advice with the members. He stated that students are more likely to persist throughout college if they are given clear and dependable information about institutional conditions, provided academic, personal, and social support, offered opportunities to be engaged as involved students, and presented with environments that promote learning This advice informs practitioners and educators about their roles on college campuses in creating an institutional culture that promotes active involvement throughout the college years (Tinto, 1999).

While Tinto's work in 1975 on retention has paved the way for many future research efforts, he admits that his earliest work on retention lacked specificity and density (Tinto, 2006). His earliest work in 1975 focused on the first year of college with specific emphasis on a student's transition into college. That same body of research used a great number of quantitative studies with mostly institutions that were residential and lacked a focus on diverse student bodies. Tinto's (1975) retention efforts could not be 
generalized to two year institutions or diverse populations of students. However, his continued efforts have led to a greater understanding of retention (Tinto, 2006).

Tinto (2006) has increased his research efforts on diverse student bodies leading to a better understanding of minority populations. In early retention studies, Tinto (1975) believed that students needed to leave their previous communities in order to be fully integrated into college life. Tinto (1988) argued that this separation can cause stress in a student's life. Yet, he believed that such separation was extremely necessary to staying in college. However, more current research revealed that some students, many of which from minority populations must remain connected to their past communities in order for successful retention at colleges and universities (Terenzini et al., 1994). Tinto (1982) has learned that the achievement process of African-American students and female students differs substantially from Caucasian students and male students. Since these differences are substantial, it may require researchers to study these subgroups of students with separate models of behavior. With increased retention research, Tinto (2006) also has had a better understanding of non-residential students learning that these students must be involved in the classroom and have support when external events on the student's lives occur.

Caison (2005) found that Tinto's (1975) understanding of goal commitment and student departure successfully corresponds to her own research study. She determined that a student's first year GPA is directly related to his/her goal commitment and intentions on staying in college (Caison, 2005). 
Tinto (1975) determined that students' entry characteristics impact students' departure decisions.

This theoretical model of dropout... argues that the process of dropout from college can be viewed as a longitudinal process of interactions between the individual and the academic and social systems of the college during which a person's experiences in those systems (as measured by his normative and structural integration) continually modify his goal and institutional commitments in ways which lead to persistence and/or to varying forms of dropout (Tinto, 1975 , p. 94).

Tinto (1982) also argued that finances can contribute to a student's disengagement in college. He proposed that financial challenges can pose a difficulty for students especially early on in their college career. When the degree seems far-off from achieving, a student decides to dropout because of such financial issues. He suggested that researchers, even himself, must take into consideration finances when establishing dropout models for students. Tinto's (1982) article also reminds us that leaving is often significantly related to academic and social integration as he has noted in previous research (Tinto, 1975; Tinto 1988; Tinto 2006). He reminds educators and professional involved in students' lives that the more interaction these individuals have with the students the greater the likelihood of students staying at their institution. This interaction does not have to be formal; informal interactions can be as successful in decreasing attrition. Figure 2 outlines Tinto's model of student departure. Schreiner's understanding of student thriving, in addition to Tinto's (1975) model of student departure and Spady's (1970b) model of student dropout impacted the conceptual framework for this research. 


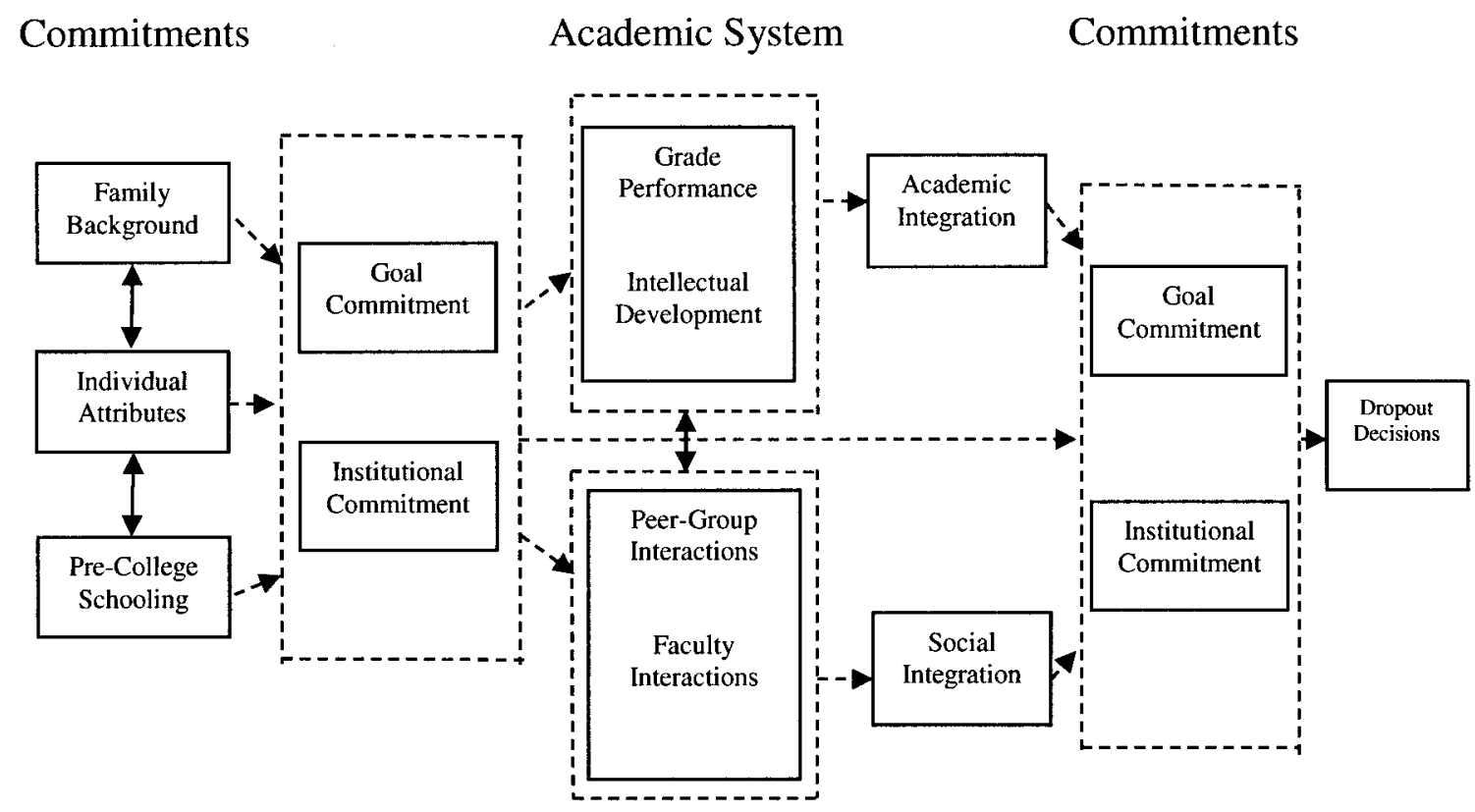

Social System

Figure 2: Tinto's Model of Student Departure

\section{Schreiner's Understanding of Student Thriving}

Schreiner (2010a) developed the Sophomore Experience Survey as an instrument to understand both the satisfaction and experience of second year students at colleges and universities. Juillerat (2000) was the first to collect data quantitatively on second year students to understand the dissatisfaction of second year college students at faith-based institutions. Schreiner's (2010a) instrument was developed as a follow-up study to Juillerat's (2000) study in order to have a broader knowledge of second year college student experiences at institutions throughout the United States. The Sophomore Experience Survey was built on the notion that demographic variables, the Thriving Quotient, and campus experiences and perceptions impacted a second year student's college experience. 
Student thriving is the main concept of Schreiner's (2012) work. Her contribution to the idea of student thriving has led many other researchers to study student thriving in hopes of gaining more insight on the college student experience (Nelson \& Vetter, 2012; Parades-Collins, 2012; Sriram \& Vetter, 2012). The discoveries these researchers have made support Schreiner's (2012) understanding of student thriving (Nelson \& Vetter, 2012; Parades-Collins, 2012; Sriram \& Vetter, 2012. The term thriving was developed from the psychology literature by Keyes and Haidt (2003). Keys and Haidt (2003) used the term flourishing to explain midlife adults who were actively engaged with others. The foundation of flourishing adults is emotional energy and optimistic functioning. These adults have healthy relationships, are hopeful for the future, are dynamic in their work, and find importance in their lives. Keys and Haidt's (2003) understanding of flourishing has a foundation of psychological well-being but also includes elements of college student success including academic engagement, openness to differences as well as effort regulation among other elements. Schreiner (2010a) added the elements of academic success and goal orientation to Keyes and Haidt (2003) concept of flourishing and called the new concept thriving.

Schreiner (2012) believes that thriving students are able to successfully experience transitions in their lives. These transitions lead to personal development. Students experience thriving in various areas of college life: academics, intrapersonal development, and interpersonal development. Schreiner (2012) believes that a student's transitions in college can be successful through having a positive outlook, support structures, and recognition of effective strategies to deal with those transitions. Schreiner (2010b) suggests that the Thriving Quotient can provide a way to measure student 
thriving and then provide intervention strategies for those students when they struggle to thrive in the community.

Spady's, Tinto's and Schreiner's Impact on the Conceptual Model of this Study The conceptual model for the current study was impacted by the theories of Spady (1970b) and Tinto (1975) as well as Schreiner's (2010a; 2010b; 2012) understanding of student thriving. Both Spady (1970b) and Tinto (1975) suggest that social integration influences a student's dropout decision. Social integration is reflected in many of the questions in the Thriving Quotient as well as in the areas of campus involvement and student satisfaction as outlined in the framework for this study. Such questions from the Thriving Quotient that relate to social interaction and a student's ability to form friendships include: other people seem to have more friends than I do, I often feel lonely because I have few close friends with whom to share my concerns, and I don't have many people who want to listen when I need to talk. Spady (1970b) suggests that social rewards, such as membership in campus organizations and part-time campus work, impact a student's social connection to an institution. Part-time campus work is reflected in the Sophomore Experiences Survey's question concerning hours worked on and off campus. It makes sense that hours worked on and off campus could be a potential influence for college students as Spady' (1970) theory suggested that part-time campus work can effect dropout decisions.

In the case of the current study's conceptual model, dropout decision would be related to the questions of intent to re-enroll and intent to graduate. Tinto (1975) learned that a student's integration into the community directly relates to a student's persistence into college. The variables of campus involvement, student satisfaction, student-faculty 
interaction, and the Thriving Quotient all are comprised of questions directly related to how well a student integrates with various facets of the college community (see Appendix A and Appendix B). Tinto (1975) also learned that future educational expectations effect a student's dropout decision. The current study hypothesized that major certainty would be a significant predictor variable for intent to re-enroll and intent to graduate. Both Spady (1970b) and Tinto (1975) propose that family background and individual attributes influence dropout decisions. This study was particularly concerned with the impact of first generation status on students' intent to re-enroll and intent to graduate.

Schreiner's (2010a; 2010b; 2012) Thriving Quotient was used in this study. Using this tested and reliable measured developed by Schreiner (2010a; 2010b; 2012) this research hoped to provide a glimpse of student thriving. The concept of student thriving was thought to be predictive of first generation and continuing generation intent to reenroll and intent to graduate. While Schreiner (2010a) did not combine all of the same questions used in this current study to create the variables of student-faculty interaction, campus involvement, and student satisfaction, all of the questions used in the current study did originate from Schreiner's (2010) Sophomore Experiences Survey. Overall, Spady's (1970b) and Tinto's (1975) theory as well as Schreiner's (2010a; 2010b; 2012) understanding of student thriving served as strong foundations for the conceptual model of this study as outlined in Figure 3. 


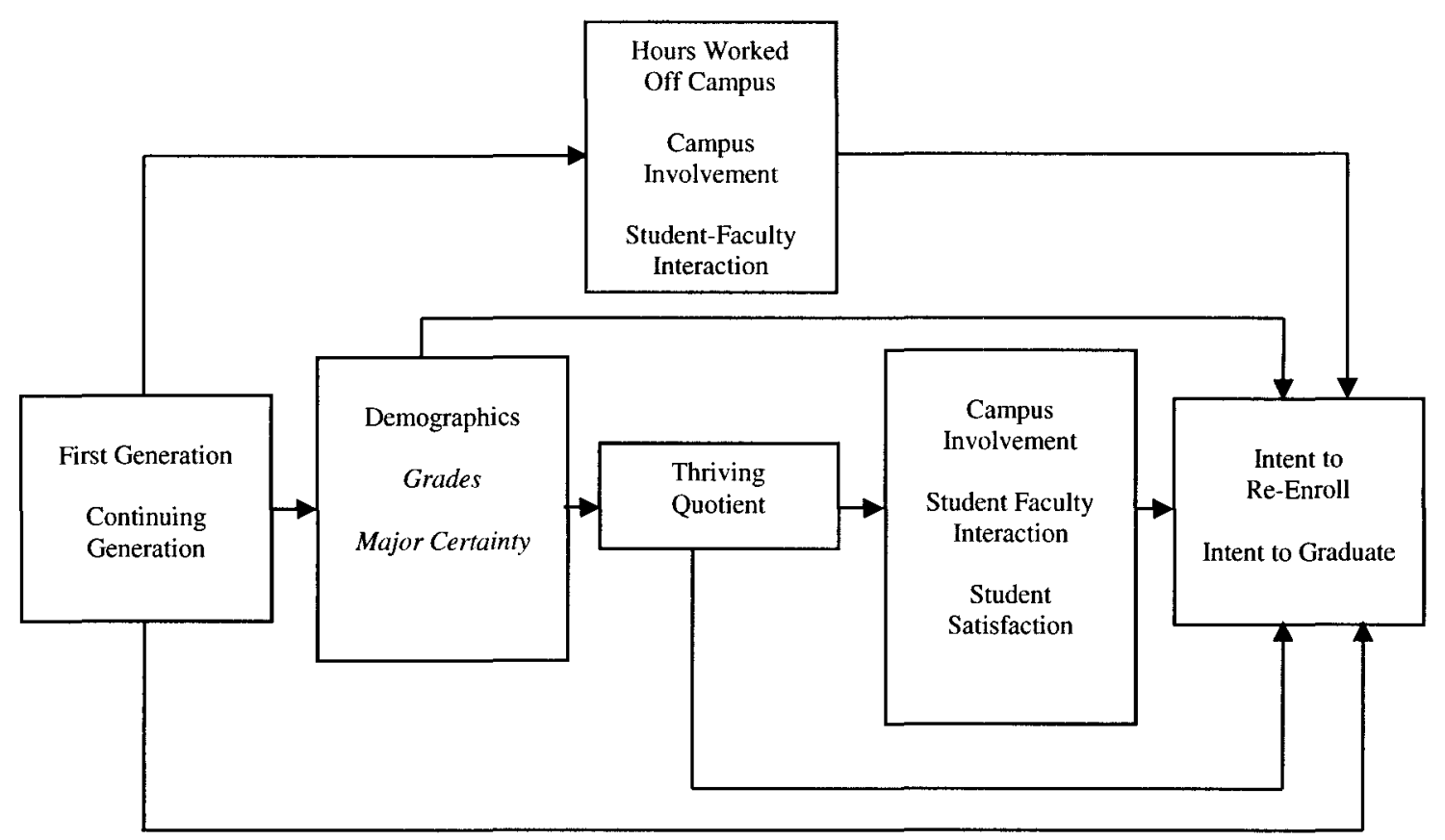

Figure 3: Conceptual Model for Current Study

College Student Persistence and Attrition

Students leave college for a variety of reasons (Mallette \& Cabrera, 1991;

Masburn, 2000/2001; Newlon \& Gaither, 1980; Peltier, Laden \& Matranga, 1999;

Woosley, 2003/2004). Peltier, Laden, and Matranga (1999) believed that as institutions

compete for students their research in the area of student persistence has become central to their understanding of why students stay or leave college. To present their research on student persistence, Peltier, Laden, and Matranga (1999) performed a meta-analysis of research results. This analysis showcased various student persistence studies throughout the United States focused on campus involvement, ethnicity, gender, age, on campus living versus off campus living, as well as membership in social organizations. One important study that Peltier, Laden, and Matranga (1999) reviewed was a study conducted by Daly and Breegle (1989) in Maryland. These researchers discovered that 
"[college] graduates [had a]...higher participation rate in extracurricular activities than non-persisters" (p. 359). This research reminds professionals in higher education of the importance in encouraging students to participate in out of the classroom experiences.

Persistence studies have revealed various factors that are impactful on collegiate attrition (Peltier, Landen, \& Matranga, 1999). A student's campus involvement plays an important role in their success in college. Milem and Berger (1997) discovered that campus involvement during a student's first semester impacted their college experience as well as impacted their future involvement throughout college. The ethnicity of the student can also contribute to the persistence of college students. Tinto (2006) in his research revealed that minority students are stressed when separated from their families. Particularly, Black, Native American and Hispanic students need to be encouraged to continue their relationships with family members as these students often feel most stressed when separation occurs (Terenzini et al., 1994). Age can also impact persistence for students. First generation college students that are over the age of 24 have a higher likelihood of dropping out of college (Jehangir, 2010a). Murtaugh, Burns, and Schuster (1999) in their study at Oregon State University learned that the older a student was the higher likelihood they were to drop out of Oregon State University. Sandler (1998) discovered that for adult students their confidence on completing coursework and preparing for their career goals must be understood by educators as these factors can lead to dropout decisions. If these students feel that their college degree will lead to better employment they were less likely to dropout (Peterson \& delMas, 1996).

Students who live on campus have reported higher levels of satisfaction as compared to those students who live off campus (Spady, 1970a). Pascarella and Terenzini 
(2005) learned that living on campus influences retention and graduation. Living on campus leads to greater campus involvement and personal growth. Whalen, Saunders, and Shelley (2009) discovered that on-campus living was a significant predictor of six year graduation/retention rates. Pascarella (1985) determined that living on campus impacted a student's intellectual and social self-concepts through relationships with peers. Membership in social organizations also contributes to student persistence in college. Schuh, Triponey, Heim, and Nishimura (1992) noted that the bond created in African-American Greek-lettered organizations led to a direct impact on attrition for those students as they often stayed at the institution because of their commitment to the organization.

Additional research has been conducted on college student attrition (Janasiewicz, 1987; Mallette \& Cabrera; 1991; Masburn, 2000/2001; Milem \& Berger, 1997; Woosley, 2003/2004). College student attrition can be caused by lack of financial resources, student satisfaction, academic decisions, and lack of support (Janasiewicz, 1987; Mallette \& Cabrera; 1991; Masburn, 2000/2001; Milem \& Berger, 1997; Woosley, 2003/2004). Janasiewicz (1987) studied the withdrawal factors of first year and second year students with a small number of juniors in the mix at a large state institution through a survey instrument. The survey revealed that students withdrew from the institution because of dissatisfaction with the college, financial or family problems, personal or emotional problems, and homesickness. Mallette and Alberto (1991) used the Freshmen Experience Survey to survey first-time freshmen at a large state institution. Using logistic regression equations on the data from 953 surveys collected, these researchers discovered that academic performance, final institutional commitment, finance attitude, and faculty 
concerns were statistically significant in clarifying the differences between dropouts and persisters (Mallette \& Cabrera, 1991).

Positive psychology can also be connected to the understanding of college student persistence and attrition as a means to understanding student satisfaction. Positive psychology is the study of happiness as created by three pillars: positive emotions, positive virtues and strengths, and positive environments (i.e. family and schools) (Seligman, 2002). Happiness leads individuals to believe that they have a good life (Peterson, 2006). King and Napa (1998) in their study of college students and adults outside of the college community learned that people desire happiness in their lives. Baxter Magolda's (2001) found that college students seek happiness as an ultimate goal. Fredrickson (2002) discovered that in helping students focus on the positive rather than focus on problems, intellectual and social development can occur. Encouraging positivity within students can occur through programming efforts, college student involvement, and activities with setting goals. These efforts can lead to a student's satisfaction and ultimately impact their decisions to persistence at a college or university.

\section{Factors that Impact College Student Attrition}

Under the theoretical models of Spady (1970b) and Tinto (1975), studies have been done to identify the factors that impact college student attrition. In one specific example, Newlon and Gaither (1980) examined the factors that contributed to attrition for college students at California State University, Northridge. Using a quantitative analysis of existing data, Newlon and Gaither (1980) discovered that the entering major of college students had a significant impact on their persistence throughout the first two years of college. Those with an Arts and Humanities major or undeclared majors had a decreased 
chance of persisting throughout college as compared to Communications, Computer Science, Business, Engineering, and Professional Studies majors. This study revealed that declaring a major does assist a student in persisting in college. Not only is the declaration of a major important but the type of major is also impactful. Students who are majoring in professional programs such as Communications, Computer Science, Business, Engineering, and Professional Studies have higher persistence rates than those students in Arts and Humanities majors. Newlon and Gaither's (1980) research suggested that students have higher persistence rates in professional programs because students attempting to receive a professional program degree believe that a better job will result from such a degree.

Masburn (2000/2001), in an attempt to understand the psychological process of the college student dropout, studied 185 full-time first year and second year students. Basing his research on the analysis of Pantages and Creedon (1978), he believed that college student dropout occurred because of several factors: academic, motivational, demographic, personality, college environment, financial, and health (Masburn, 2000/2001). Pantages and Creedon (1978) reviewed previous attrition related studies identifying the reasons for college student dropout. These researchers also spoke directly with students to understand their withdraw decisions. As outlined above, the researchers learned that factors related to academics, motivation, demographics, personality, college environment, finances and health all had an impact on students' withdraw behaviors (Pantages \& Creedon, 1978).

Masburn (2000/2001) gave a questionnaire to all 185 students which contained three sections: student demographic information, student satisfaction with the academic 
environment, and college-wide satisfaction with emphasis on thoughts of dropping out. The main variable of this study, student dropout, was analyzed one year after the questionnaire was completed. Using confirmatory factory analysis and structural equations modeling results were revealed. Masburn (2000/2001) determined "...that the relationship between student satisfaction and dropout is mediated by the student's withdrawal cognition... [and that] satisfaction has a direct effect on cognitions about dropout...[which] directly affect student dropout behavior" (p. 186). Withdrawal cognition included "...thoughts of dropout, search intentions, and dropout intentions" (Masburn, 2000/2001, p.175). These results may have an impact on the creation and evaluation of programs that provide resources to curb student dropout decisions while also understanding the benefits of these specific programs. Such programs may include a tutoring center that provides students additional assistance with academics. These resources outside of the academic realm may impact a student's decision to dropout. Researchers often consider those students who do not return for a following year or semester as dropouts (Janasiewicz, 1987). To understand the determinants of withdrawal behavior, Mallette and Alberto (1991) performed an exploratory study on 2,954 entering first year students at North Carolina State University. The purpose of the study was to understand variables of student integration as constructed by Tinto (1975), and if those variables had an effect on dropout decisions. The goal of the study was to learn if financial attitudes differed between institutional persisters, dropouts, and transfers (Mallette \& Cabrera, 1991). In order to analyze their study's variables, academic integration, social integration, final goal commitment, and final institutional commitment, students were given a survey created from Pascarella and Terenzini's 1980 institutional 
integration scale and Nettles, Gosman, Theoney, and Danridge's 1985 finance attitude items (as cited in Mallette \& Cabrera, 1991). Using both exploratory and confirmatory factor analyses, researchers revealed that a clearer understanding of the variations of withdrawal behaviors for students was needed. Results revealed that voluntary withdrawal behavior and voluntary dropout behavior was dissimilar. Voluntary withdrawal behavior was found to be a multidimensional construct while voluntary dropout behavior was impacted by differing determinants (Mallette \& Cabrera, 1991). The findings of this study suggested that institutions need programs that emphasis student-faculty interaction, educate students on finances, and discuss academic success are likely to decrease dropout decisions among students (Mallette \& Cabrera, 1991).

An additional study that supports the use of both academic and social integration in the creation of retention efforts was performed by Milem and Berger (1997) at a highly selective private institution in the southeastern United States. In this study, 718 first year students participated in a longitudinal, quantitative study aimed at understanding how the environment impacts student integration with particular focus on a student's behavior and perception of the integration process (Milem \& Berger, 1997). The variables studied in this analysis included seven groups of independent variables which included academic and social integration, as well as a dependent variable of student persistence. One key finding in this research was that student involvement during their first semester in college impacted their future involvement and perceptions of involvement throughout their remaining time at that institution. Peer support was critical for these students and played a vital role in their perceived institutional support. Lastly, faculty involvement early on in a student's college experience increased that student's perception of institutional support. 
The results of this study encourage practitioners to find ways to integrate peers in the support of other students, offer opportunities for student involvement within the first semester of a first year student's academic career, and create moments for students to engage with faculty outside of the classroom (Milem \& Berger, 1997).

Woosley (2003/2004) investigated the difference between students who withdraw and then re-enroll and those who withdraw and do not re-enroll. Using institutional and survey data from 613 undergraduate students at a Midwest public university, Woosley (2003/2004) reviewed the various characteristics of this student population in regard to withdrawing and re-enrolling behaviors. Through Chi-square tests, independent t-tests, two way Chi-square tests, and some basic descriptive analysis, Woosley (2003/2004) determined that students without long-term educational plans were less likely to re-enroll after withdrawing from college. Woosley (2003/2004) also discovered that those students who entered a college or university with a decreased commitment toward that institution were less likely to re-enroll after they had withdrawn from that institution. Lastly, Woosley (2003/2004) found, like other researchers (Milem \& Berger, 1997; Janasiewicz, 1987), that social and academic integration played an important role in the withdrawal of a college students and their likelihood to consider re-enrolling. Woosley (2003/2004) strongly recommended professionals in higher education to evaluate withdrawal policies while always considering the fact that students could possibly re-enroll at the institution at a later time. Students in Woosley's (2003/2004) study who had a goal commitment to complete a Bachelor's degree were more likely to re-enroll. Students with a positive outlook on the university were also found to be more likely to re-enroll. Students stated that dissatisfaction and a feeling of isolation led to their withdrawal. Without integration 
both socially and academically, students were less likely to re-enroll (Woosley, 2003/2004).

For many researchers financial challenges are believed to be one of the primary causes for students leaving an institution (Chen \& DesJardins, 2008; Tinto, 1975). Even though no study will be able to understand all the leaving behaviors of college students, Janasiewicz (1987) was determined to recognize the leaving behavior of students at Florida State University. Many of the students at Florida State University never actually formally withdrew from college but rather neglected to register for classes for the following semester. This study was performed to understand why students leave college while also understanding future ideas for research in the area of student persistence with specific focus on student financial concerns (Janasiewicz, 1987). The “...three distinct models of leaving behavior [were]...Discouraged Student Model, an Academic Model, and a Financial Model" (Janasiewicz, 1987, p. 27). The Discouraged Student Model occurred when the institution did not provide the necessary support for the student. Students in this model unsuccessfully completed academic work and had little plans for their future career. The Academic Model encompassed students who left for specific career and academic reasons. Lastly, the Financial Model included students who withdrew because of financial challenges. These models suggested to Florida State University advisors and advisors across the country at differing institutions that they must get to know their students. Beyond knowing their students, they must support them, provide financial resources, and help the student decide if the institution is the right fit for them (Janasiewicz, 1987). 
Masburn (2000/2001) in his research determined that "withdrawal cognitions" such as the idea of quitting, dropping out and looking at other college and universities for potential enrollment resulted in a student's dissatisfaction in college. Milem and Berger (1997) when studying first year students found that greater involvement within college life especially with faculty members lead to higher levels of satisfaction in college. For many of these students, institutional commitment was a strong predictor of the intention to re-enroll (Milem \& Berger, 1997). Lastly, Woosley's (2003/2004) research on 613 undergraduate students through collection of institutional data and survey answers revealed that $41 \%$ of students who withdrew because of dissatisfaction with grades and $43 \%$ of students who withdrew because of health problems re-enrolled at a later date at the institution. However, those students who listed that they decided to attend another college, had conflicts between school and a job, felt isolated or alone, and did not like the size of the university were significantly less likely to re-enroll as compared to their peers who withdrew for other reasons (Woosley, 2003/2004).

Yet, research conducted with a theoretical foundation of Spady (1970b) and Tinto (1975) confirms that inadequate social and academic assimilation into the college community can lead to college student withdrawal (Mallette \& Cabrera, 1991; Milem \& Berger, 1997). Institutions need to seek out opportunities to create environments that assist with student integration. Additionally, researchers must also be concerned with the variables that can assist in predicting college student retention.

While not directly related to college students, Rootman (1972) helped explain the overall withdrawal behavior of adults. This study was beneficial to review as it provided an understanding of the behaviors of adults which, with limitations, can be generalized to 
other populations. Rootman (1972) with participants from the United States Coasts Guard Academy learned that person-role fit and interpersonal fit are the variables that explain most of the variance in withdrawal decisions. With 14 instruments administered to 343 adults, Rootman (1972) reviewed the variables of voluntary withdraw, involuntary withdraw, personality, actual attachment from insiders, discussion of leaving with outsiders, discussing of leaving with insiders, section change, interests, perceived attachment from insiders, and values. His study revealed that individual fit played a central role in the attrition of United States Coast Guard candidates. Even though these individuals were not college students, the study is important as the United States Coast Guard Academy has the highest attrition rate for all United States Service academies and can provide insight into the attrition rates of adults. Rootman (1972) encouraged his research to be furthered in college and university settings as an understanding of student fit seems to be imperative for all institutions of higher education.

\section{Predicting College Student Retention}

Beyond recognizing the factors that impact college student attrition, some studies seek to understand the student variables that might predict retention. One of the primary goals of this dissertation was to understand the role of precollege characteristics, specifically those of first generation college students, and their impact on attrition rates at private institutions in Kentucky. With this goal in mind, it is important that research revealing the student variables that can predict retention be considered.

Reason (2003) outlined the student variables that might predict retention in his review of research surrounding the area of retention. He noted that many studies suggest that student attrition occurs more often than not during the first and second years of 
college. In his own study of 39,000 students who completed the ACT assessment, Reason (2004) suggested that higher ACT Composite scores increase the chance for students to graduate from college. He also identified the percentage increase in ACT Composite scores that accounted for the "...likelihood a student would be retained" at a given institution (Reason, 2003, p. 186).

Murtaugh, Burns, and Schuster (1999) predicted the retention of students at Oregon State University (OSU) from 1991 to 1996. Using an extensive database, these researchers looked at the variables that contributed to student retention at OSU. Using the time to withdrawal for a student as the dependent variable and demographic and academic data as the independent variables for the study, researchers performed a longitudinal, quantitative study with univariate analysis. Results revealed that in-state students had lower attrition rates compared to out of state students and that age played a significant role in the attrition rates of enrolled students. The older a student was at OSU the less likely he/she was to graduate from the institution. OSU determined that they must offer more relevant courses at times and locations more convenient for older students and also that scholarships are critical in assisting students with financial challenges (Murtaugh, Burns, \& Schuster, 1999). With limited scholarship opportunities and accessibility for summer school courses their research revealed that in-state students had higher retention rates as compared to out of state students (Murtaugh, Burns \& Shuster, 1999).

Understanding factors such as academic preparedness (Astin, Korn, \& Green, 1987; Tross et al., 2000). and residency (Peltier, Laden, and Matranga, 1999) of a student better prepare institutions for the challenges that college students may experience. 
Researchers have found that students with high grade point averages in high school and college admissions tests (ACT/SAT) are predictors of student retention (Astin, Korn, \& Green, 1987; Tross et al., 2000). Peltier, Laden, and Matranga (1999) in their review of research on student persistence learned that students (no matter their background characteristics) exceeded their predicted learning and personal development if they lived in residence halls. Institutions must also focus on the characteristics of their incoming students with particular emphasis on those students who are first generation college students (London 1989; Longwell-Grice \& Longwell-Grice, 2008). London (1989) concluded through interviews of first generation college students that they were often scared, worried and felt alone leaving them to feel like dropping out was their only option when coping with their dissatisfaction. Longwell-Grice and Longwell-Grice (2008) found that first generation college students needed mentors such as faculty members to teach them the ropes of college and provide them with information on what to expect in college.

\section{First Generation College Students}

One of the greatest concerns for institutions across the United States is the retention of their students. Especially for private institutions, the retaining of college students helps ensure budgets are maintained and financial obligations are upheld. Many researchers have focused on learning more about how to increase retention numbers and provide retention efforts for all students (Lohfink \& Paulsen, 2005; London, 1989; Longwell-Grice \& Longwell-Grice, 2008; Pascarella \& Terenzini, 2005; Terenzini et al., 1994; Tinto, 1975). One of the factors that is of critical importance to study in the area of retention and attrition includes the parental educational level of incoming college 
students. Those students with parents who have not completed their degree in higher education nor have no college education are considered first generation college students (U.S. Department of Education, 1998).

First generation college students often experience greater isolation during their college experience (Richardson \& Skinner, 1992; Rodriguez, 1982). Understanding the lives of first generation college students provides vital information for professionals in higher education as they work to support these students. Engle \&Tinto (2008) discovered that the average unmet need for first generation college students was $\$ 6,000$. Many first generation college students must hold off-campus jobs in order to meet their financial needs distracting them from their coursework. Rendon (1996) learned that first generation college students have a difficult time in college because of the little connection they find between the classroom curriculum and their own lives.

\section{Self-Perceptions}

London (1989) was interested in how student persistence for first generation college students was connected to family dynamics with specific understanding of how first generation college students navigate their competing roles of family member and student. To address London's (1989) questions he recruited 15 students from various Boston, Massachusetts area colleges and universities. Through qualitative measures such as interviews and pointed questions, London (1989) determined a great deal about first generation college students. He learned that the path of a first generation college student can be challenging and that these students are often "...confused, frightened, and alienated, only to drift away and drop out" (London, 1989, p. 168). Much of the drama in 
a first generation college student's life for London (1989) was associated with their "family role assignments" and their separation from the family (p. 147).

Family role assignments are part of family theory which suggests that individuals are a part of "...a division of emotional labor with different members responsible for designated psychology tasks" (London, 1989, p. 146). Some examples of family assignments include "achieving child" or "mediating child" (London, 1989, p. 146). He revealed that students find their "family voices" to be powerful influences during their college career (London, 1989, p. 166). These family voices are often from parents or elder family members either pushing them to success in college or asking them to pull away from college and become more present in the household (London, 1989). Professionals in higher education must be aware of "family voices" while creating opportunities for students to feel empowered to make their own decisions while also respecting the wishes of the elders in their families.

Longwell-Grice and Longwell-Grice (2008) followed the lives of four first generation, working class, white male college students in an attempt to learn about their opinions of faculty support at colleges and universities. They learned that first generation college students change as they transition from high school to college (Longwell-Grice \& Longwell-Grice, 2008). They also noted that young men found it difficult to both a family member and as college students while also trying to meet the expectations of the institution and reach academic achievement (Longwell-Grice \& Longwell-Grice, 2008). These students need mentors to guide them through their collegiate experience and successful retention programs to keep them connected to the institution. It was important 
that these students had a sense of belonging on campus in order to successfully be retained at their institution (Longwell-Grice \& Longwell-Grice, 2008).

\section{Mitigating Factors}

Terenzini, Springer, Yaeger, Pascarella, and Nora (1996) performed a study that showcased the characteristics of first generation college students in hopes of comparing the precollege characteristics and experiences of first generation college students to those who are not first generation college students. Using a longitudinal, quantitative design of 3,840 students in a national data sample from completed surveys, Terenzini et al. (1996) performed logistic regression, multiple regression, and discriminant function analysis to answer their questions. With precollege characteristics as the independent variables and group membership (first generation or not) as the dependent variable, these researchers discovered that

“...compared to their traditional peers, first generation students are more likely to come from low-income families, to be Hispanic, to have weaker cognitive skills (in reading, math, and critical thinking), to have lower degree aspirations, and to have been less involved with peers and teachers in high school. First generation students...take longer to complete their degree programs, and report receiving less encouragement from their parents to attend college" (Terenzini et al., 1996, p. 16).

First generation college students often work more hours per week at an offcampus job and spend fewer hours studying as compared to continuing generation college students. These differences between first generation college students and continuing generation college students can have an impact on how long it takes a first generation 
college student to complete his/her degree as compared to a continuing generation college students. First generation college students also reported receiving less encouragement from their parents to attend college (Terenzini et al., 1996). Researchers propose a decrease in encouragement occurs because many these students often serve as caregivers for their families (Jehangir, 2010a; Terenzini et al., 1996).

Since first generation college students report receiving less encouragement from their parents to attend college, it becomes imperative to understand the effect of social capital on first generation college students (Terenzini et al., 1996). Social capital is defined by the relationships that an individual has with others and how that individual gains access to resources through those relationships (Coleman, 1988). Wells (2008) used a national data set to understand the impact of social capital on race/ethnic group as well as other demographic variables including first generation status. Wells (2008) discovered that social capital had a significant impact of the persistence of students from their first year to their second year. Those students who had parents with a college education and peers who planned to attend college were more likely to persist through college. First generation college students often lack this social capital (parents may not have graduated or attended college and peers may not be attending college) therefore decreasing their likelihood of persisting through college. Colleges and universities must create programs and policies that assist first generation college students in the enrollment process as well as provide an understanding on how to navigate the college experience.

\section{Academics}

Choys's (2001) and Riehl's (1994) research revealed that first generation college students generally have lower academic preparation by standardized measures such as the 
American College Test (ACT), high school ranks as well as high school Grade Point Averages. Thayer (2000) also suggested that first generation college students enter college with less academic preparation and have been provided less information on what the academic experience is like in college. Pascarella et al. (1996) discovered that many first generation college students as compared to continuing generation college students will make significant improvements in their critical thinking and math skills during their first year (as compared to continuing generation college students), however their reading comprehension scores will still significantly fall behind those of continuing generation college students. This same research suggested that first generation college students will need to spend more time studying as compared to continuing generation college students in order to improve their reading comprehension scores.

Bui (2002) performed a study on 64 first generation college students recruited from the Program Leading to Undergraduate Success at the University of California, Los Angeles (UCLA) giving them a questionnaire to assess their background information, reasoning for attending college, and their first-year experience. Students were chosen from this program as the program specifically served first generation college students with peer resources, mentors, and faculty advising services. After multivariate analysis was performed, Bui (2002) learned that these first generation college students as compared to continuing generation college students were more likely to be pursuing a degree to assist their families later in life rather than for their own personal education. First generation college students also considered themselves to be less prepared as their continuing generation counterparts and were more worried about failing out of college as compared to continuing generation college students. Lastly, first generation college 
students felt like they had to put more effort into studying than did continuing generation college students (Bui, 2002). Since differences in college experiences have been found to exist between first generation and continuing generation college students, it is important to understand the impact that cultural capital has on those students.

Collier and Morgan (2008) wanted to better understand the role cultural capital has on a student's understanding of faculty expectations on their academic performance. Collier and Morgan (2008) believed that students with less cultural capital, those students with parents without college experiences, had a lower understanding of the student role and the ability to respond to the expectations of faculty. To determine if their hypothesis was accurate, Collier and Morgan (2008) studied first generation college students at Portland State University. These researchers conducted focus groups which included 68 first generation college students. The researchers also conducted interviews of first generation college students to gain a better understanding of their academic experience. The researchers learned that both first generation and continuing generation college students struggled to understand the expectations of their faculty yet first generation college students had greater difficulties than continuing generation college students in understanding those expectations. First generation college students reported challenges with time management and prioritizing assignments. Many first generation college students reported that they had little outside help with classroom assignments and often had trouble time managing because of outside commitments (e.g. family obligations and off-campus jobs).

Many first generation college students discussed the challenges they faced in understanding the faculty member's jargon and use of language in the classroom. First 
generation college students had greater difficulty understanding what the faculty member meant in lectures as compared to continuing generation college students. Lastly, Collier and Morgan (2008) discovered that first generation college students had less cultural capital as compared to continuing generation college students causing them a more difficult time understanding what a professor wanted in an assignment and what it would take to succeed in the course. Collier and Morgan (2008) suggest that because a first generation college student has family based differences in regard to cultural capital, their knowledge of college academic expectations is different than that of a continuing generation college students. Beyond understanding the role of cultural capital on those students, it is also imperative to have an understanding of the impact of various programming initiatives for first generation college students.

\section{Programming Initiatives}

Jehangir (2010b) wanted to better understand the impact of multicultural learning communities on first generation college students. These communities were created to assist first generation college students as they experienced marginalization and isolation at a large, predominately Caucasian research institution. Courses in the multicultural learning communities were designed to encourage active participation in and outside the classroom with their peers while also encouraging them to reach out to their faculty and advisors. In total, there were 128 first generation college students that participated in Jehangir's (2010b) study between fall of 2006 and spring of 2007. Weekly reflective writings and a final paper were the data for this study. Follow-up interviews were conducted with 25 participants in the study. Through analysis of the weekly reflective writings and a final paper, Jehangir (2010b) learned that first generation college students' 
participation in the multicultural learning community allowed them an opportunity to express themselves and present their lived experiences to others. They had opportunities to discuss the challenges they faced as first generation college students and their lack of cultural capital. These students, because of the multicultural learning communities, no longer felt marginalized and isolated.

Inkelas, Daver, Vogt, and Leonard (2007) also researched the importance of learning communities for first generation college students. With a sample of 1,335 first generation college students at 33 different institutions (during the spring of 2004), these researchers collected data through a 258 item Internet-based survey instrument. Their ultimate goal in this research effort was to better understand the role that the living learning communities had on first generation college students' academic and social transition in college. The results indicated that living/learning communities were beneficial to first generation college students. These programs provided positive academic and social transition for first generation college students into college life. Since these students experienced positive transitions, their self-confidence increased. Also, these students, as members of the living/learning communities, had access to resources available in the residence halls. These resources such as structured study groups and social programming lead the students to feel more socially connected to their environment. In understanding Inkelas, Daver, Vogt, and Leonard's (2007) research it is apparent that first generation college students' participation in living/leaving communities is both valuable and impactful. 


\section{The Second Year Student}

In a study by Richmond and Lemons (1985), second year students were identified as experiencing difficulties during their second year if they had "...doubts regarding the choice of a career, dissatisfaction with personal relationships, and a heightened awareness of and concern for the financial aspects of one's college education" (p. 176). As Perry (1970) notes in his research, second year students sometimes experience challenges during their second year because developmentally they are incapable to cope successfully with the multiple choices provided in college. Erickson (1968) also noted that sophomores experienced both identity issues and uneasiness with conflict which intensifies their troubled feelings about career choices, value decisions, and lifestyle choices (as cited in Wilder, 1993). Recent efforts have been made to better understand the second year slump, and while these efforts are limited, they are helpful. Graunke and Woosley (2005) discovered that sophomores who had chosen a major had higher grades and more satisfaction with their academic courses.

Not all second year students experience challenges during their second year in college. In 1976, Margolis described the second year as a period of identity crisis involving a student's academic, social, and personal life. Of course, there were second year students that did not experience such an identity crisis. Later in 1982, Furr and Gannaway (1982) found that difficulties during the second year was a "...period of confusion and uncertainty" that led to dissatisfaction (p. 340). While some second year students were dissatisfied, other second year students were satisfied with their second year experience. However, research shows that the second year in college life can be one of the greatest challenges for many students (Gahagan \& Hunter, 2006; Lemons \& 
Richmond, 1987; Morgan \& Davis, 1981; Wilder, 1993). Therefore, it is imperative that researchers continue to study the second year because of the challenges students face and the potential impact those challenges have on college student persistence.

\section{Self-Perceptions}

Terenzini and Wright (1987) sought to understand if students' perceptions of their personal growth correlated with their experience during their first two years of college and if the points of influences of student's personal growth differed throughout those two years. Based on Tinto's (1975) theoretical model, 1,105 first year students completed a questionnaire during new student orientation. Throughout the next two academic years, students completed additional questionnaires that related to their college experiences. Four hundred and sixty responses were usable and analyzed for significance once the study was reviewed. Using students' pre-college characteristics as the dependent variables and college experience variables as the independent variable, Terenzini and Wright (1987), discovered that personal growth during their first year of college related to a second year student's social and academic integration. With the help of the linear structural relations data analysis model these researchers concluded that academic and social integration during the first two year was critical (Terenzini \& Wright, 1987).

Loeb and Magee (1992) provided an additional study interested in investigating the changes of attitude and self-perceptions of college students from their first year to second year in college. A questionnaire was given to 141 first year students during their second day of college. Twelve weeks later a similar follow up questionnaire was provided to students who were still enrolled during their first semester. A similar questionnaire was then mailed to all students who were still enrolled at the university 
during their second year of college. A MANOVA revealed that students' attitudes and self-perceptions did change between their first and second year in college. Through the college experience, these students became more socially accepting and tolerant of those that were different than themselves. An increased concern for environmental and political issues on local and national levels occurred for these students in their second year, as compared to their concern in their first year of college life. Lastly, since students in their second year were found to be more adjusted to college life than first year students, several second year students were found to be more self-confident than during their first year in college.

Loeb and Magee (1992) believed that the interactions students had with people different from themselves and learning about those differences in the classroom lead to change in these students' attitude about people different from themselves. In this study, students in their second year had considerable attitude shifts concerning environmental and political issues (Loeb \& Magee, 1992). One change that was prevalent among many of the students was their "interpersonal relationships" and "trusting" ability of others (Loeb \& Magee, 1992, p. 354). Loeb and Magee (1992) suggest that students experience great developmental changes during their first two years of college as evident by the data discovered in their own research.

\section{Mitigating Factors}

In their 1969 book, "The Impact of College on Students," Feldman and Newcomb suggest that as students' progress through college their 'openness' increases, their "...conservatism in regard to public issues" decreases, and their "...sensitivity to aesthetic and 'inner' experiences" grows (p. 48). Students were found to "... show [a] declining 
commitment to religion, increases in intellectual interests and capacities and increases in independence, dominance, and confidence as well as in readiness to express impulses" (Feldman \& Newcomb, 1969, p. 48). Pascarella and Terenzini (2005) continued the work of Feldman and Newcomb (1969) discovering that college students have increased involvement in civic and community service efforts after graduation, have more opportunities to connect to influential social networks, and have a commitment to 'orientated' goals throughout their lives (p. 342).

Yet, student changes and personal growth throughout college are not met without challenges. Research shows that the second year can be one of the most difficult times in students' lives (Gahagan \& Hunter, 2006; Lemons \& Richmond, 1987; Morgan \& Davis, 1981; Wilder, 1993). Gahagan \& Hunter (2006) learned through their research that financial hardships play an instrumental role in the attrition of second year students. This increased concern for how to pay for college lead many second year students to worry about their education. Lemons and Richmond (1987), using Chickering as their theoretical model, determined that second year students needed student affairs practitioners' support with adjustment and coping challenges during their collegiate experience. Lemons and Richmond (1987) learned that some second year students were struggling with Chickering's vector of "developing autonomy." Those second year students that struggled most in this vector where those students who wanted instrumental independence but worried about how to finance their college education. These students may become frustrated because they cannot finance their education on their own and may have to seek assistance potentially from their families. Gohn, Swartz, and Donnelly (2001) also discovered one of the greatest concerns for second year students was how to 
pay for college or if they would be able to keep their scholarships that they received when they entered school. Many were worried about financial debt and how they would be able to pay off their loans in the future

Morgan and Davis (1981) reported that students during their second year felt isolated and neglected. In their case study research on second year students, they wanted to address the challenges that second year students experienced. After a student designed a proposal on how to address challenges within the second year of college, Morgan and Davis (1981) realized that second year students did not feel valued and in an effort to address this issue, a second year student organization was established in order to keep second year students up to date on what was happening at the college. Later, a questionnaire was given to all second year students to understand their overall experience in college. Through qualitative measures, such as coding, the researchers revealed that specific variables, like the choice of a roommate impacted a second year student's experience. Student's compatibility with their roommates appeared to affect their overall second year experience. Morgan and Davis's (1981) research encourages practitioners to take a look at how they address the needs of their second year students.

The isolation these researchers revealed may have occurred since many sophomores had not yet held a leadership position and student affairs offices lacked the programming and attention for these lost students (Pattengale \& Schreiner, 2000). These students are considered lost because of the distance they experience in their community and the focus they put on individual activities rather than social activities (Gardner, 2000). Researchers suggest that institutions are overlooking second year students however they have needs that differ from other classes (Graunke \& Woosley, 2005). 
Gardner (2000) discovered that second year students were less likely to be dynamically engaged in their own learning and relied less on faculty for both academic and personal support. Gardner (2000) also found that second year students spent more time on social activities as compared to academic activities. These feelings of isolation for second year students may even be more pronounced today as many institutions put a great deal of energy into the establishment and enhancement of first-year initiatives (Schaller, 2005).

Margolis' (1976) research showed how first year students are placed in their own societies. They generally live with other first year students and the programming efforts in their residence halls are tailored to their needs. Some of these students may feel isolated yet they are surrounded by students experiencing similar feelings. Few programmatic efforts such as the one described above exist for second year students. Beyond the first year experience, students are often placed in residence halls with various classes (sophomore, junior or senior) of students so the support groups these students once knew no longer exist on such a strong level. William Jewell College in Missouri has realized the importance of second year initiatives. As an institution noted for its outstanding working in first-year initiatives, the retention rate of the institution had risen from 72 percent to 86 percent since the programs beginning in 1997. However, the retention rates for students after their third semester were frustrating. First year students were provided opportunities for a great deal of personal attention yet second year students felt neglected. New second year programming initiatives have been put in place to manage the challenges second year students were feeling. Programming initiatives included service projects, second year class retreats, and more intentional interactions with advisors and faculty members (Winslow, 2006). 
Schaller (2005) interviewed 19, traditional age students at a private Catholic university to understand their second year experience in college. Analysis revealed that students experienced four stages in their lives: random exploration, focused exploration, tentative choices, and commitment. Each of these stages included three aspects of their lives: how they viewed themselves, how they viewed their relationships, and how they viewed their academic experiences and decisions. Most of the students studied existed in either the focused exploration or tentative choices stage in all three aspects of college. Many second year students were in focused exploration stage because they were beginning to express frustration about their personal and academic life. Many students were questioning choices they had made during the random exploration stage and were wondering if they were wrong in their decisions. Some of these second year students felt a great deal of pressure to choose a major and decide on future careers. Other second year students existed in tentative choices stage. These second year students were moving out of the focused exploration stages and making choices, many tentatively, for their future. These students were beginning to see their future more clearly. However, few second year students experienced the commitment stage. It was difficult for these students to make confident decisions about their future. These students were unable to feel the relief when making a solid decision and sticking to it (Schaller, 2005).

Many second year students studied were in the focused exploration stage and were more award of their own decisions and what was happening in the world around them (Schaller, 2005). In the focused exploration stage second year students found this time of their college life to be full of frustration, as they were very uncertain about the decisions they were making. In the tentative choices stage second year students made 
decisions about careers and relationships which lead to outcomes for the future. Schaller (2005) suggests that second year students must have time to reflect, explore, and be given support in all of their endeavors. She closes with this final statement in her article:

I have begun to encourage educators to label the sophomore year in ways that encourage students to take responsibility for their learning. This can be the year in college when students determine their own direction, actively select their friends, identify what they want for their future, and begin to take ownership of their own learning experiences (Schaller, 2005, p. 24).

\section{Academics}

Wilder (1993) suggested that during a student's second year in college, he or she experienced developmental challenges that impact academic performance. Wilder (1993) attempted to understand the decreased academic performance of second year students at Western Kentucky University. She defined second year students as “...students [who] were enrolled for four semesters consecutively during their freshmen and sophomore year" (Wilder, 1993, p. 20). She compared two groups of second year students: those who were maintaining a strong academic performance and those that were not. Using three instruments, the Biodata Form, the State Trait Anxiety Inventory, and the Children's Academic Motivation Inventory, she discovered some interesting findings. Through the use of discriminant analysis she revealed that during the second year student-faculty interactions, absenteeism, campus involvement and lack of dedication to institution distinguished the most differences between the two groups (Wilder, 1993). Her study suggests to practitioners the need for intentional faculty-staff interactions with students, 
increased advising efforts, and the development of programs aimed at academically supporting second year students (Wilder, 1993).

Gohn, Swartz, and Donnelly (2001) did additional research using case studies to recognize the persistence of second year students. They used interviews of 11 second year students at a large research university to understand the academic factors, emotional and personal support factors, commitment and aspiration factors, as well as financial factors that impacted student retention. Some quantitative data such as ACT scores, graduation and retention rates, and cumulative GPAs were used to better understand second year retention (Gohn, Swartz, \& Donnelly, 2001). Through coding of interview data and basic descriptive analysis of quantitative data, Gohn, Swartz, and Donnelly (2001) found that the level of commitment and aspirations for second year students had changed significantly from their first year in college. Second year students were more comfortable in their environment, more committed to their major of study, had strong friendships with other students, and were thought to be less stressed. These students were comfortable with their major but they were unsure as to how their major would translate into a career one day.

Gohn, Swartz, and Donnelly's (2001) research suggests to professionals that institutions must provide academic support systems for second year students, offer career services that focus on what to do with specific majors once a student graduates, as well as increased efforts to connect students with faculty members beyond the classroom experience. In order to learn more about the role of faculty for second year students, Graunke and Woosley (2005) performed an extensive study to understand the issues that impact the academic success of second year students. Using survey results from 1,093 
second year students (those students who had completed between 42 and 57 credit hours) an analysis of the quantitative data were performed. With GPA as the dependent variable and demographic and academic experiences and attitudes as the independent variables, researchers determined that a purposeful effort from faculty and student affairs practitioners was necessary to help sophomores choose their major.

Graunke and Woosley's (2005) research reported that increased faculty interaction with second year students led to greater academic success. Similar studies discovered that second year students spent more time with social activities and less time on academic commitments (Gardner, 2000). Though the second year may be the toughest for college students, the academic programming efforts geared to second year students do not parallel those academic programming efforts tailored to first year students (Pattengale \& Schreiner, 2000). Graunke and Woosley (2005) also learned that certainty in choice of major was a significant predictor of academic success. These researchers believed that students who decided on a major had increased motivation and focus which lead to greater dedication and integration in courses. Graunke and Woosley (2005) suggest that academic programming focused on major selection is imperative during the second year. Lastly, Graunke and Woosley (2005) discovered that since many second year students are taking more major courses rather than general requirements faculty interactions were more motivating for these students. If these students had decided on a major, the feedback from their faculty members teaching major courses seemed to be more motivating and have greater impact. 


\section{Programming Initiatives}

Flanagan and Black (1991) recognized the need for additional second year programming. These researchers believed that without successful academic, social, and financial integration into the college community second year students would dropout. Data revealed that through studying 23 institutions the average retention rate from the second to third year of those institutions was $75 \%$ which was 12 points lower than those institutions' first year retention rate. Looking at retention as the main variable of this study, Flanagan and Black (1991) revealed that frontloading was occurring in first year programs but there was a lack of such initiatives in the second year. This research influenced Flanagan's home institution to create an initiative for second year students. The "Crisis, Conflict, Consensus" voluntary program lasted one week prior to the beginning of school and provided second year students an opportunity for individual discussions with a faculty member. This faculty member was charged with leading interdisciplinary groups to discuss the problem of national identity. Each faculty member assigned to the group also served as the academic advisor to each of the students in his/her group. Relationships were developed through this program and students began to trust their advisor with academic questions (Flanagan \& Black, 1991).

Lorenzetti (2006) suggests that the second year students are not supported like first year students nor like juniors and seniors who have determined their major; they are students who feel alone and disconnected. One of the major programmatic initiatives that Lorenzetti (2006) reviewed was the second year student programming model. Using current university resources, second year students could be offered programmatic 
initiatives in the residence halls tailored just for them. These programs could help students' develop life skills and deal with the second year slump (Lorenzetti, 2006).

Sanchez-Leguelinel (2008) was also concerned with understanding some of the initiatives that have been created to address the needs of second year students. Using the Student Satisfaction survey, Sanchez-Leguelinel (2008) quantitatively analyzed data on a Sophomore Peer Counseling Program. Two hundred and ten second year students participated in a peer counseling program aimed at "...increasing retention, academic performance, and college satisfaction" (Sanchez-Leguelinel, 2008, p. 637). Through an exploratory factor analysis and a one-way ANOVA, Sanchez-Leguelinel concluded that second year students enjoyed peer counseling. These one on one meetings permitted students the opportunity to discuss their struggles during their second year and develop ideas for solutions to those challenges. Overall, this study suggests to colleges and universities the need for one on one attention for second year students and that such attention can be achieved through peer counseling.

The National Resource Center for The First-Year Experience and Students in Transition at the University of South Carolina created a monograph to provide information on the lives of second year students. Chapter eight of the monograph titled "Learning from the Best: Recommendations for Sophomore Initiatives" provides concrete ideas for professionals in higher education as they work with second year students. Some of the major suggestions include performing research on the undergraduate population, providing seminars on career planning and exploring undergraduate majors, offer solid advising programs to students, conducting leadership development series, and using student mentors to assist other peers. Tobolowsky \& Cox 
(2007) recommend that that colleges and universities look at their second year programs and make sure they meet all of the needs of these students. Taking a research-based approach at recognizing second year students' perceptions, experiences, and academic issues will offer practitioners the opportunity to successfully construct programs that meet the needs of these students.

\section{Summary}

This review showcases some of the most significant findings in regard to retention and attrition in higher education with specific focus on the second year students. Academic and social integration, as proposed by Tinto (1975), are important for all college students as they adjust and acclimate to the college culture. Specifically for second year students, faculty involvement outside of the classroom assists those students in fighting off struggles during their collegiate years (Schaller, 2005). First generation college students need a great deal of support during their collegiate years. A review of many articles focused on first generation college student reveals that these students come to college less academically prepared and with less knowledge about the college experience as compared to their continuing generation counterparts (Thayer, 2000). These students also face challenges when adjusting to college life, feeling less welcomed and supported in their college journey (Pike \& Kuh, 2005). Research on attrition concerns at colleges and universities has pushed practitioners and scholars to adjust their way of life (Braxton, 2000). Yet, continued efforts must be made to address attrition concerns from all classes (i.e., first year, second year) of students (Hunter, Tobolowsky, \& Gardner, 2010) 


\section{CHAPTER III}

\section{METHODOLOGY}

\section{Overview}

This study examined the factors that predicted second year student persistence for students who had enrolled at four private institutions in the state of Kentucky. This study provided an increased understanding as to why second year student attrition occurs. This study reviewed those pre-entry variables that predicted persistence beyond the second year. Students were surveyed during the end of their fourth semester in college. Spady's (1970b) model of student dropout and Tinto's (1975) model of student departure served as the theoretical foundation for this study. Chapter III describes the methodology that was be employed to address the research questions and hypotheses as outlined in Chapter I.

\section{Population and Sample}

The population for this study was second year college students at the end of their fourth semester of college at four private institutions in Kentucky: College A, College B, College C, and College D. These four private institutions share similarities and also have differences. All four institutions are co-educational, liberal arts institutions located near or in a Kentucky city. All of these institutions boast a large percentage of students living on campus in residence halls. Over $80 \%$ of faculty members at each of the four 
institutions hold the highest degree in their field; College D has the highest number of faculty members with the highest degrees in their field at $96 \%$. Each institution distinguishes itself with rigorous and excellent academic programs. However, some variations in the institutions exist. A comparison of the four institutions studied in this dissertation is outlined in Table 1. College $\mathrm{D}$ has the lowest comprehensive cost of $\$ 36,600$ for the 2011-2012 academic year. College D has the smallest enrollment for the 2011-2012 academic year with just over 1000 students. College A offers the most majors; over 50. College B has the highest average ACT score of 28.5 for incoming students. College $\mathrm{C}$ has the lowest average ACT score of 24 for incoming students.

Noel-Levitz (2011) has determined in their assessments that nearly $7 \%$ to $14 \%$ of second year students leave during their second year. For private institutions, on average, $16.3 \%$ of students leave between census day of their second year of course work and census day of their third year of course work (Noel-Levitz, 2011). The four private institutions analyzed in this study had a 5\% to $21 \%$ attrition rate of their second year students between census day of their second year of course work (fall 2010) and census day of their third year of course work (fall 2011). Overall, there are both similarities and differences between these four private, liberal arts institutions in Kentucky.

\section{Table 1}

Comparison of the Four Institutions Studied in this Dissertation

\begin{tabular}{|c|l|l|l|l|}
\hline & College A & College B & College C & College D \\
\hline $\begin{array}{c}\text { \# of Faculty Members } \\
\text { with hightest degree in } \\
\text { field }\end{array}$ & $82 \%$ & $94 \%$ & $95 \%$ & $96 \%$ \\
\hline Tuition, Room \& Board & $\$ 41,740$ & $\$ 42,500$ & $\$ 36,910$ & \\
\hline Enrollment & $2000-2500$ & $1300-1500$ & $1200-1500$ & $\$ 36,600$ \\
\hline \# of Majors & Over 50 & 26 & 42 & $1000-1400$ \\
\hline
\end{tabular}




\begin{tabular}{|c|c|c|c|c|}
\hline Average ACT score & 24.5 & 28.5 & 24 & 27 \\
\hline Average Age & $17-23$ & $17-23$ & $17-23$ & $17-23$ \\
\hline Gender & $\begin{array}{l}60.0 \% \text { female } \\
40.0 \% \text { male }\end{array}$ & $\begin{array}{l}53.7 \% \text { female } \\
46.7 \% \text { male }\end{array}$ & $\begin{array}{l}57.7 \% \text { female } \\
45.3 \% \text { male }\end{array}$ & $\begin{array}{l}58.1 \% \text { female } \\
41.9 \% \text { male }\end{array}$ \\
\hline Race/Ethnicity & $\begin{array}{l}\text { American Indian or } \\
\text { Alaska Native: } 0.1 \% \\
\text { Asian: } 2.2 \% \\
\text { Black or African } \\
\text { American: } 4.1 \% \\
\text { Hispanic or Latino of } \\
\text { Any Race: } 3.5 \% \\
\text { Native Hawaiian or } \\
\text { Other Pacific } \\
\text { Islander: } 0 \% \\
\text { Non-Resident } \\
\text { Alien/International: } \\
1.5 \% \\
\text { White: } 82 \% \\
\text { Decline Answer: } \\
4.4 \%\end{array}$ & $\begin{array}{l}\text { American Indian } \\
\text { or Alaska } \\
\text { Native: } 0 \% \\
\text { Asian: } 5.5 \% \\
\text { Black or African } \\
\text { American: } 4.7 \% \\
\text { Hispanic or } \\
\text { Latino of Any } \\
\text { Race: } 0 \% \\
\text { Native Hawaiian } \\
\text { or Other Pacific } \\
\text { Islander: } 0 \% \\
\text { White: } 86.3 \% \\
2 \text { or More } \\
\text { Races: } 2.8 \% \\
\text { Decline Answer: } \\
7 \%\end{array}$ & $\begin{array}{l}\text { American Indian or } \\
\text { Alaska Native: } 0.2 \% \\
\text { Asian: } 0.5 \% \\
\text { Black or African } \\
\text { American: } 8.6 \% \\
\text { Hispanic or Latino of } \\
\text { Any Race: } 2.0 \% \\
\text { Native Hawaiian or } \\
\text { Other Pacific Islander: } \\
0 \% \\
\text { Non-Resident } \\
\text { Alien/International: } \\
1.6 \% \\
\text { White: } 85.8 \% \\
2 \text { or More Races: } .5 \% \\
\text { Decline Answer: } .8 \%\end{array}$ & $\begin{array}{l}\text { American Indian or } \\
\text { Alaska Native: } 0.1 \% \\
\text { Asian: } 1.7 \% \\
\text { Black or African } \\
\text { American: } 3.0 \% \\
\text { Hispanic or Latino of } \\
\text { Any Race: } 2.0 \% \\
\text { Native Hawaiian or Other } \\
\text { Pacific Islander: } 0 \% \\
\text { Non-Resident } \\
\text { Alien/International: } 1.4 \% \\
\text { White: } 86.1 \% \\
2 \text { or More Races: } 2.1 \% \\
\text { Decline Answer: } 3.6 \%\end{array}$ \\
\hline $\begin{array}{l}\text { Overall Retention Rates } \\
\text { (2111-2012) }\end{array}$ & $80.5 \%$ & $92.5 \%$ & $75.6 \%$ & $92 \%$ \\
\hline $\begin{array}{l}\text { Retention Rates for } \\
\text { Second Year Students } \\
\text { (2010-2011) }\end{array}$ & $69.3 \%$ & $95.4 \%$ & $89.2 \%$ & $89.8 \%$ \\
\hline
\end{tabular}

For purposes of this study, the population consisted of full-time, second year students who were completing their fourth semester of academic work. These students were continuously enrolled at the institution. Part-time students and transfer students were excluded from this study so these subjects were comparable to other second year 
students as defined in the research literature (Gahagan \& Hunter, 2006). In regards to the population, in fall 2011 there were 1343 total second year students enrolled at the four institutions listed above. Since the survey instrument was given out to students during the latter part of the fourth semester of college courses, the sample size was the number of students that completed the survey instrument. McMillan and Schumacher (2001), in their discussion of sample size, suggest that "the general rule in determining sample size is to obtain a sufficient number to provide a credible result" (p. 177). Stevens (2002) tells us that for social science research there needs to be around 15 subjects per the number of predictor variables in order for the equation to cross-validate producing a reliable regression equation. For this dissertation, there were 17 predictor variables therefore around 255 subjects were needed for this study in order for the equation to cross-validate producing reliable regression equations. Since there were 1343 second year students in the fall 2011 semester, a $19 \%$ response rate was needed to meet the power threshold for this study. McMillian and Schumacher (2001) remind us that the larger the sample sizes the best chance of increasing power in the study. Refer to Chapter IV for more information on the sample size.

\section{Design}

This research was a quantitative predictive study that used data collected by administering the Sophomore Experiences Survey via the Internet. This predictive study examined the relationship between predictor variables including pre-college characteristics, scores on the Thriving Quotient in the Sophomore Experiences Survey, and campus experiences and perceptions and the criterion variables of the student's intent to re-enroll after their fourth semester of their second year and intent to graduate from 
college. The term thriving was developed from the psychology literature by Keyes and Haidt (2003). Keys and Haidt (2003) used the term flourishing to explain midlife adults who were actively engaged with others. The foundation of flourishing adults is emotional vitality and positive functioning. These adults have healthy relationships, wishful for the future, productive in their life's work, and find meaning in their lives. Schreiner's (2010a) added the elements of academic success and goal orientation to Keyes and Haidt (2003) concept of flourishing and called the new concept thriving.

This study differed from Schreiner's (2010a) study as second year students in this research were only attending private institutions in Kentucky. Schreiner's study is first outlined in Hunter, Tobolowsky, and Gardner's 2010 book Helping Sophomores Succeed: Understanding and Improving the Second-Year Experience. In that study, she did not pay specific attention to first generation college students; while she did collect that information, she did not draw special attention to that demographic item. Some of the demographic items of this study were first generation status, gender, race/ethnicity, college grades, and certainty of academic major. Levels of student thriving were determined through data collected in the Thriving Quotient (L. A. Schreiner, personal communication, November 29, 2011). Personal communication through electronic mail with Dr. Schreiner explained the components of the Thriving Quotient. The criterion variables were intent to re-enroll and intent to graduate.

The sample of second year students analyzed in this study completed the Webbased Sophomore Experiences Survey in their fourth semester of college courses, the spring 2012 semester. A full year of second year experience was most ideal for this data collection as student's experiences can change dramatically over the course of a year. 
The Sophomore Experiences Survey is a Web-based survey instrument comprised of components of the Thriving Quotient (25 items) as well as demographic questions and questions measuring campus experiences and perceptions.

\section{Instrument}

\section{Description}

The instrument that was used in this study was the Sophomore Experiences Survey first developed in 2007 by Laurie A. Schreiner (Schreiner, 2010a). Schreiner developed the Sophomore Experience Survey as a mechanism to understand both the satisfaction and experience of second year students at colleges and universities. Juillerat (2000) was the first to collect data quantitatively on second year students “...comparing the satisfaction patterns of dropouts versus persisters among sophomores at faith-based private institutions" (Schreiner, 2010a, p. 43). Schreiner's instrument was developed as a follow-up study to Juillerat's (2000) study in an effort to continue the understanding of second year students' experiences using a larger sample that would be more representative of the multiple types of institutions across the United States. Design

The Sophomore Experiences Survey includes 25 items in the Thriving Quotient as well as 44 additional questions that ask about demographics and questions related to a student's involvement, faculty interaction and satisfaction. The survey took approximately 15-20 minutes to complete. Campus experiences and perceptions were determined by mean composite scores of questions related to campus involvement, student-faculty interaction, and student satisfaction. The campus involvement variable 
consisted of nine questions. The student-faculty interaction variable consisted of six questions. The student satisfaction variable consisted of nine questions.

Levels of student thriving were determined through data collected in the Thriving Quotient which were developed by questions from 10 of the original 18 independent scales in the first version of Schreiner's study on sophomore students in 2007 as outlined in Appendix A. The Thriving Quotient (a five-factor model) included the Engaged Learning Index, Academic Determination, Social Connectedness, Diverse Citizenship, and Positive Perspective (L. A. Schreiner, personal communication, November 29, 2011). Demographic information was collected through a total of 13 items on the survey instrument. These items included information on the student's gender, age, enrollment status, race/ethnicity, first generation status, certainty of their major, number of hours worked on campus, number of hours worked off campus, courses compared to first year, experiences compared to first year, degree aspirations, number of courses dropped in their second year, and college grades (Schreiner, 2010a).

\section{Sophomore Experiences Survey Thriving Quotient}

Levels of student thriving were determined through data collected in the Thriving Quotient. The Thriving Quotient (a five-factor model) was used because it contained the questions that have been found to be most predictive of sophomore success (L. A. Schreiner, personal communication, November 29, 2011). In the 2011 version of the Sophomore Experience Survey, Schreiner performed a confirmatory factor analysis on the original 18 independent scales used in the 2010 version of the $S E S$ and created the Thriving Quotient (a five-factor model). The Thriving Quotient was constructed through 
some questions from 10 of the original 18 independent scales. The 10 scales from which the Thriving Quotient was developed are listed below and outlined in Appendix A.

a) Academic Hope Scale. Academic Hope Scale (Lopez, unpublished as cited in L. A. Schreiner, personal communication, April 26, 2011).

b) Citizenship Scale-Socially Responsible Leadership Scale. Using Astin et al.'s (1996) Social Change Model of Leadership as the foundation, this 68-item survey measures the eight dimensions of the model of leadership (Tyree, 1998).

c) Diversity. This 45-item six-point Likert scale questionnaire asks students to rate their feelings from strongly agree to strongly disagree on questions concerning racial identity, homophobia, feminism, empathy, and healthy narcissism (Fuertes, et al., 2000).

d) Effort Regulation. Effort regulation is one of the six dimensions of psychology well-being through one of the questions asked by Ryff and Keyes (1995) in their study.

e) Engaged Learning Index. This index measures learning through three scales: important processing, focused attention, and vigorous participation of learners. Student's scores from these three scales of the index are connected to a student's intent to re-enroll in college, satisfaction with learning, and learning strides in college (Schreiner \& Louis, 2011).

f) Environmental Mastery. Environmental mastery is one of the six dimensions of psychology well-being through two of the questions asked by Ryff \& Keyes (1995) in their study. 
g) Optimism. This eight-item survey measures a student's perceived expectation for various outcomes. A student can either have perceived negative or perceived positive expectations for various outcomes (Scheier, Carver, \& Bridges, 1994).

h) Positive Relations. Positive relations is one of the six dimensions of psychology well-being through three of the questions asked by Ryff \& Keyes (1995) in their study.

i) Self-Regulation. This 81 -item self-report measure analyzes the motivational and learning strategies of individuals (Pintrich, Smith, Garcia, \& McKeachie, 1993).

j) Subjective Well-Being. This 48-item self-report survey assesses student's global life satisfaction (Diener, Emmons, Larsen \& Griffin, 1985).

\section{Validity and Reliability}

The first version of the Sophomore Experiences Survey was administered in spring 2007. This instrument was "... designed to measure various aspects of the sophomore experience, in additions to levels of student thriving, which was conceptualized as academic self-efficacy, hope, mindset, engaged learning, and meaning of life" (Schreiner, 2010, p. 45). A follow-up study of the 2007 version of the Sophomore Experiences Survey was administered in 2010 (L. A. Schreiner, personal communication, April 26, 2011). Using only items predictive of second year success, scales from various instruments that had been found to be reliable were used to study second year students. The 2010 administration of the Sophomore Experiences Survey yielded a total reliability of .94 (L. A. Schreiner, personal communication, April 26, 2011). Schreiner then performed a follow-up study in 2011 and developed the Thriving Quotient (a five-factor model) from 10 of the 18 original independent scales from the 2010 version of the 
Sophomore Experiences Survey. Table 2 outlines the coefficient alpha reliability estimate from each of the factors in the Thriving Quotient (a five-factor model) (L. A. Schreiner, personal communication, November 29, 2011). Table 2 is taken directly for Schreiner's personal communication on November 29, 2011 with only adjustments to formatting and removal of information not related to the coefficient alpha reliability estimate.

Table 2

Reliability Estimates for Five-Factor Model (Thriving Quotient) in the Sophomore Experiences Survey

Scale

Engaged Learning Index. Academic Determination. Social Connectedness. Diverse Citizenship. Positive Perspective.

\section{Coefficient Alpha Reliability Estimate}

$$
\begin{aligned}
& \alpha=.83 \\
& \alpha=.82 \\
& \alpha=.82 \\
& \alpha=.80 \\
& \alpha=.83
\end{aligned}
$$

Taken from L. A. Schreiner, personal communication, November 29, 2011.

Schreiner's analysis of the instrument that yielded the five factors was a confirmatory factor analysis (CFA). The CFA resulted in moderate positive correlations among the factors. This justified combining the items from the five scales into one Thriving Coefficient, that was used as the average of the items making up the five scales, and was the predictor variable used in the current study. Cronbach's alpha coefficient was calculated for the Thriving Coefficient scale. Since each separate scale had a coefficient of .80 or greater (as shown in Table 2), it was highly likely the alpha coefficient will exceed .80 for the entire scale.

\section{Predictor Variables}

The predictor variables of this study included demographic variables such as first generation status, gender, race/ethnicity, college grades and major certainty, as well 
Thriving Quotient as outlined in Table 1 in this chapter, and campus experiences and perceptions. Appendix 2 provides a copy of the survey instrument that was used. Information for these predictor variables were self-reported by second year college students.

\section{Criterion Variables}

Criterion variables for this study included the student's intent to re-enroll after their fourth semester of their second year and intent to graduate from college. Students were asked a question in the survey instrument about their intent to re-enroll as well as a question about their intent to graduate. Intent to re-enroll and intent to graduate were measured by a Likert scale from "strongly disagree" (coded 1) to "strongly agree" (coded 4). Any response on the disagree side of the scale ( 1 or 2 ) was recoded 0 and any response on the agree side of the scale ( 3 or 4 ) was recoded 1 . Thus, for purposes of data analysis with logistic regression and other analyses, these dependent variables were dichotomous.

A potential concern with using logistic regression as the central analysis method with these data can be that the distribution of cases on the dependent variables may be skewed and imbalanced. This could occur if the data, when split between strongly disagree/disagree and strongly agree/agree, are heavy on the agree end as compared to the disagree end of the spectrum. Such an imbalance may not lead to a good application of logistic regression. However, a strength of this logistic regression as the primary analysis is that it does not require normal distribution assumption on that the dependent variable (Tabachnick \& Fidell, 2007). 


\section{Data Analysis}

This study collected data through a web-based survey instrument, the Sophomore Experiences Survey, using an online data collection tool, SurveyMonkey. In an effort to protect the research subjects and provide anonymity, student identification numbers were replaced with the first letter of the institution they attend (e.g., A for College A) and then an integer number followed that letter $(1,2,3$, etc.). Using descriptive statistics, demographic data were summarized. Using logistic regression, predictor variables were analyzed as the criterion variables were dichotomous.

Statistical Analyses

The first five research questions constituted a predictive study. This predictive study examined the relationship between predictor variables including demographic items, levels of student thriving, and campus experiences and perceptions and the criterion variables of the student's intent to re-enroll after their fourth semester of their second year and intent to graduate. Logistic regression and Ordinary Least Squares regression were used to measure the predictive nature and magnitude of the relationship between the variables (demographic, the Thriving Quotient, and campus experiences and perceptions) and the criterion variables of the student's intent to re-enroll after their fourth semester of their second year and intent to graduate.

Student demographic items were entered as the first set of control variables (block one). Once demographic items were entered as controls, the items related to Thriving Quotient were entered (block two). The last set of information entered into the regression equations was the campus experiences and perception (block three). These blocks are outlined in Table 3. The order of these blocks was determined using guidance from 
Schreiner's study in 2007 (Schreiner, 2010). The criterion variables for this study included the student's intent to re-enroll after their fourth semester of their second year and intent to graduate from college. The information for the student's intent to re-enroll after their fourth semester of their second year and intent to graduate were gathered through questions in the Sophomore Experiences Survey.

The sixth and seventh research questions constituted a comparative study. Crosstabulations and chi-square statistics were used to address each of these questions. For research question six, the independent variable was student status (1=continuing generation; $0=$ first generation) and the dependent variable was dichotomized intent to reenroll ( $1=$ Yes; $0=$ No). For research question seven, the independent variable was student status $(1=$ continuing generation; $0=$ first generation $)$ and the dependent variable was dichotomized intent to graduate $(1=\mathrm{Yes} ; 0=\mathrm{No})$.

Table 4 provides a summary of the statistical analyses used in the study. 
Table 3

Summary of Blocks Used in the Study

Block 1 (Demographic Items)

First generation status

Gender

Age

College grades

Enrollment status

Hours worked off campus

Hours worked on campus

Block 2 (Five-Factor Model)
Race/Ethnicity

Major certainty

Degree goal

Dropped courses

Experience compared to first year

Courses compared to first year

Thriving Quotient (25 questions

create the Thriving Quotient)

Block 3 (Campus Experiences and Perceptions)

Campus involvement

Student-faculty interaction

Student satisfaction 
Table 4

Statistical Analyses Used in the Study

\begin{tabular}{|c|c|c|c|c|}
\hline $\begin{array}{l}\text { Research } \\
\text { Question }\end{array}$ & Analysis & $\begin{array}{c}\text { Number } \\
\text { of } \\
\text { analyses }\end{array}$ & Predictor variables & Dependent variables \\
\hline 1 & $\begin{array}{l}\text { Logistic } \\
\text { regression } \\
\text { Ordinary } \\
\text { Least } \\
\text { Squares } \\
\text { regression }\end{array}$ & 4 & $\begin{array}{l}\text { Pre-college } \\
\text { characteristics }\end{array}$ & $\begin{array}{l}\text { 1. intent to re-enroll } \\
\text { 2. intent to graduate }\end{array}$ \\
\hline 2 & $\begin{array}{l}\text { Logistic } \\
\text { regression }\end{array}$ & 4 & Thriving coefficient & $\begin{array}{l}\text { 1. intent to re-enroll } \\
\text { 2. intent to graduate }\end{array}$ \\
\hline 3 & $\begin{array}{l}\text { Logistic } \\
\text { regression } \\
\text { Ordinary } \\
\text { Least } \\
\text { Squares } \\
\text { regression }\end{array}$ & 4 & $\begin{array}{l}\text { Campus experiences and } \\
\text { perceptions }\end{array}$ & $\begin{array}{l}\text { 1. intent to re-enroll } \\
\text { 2. intent to graduate }\end{array}$ \\
\hline $4 \& 5$ & $\begin{array}{l}\text { Logistic } \\
\text { regression } \\
\text { Ordinary } \\
\text { Least } \\
\text { Squares } \\
\text { regression }\end{array}$ & 8 & $\begin{array}{l}\text { Pre-college } \\
\text { characteristics, } \\
\text { Thriving coefficient, } \\
\text { Campus experiences and } \\
\text { perceptions }\end{array}$ & $\begin{array}{l}\text { For first generation } \\
\text { students: } \\
\text { 1. intent to re-enroll } \\
\text { 2. intent to graduate } \\
\text { For continuing } \\
\text { generation students: } \\
\text { 1. intent to re-enroll } \\
\text { 2. intent to graduate }\end{array}$ \\
\hline 6 & $\begin{array}{l}\text { Crosstabs } \\
\text { and } \\
\text { chi-square }\end{array}$ & 1 & $\begin{array}{l}\text { Student status } \\
\text { (first generation or } \\
\text { continuing generation) }\end{array}$ & $\begin{array}{l}\text { Intent to re-enroll } \\
\text { (Yes or No) }\end{array}$ \\
\hline 7 & $\begin{array}{l}\text { Crosstabs } \\
\text { and } \\
\text { chi-square }\end{array}$ & 1 & $\begin{array}{l}\text { Student status } \\
\text { (first generation or } \\
\text { continuing generation) }\end{array}$ & $\begin{array}{l}\text { Intent to graduate } \\
\text { (Yes or No) }\end{array}$ \\
\hline
\end{tabular}




\section{CHAPTER IV}

\section{RESULTS}

The study examined a number of variables pertaining to attitudes and educational experiences of college second year students. The participants in this study were secondyear students from four private colleges in Kentucky. The online survey was performed in the spring semester of 2012. Data were collected between April 9, 2012 and June 12, 2012.

The results will be presented in three major sections. First, descriptive statistics will be presented on a number of variables collected in the study. This will include description of the sampling procedures and the response rate. Second, there will be a section describing the scales used in the study. This section will include a report of the internal consistency reliability of the scales. The third section will present the results of analyses that addressed the research posed by the author of the study.

Descriptive Statistics on Survey Variables

Following the procedure outlined in Chapter 3, online questionnaires were sent to a total of 1293 students (number of second year students in the spring 2012 semester) at four colleges. For the majority of analyses, the number of respondents was 214 ; this constitutes a $17 \%$ response rate. The anticipated population for this study was to consist 
of full-time, second year students who were completing their fourth semester of academic work.

The sample of second year students analyzed in this research completed the Webbased Sophomore Experiences Survey in their fourth semester of college courses, the spring 2012 semester. The Sophomore Experiences Survey is a Web-based survey instrument comprised of components of the Thriving Quotient ( 25 items) as well as demographic questions and questions measuring campus involvement, student-faculty interaction, and student satisfaction. The instrument used in this study was a modified version of the Sophomore Experiences Survey developed in 2007 by Laurie A. Schreiner (Schreiner, 2010). Schreiner developed the Sophomore Experience Survey as an instrument to understand both the satisfaction and experience of second year students at higher education institutions. Schreiner's instrument was developed as a follow-up study to Juillerat's (2000) study in an effort to continue the understanding of second year students' experiences using a larger sample that would be more representative of the multiple types of institutions across the United States.

Students were contacted via electronic mail and asked to complete the online questionnaire. Three follow-up emails were also sent as reminders to the subjects in order to gain their survey responses. The survey took subjects approximately $15-20$ minutes to complete. The initial questions on the survey contained an informed consent preamble that had been approved the Internal Review Boards of all four participating institutions in the study as well as the researcher's home institution. After subjects consented to participating in the study, subjects were then asked information regarding demographics, campus experiences and perceptions, as well as questions regarding the Thriving 
Quotient. The Thriving Quotient (a five-factor model) includes the Engaged Learning Index, Diverse Citizenship, Academic Determination, Positive Perspective, and Social Connectedness (L. A. Schreiner, personal communication, November 29, 2011 ). Demographic information was collected through a total of 13 items on the survey instrument. These items included information on the student's gender, age, enrollment status, race/ethnicity, first generation status, certainty of their major, number of hours worked on campus, number of hours worked off campus, courses compared to first year, experiences compared to first year, degree aspirations, number of courses dropped in their second year, and college grades.

Table 5 shows summary statistics on three key demographic variables: sex, age and ethnic group. As can be seen in the table, most respondents (almost 75\%) were female and the great majority of were 19 or 20 years old. The mean age was 19.6 . Regarding ethnicity, the great majority of respondents (about 89\%) identified themselves as White. In addition to the item that asked students to select an ethnic category from a list, respondents could provide an ethnic designation of their own. Five respondents used this option. Responses were: (a) South Asian Indian, (b) Prefer no response, (c) Peruvian, (d) Hispanic, and (e) Appalachian. The respondents who identified as Peruvian and Hispanic were added to the Other Latino category for analysis. 
Table 5

Frequency Distributions for Sex, Age, and Ethnic Group

\begin{tabular}{|ll|r|r|}
\hline \multicolumn{2}{|l|}{ Variable } & \multicolumn{1}{c|}{$\mathrm{n}$} & \multicolumn{1}{c|}{$\%$} \\
\hline & & & \\
Sex & Female & 185 & 73.1 \\
& Male & 68 & 26.9 \\
& Total & 253 & 100.0 \\
& & & \\
\hline
\end{tabular}

\begin{tabular}{|rl|r|r|}
\hline & 18.00 & 8 & 3.1 \\
& 19.00 & 93 & 36.6 \\
Age & 20.00 & 147 & 57.9 \\
& 21.00 & 5 & 2.0 \\
& 23.00 & 1 & .4 \\
& Total & 254 & 100.0 \\
\hline
\end{tabular}

\begin{tabular}{|ll|r|r|}
\hline & African-American & 7 & 2.9 \\
& Asian-American & 3 & 1.2 \\
Ethnic & Caucasian/White & 216 & 89.3 \\
Group & Mexican-American & 7 & 2.9 \\
& Other & 2 & .8 \\
& Other Latino & 3 & 1.2 \\
& Total & 4 & 1.7 \\
& 242 & 100.0 \\
\hline
\end{tabular}

Table 6 gives frequency distributions for the variables enrollment status and college. Of the 254 students who answered the question regarding enrollment status the majority were full-time students; 252 (99.2\%). Regarding college, the largest percentage of the respondents $(39.3 \%)$ were from College B. 
Table 6

Frequency Distributions for Enrollment Status and College

\begin{tabular}{|ll|r|r|}
\hline Variable & & \multicolumn{1}{|c|}{$\mathrm{n}$} & \multicolumn{1}{c|}{$\%$} \\
\hline Enrollment & Full-time & 252 & 99.2 \\
Status & Part-time & 2 & .8 \\
& Total & 254 & 100.0 \\
& & & \\
\hline
\end{tabular}

\begin{tabular}{|ll|r|r|}
\hline & & & \\
& A & 62 & 25.6 \\
College & B & 95 & 39.3 \\
& C & 38 & 15.7 \\
& D & 47 & 19.4 \\
& Total & 242 & 100.0 \\
& & & \\
\hline
\end{tabular}

Table 7 shows descriptive statistics for number of college credits students earned including the spring 2012 semester when the survey was completed as well as the number of credit students were taking in the spring 2012 semester. The average number of college credits a student had earned from their first year through the spring 2012 semester was 51.8. The respondents, on average, were taking 12.2 credits during their spring 2012 semester. 


\section{Table 7}

Descriptive Statistics for Number of College Credits Student Earned (Including

This Semester) and Number of Credits Student Is Taking This Semester

\begin{tabular}{|l|c|c|c|}
\hline Variable & $n$ & $M$ & $S D$ \\
\hline Total number of college credits & 298 & 51.8 & 20.6 \\
College credits for current semester & 303 & 12.2 & 4.9 \\
\hline
\end{tabular}

$n=$ number of students who answered each question

Note. Eleven students stated that they were not second year students. Twelve students stated they were transfer students. These students were included in the descriptive statistics but removed from the analysis for all seven research questions.

Table 8 shows the frequency distribution for responses to the item "what is the level of education for your parent who has the highest level of education?" Many of the respondents (26\%) had at least one parent with a bachelor's degree as his/her highest level of education. For purposes of this research, $10.6 \%$ of respondents had at least one parent with the highest level of education as high school graduate, GED, or some high school. These $10.6 \%$ of respondents are regarded as first-generation in this study. The United States Department of Education defines first generation students “.... as a student whose parents [neither of which] have[any] postsecondary education"' (U.S. Department of Education, 1998, p. 1). In some cases“...first generation students are defined as students whose parents [neither of which] earned a bachelor's degree" (U.S. Department of Education, 1998, p. 1). For the purposes of this dissertation, first generation students 
were defined as any student "as a student whose parents [neither of which] have [any] postsecondary education" (U.S. Department of Education, 1998, p. 1).

The remaining $89.4 \%$ of the respondents were regarded as continuing-generation students. A continuing-generation student, in this research, was defined as any student with at least one parent who has attended some college. While Pike and Kuh (2005) suggest that a continuing generation college student is a student with at least one parent that has earned a baccalaureate degree, research shows that students with parents who have attended some college better understand the college experience than first generation college students. Students with parents with some college experience and those with at least one parent with a baccalaureate degree have enough social capital needed for assistance to navigate the transition to college and the college environment (Purswell, Yazedjian, \& Toews, 2008). 


\section{Table 8}

Frequency Distribution for Responses to the Item

"What is the Level of Education for Your Parent?

Who Has the Highest Level of Education?"

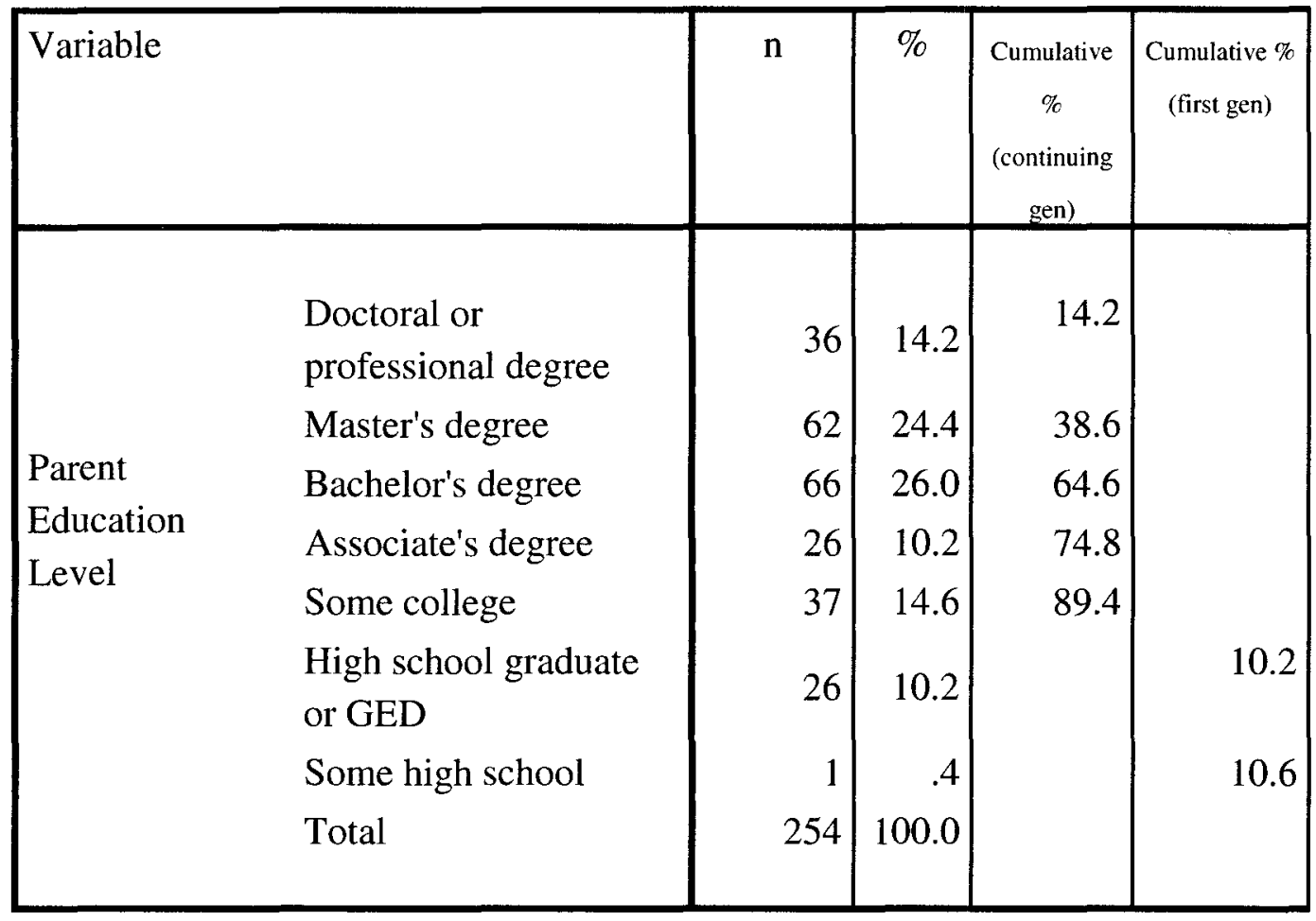

Table 9 provides a frequency distribution for the responses to the item asking the highest level of education to which the student aspires. The largest percentage of subjects (48.8\%) aspired to obtain a doctoral degree in their lifetime. Of the 254 students who answered this question, 104 (40.9\%) of respondents aspired to obtain a master's degree. 
Table 9

Frequency Distribution for Responses to Item Asking the

Highest Level of Education to Which the Student Aspires

\begin{tabular}{|ll|r|r|}
\hline Variable & $\mathrm{n}$ & \multicolumn{1}{|c|}{$\%$} \\
\hline & & & \\
& Doctoral or Professional & 124 & 48.8 \\
Aspirational & Master's & 104 & 40.9 \\
Education & Bachelor's & 19 & 7.5 \\
Level & Teaching credential & 3 & 1.2 \\
& Other & 4 & 1.6 \\
& Total & 254 & 100.0 \\
& & & \\
\hline
\end{tabular}

Note. Four students who selected the Other option listed answers to this item.

The answers were: (a) Professional degree, (b) Pharmacy, (c) Dual Law-Master's, and (d) CPA.

Table 10 gives the frequency distributions for responses to items on grades the first year of college and grades the second year of college. Many respondents during their first year of college are obtaining mostly A's, A's and B's, or mostly B's (77.7\%). Only one respondent had D's and F's during his/her first year of college. During the respondents second year of college, many students reported they had received mostly A's, A's and B's, or mostly B's (82.7\%). No students during their second year reported obtaining D's and F's. 
Table 10

Frequency Distributions for Responses to Items on Grades the First

Year of College and Grades in the Second Year of College

\begin{tabular}{|ll|r|r|}
\hline Variable & \multicolumn{1}{|c|}{$\mathrm{n}$} & \multicolumn{1}{c|}{$\%$} \\
\hline & Mostly A's & 55 & 21.7 \\
& A's and B's & 103 & 40.6 \\
Grades in & Mostly B's & 39 & 15.4 \\
First Year of & B's and C's & 46 & 18.1 \\
College & Mostly C's & 7 & 2.8 \\
& C's and D's & 3 & 1.2 \\
& D's and F's & 1 & .4 \\
& Total & 254 & 100.0 \\
& & & \\
& &
\end{tabular}

\begin{tabular}{|ll|r|r|}
\hline & Mostly A's & 57 & 22.4 \\
Grades in & A's and B's & 100 & 39.4 \\
Second Year of & Mostly B's & 53 & 20.9 \\
College & B's and C's & 35 & 13.8 \\
& Mostly C's & 8 & 3.1 \\
& C's and D's & 1 & .4 \\
& Total & 254 & 100.0 \\
\hline
\end{tabular}

Table 11 gives a frequency distribution for the responses to items on how many hours per week a student worked at an off-campus or at an on-campus job. The majority of students (64\%) reported they worked no hours at an off-campus job. Of those students who reported they worked an off-campus job, the majority of them worked 10 hours or 
less a week. A large percentage of students $(44.2 \%)$ reported they did not work an oncampus job. However, 60 subjects $(24.8 \%)$ reported that they worked 6-10 hours a week at an on-campus job.

\section{Table 11}

Frequency Distributions for Responses to Items

On How Many Hours Per Week the Student Worked

In An Off-Campus Job Or An On-Campus Job

\begin{tabular}{|c|c|c|c|}
\hline Variable & & $\mathrm{n}$ & $\%$ \\
\hline \multirow{9}{*}{$\begin{array}{l}\text { Hours Worked Per } \\
\text { Week Off-Campus }\end{array}$} & More than 30 & 3 & 1.2 \\
\hline & $26-30$ & 3 & 1.2 \\
\hline & $21-25$ & 10 & 4.1 \\
\hline & $16-20$ & 13 & 5.4 \\
\hline & $11-15$ & 10 & 4.1 \\
\hline & $6-10$ & 22 & 9.1 \\
\hline & 5 or less & 26 & 10.7 \\
\hline & None & 155 & 64.0 \\
\hline & Total & 242 & 100.0 \\
\hline \multirow{9}{*}{$\begin{array}{l}\text { Hours Worked Per } \\
\text { Week On-Campus }\end{array}$} & More than 30 & 4 & 1.7 \\
\hline & $26-30$ & 1 & .4 \\
\hline & $21-25$ & 3 & 1.2 \\
\hline & $16-20$ & 7 & 2.9 \\
\hline & $11-15$ & 15 & 6.2 \\
\hline & $6-10$ & 60 & 24.8 \\
\hline & 5 or less & 45 & 18.6 \\
\hline & None & 107 & 44.2 \\
\hline & Total & 242 & 100.0 \\
\hline
\end{tabular}


Table 12 shows a frequency distribution for responses to the item asking "how sure are you of your college major?" The majority $(90.5 \%)$ of respondents were very sure or sure of their college major. Only 4 students $(1.7 \%)$ were very unsure of their college major.

Table 12

Frequency Distribution for Responses to Item Asking

"How Sure Are You of Your College Major?"

\begin{tabular}{|ll|r|r|}
\hline Variable & \multicolumn{1}{c|}{$\mathrm{n}$} & \multicolumn{1}{c|}{$\%$} \\
\hline & Very sure & 153 & 63.2 \\
& Sure & 66 & 27.3 \\
How sure are you of & Somewhat sure & 17 & 7.0 \\
your college major? & Unsure & 2 & .8 \\
& Very unsure & 4 & 1.7 \\
& Total & 242 & 100.0 \\
& & & \\
\hline
\end{tabular}

Table 13 provides the frequency distributions for responses to items asking "compared to your first year of college, this year has been:" and "compared to the courses you took in your first year of college, the courses this year have been:" Compared to their first year of college, several of these students (59.5\%) found their second year to be much better or better than their first year. Compared to the courses these students took in their first year of college, the second year course work for many of these students $(52.1 \%)$ perceived it to be much better or better. 
Table 13

Frequency Distributions for Responses to Items Asking

"Compared to Your First Year of College, This Year Has Been:" And

"Compared to The Courses You Took In Your First Year of College, The

Courses This Year Have Been:"

\begin{tabular}{|c|c|c|c|}
\hline Variable & & $\mathrm{n}$ & $\%$ \\
\hline \multirow{6}{*}{$\begin{array}{l}\text { This year of college } \\
\text { compared to last year }\end{array}$} & Much better & 44 & 18.2 \\
\hline & Better & 100 & 41.3 \\
\hline & About the same & 69 & 28.5 \\
\hline & Worse & 26 & 10.7 \\
\hline & Much worse & 3 & 1.2 \\
\hline & Total & 242 & 100.0 \\
\hline \multirow{6}{*}{$\begin{array}{l}\text { Courses this year } \\
\text { compared to courses } \\
\text { last year }\end{array}$} & Much better & 27 & 11.2 \\
\hline & Better & 99 & 40.9 \\
\hline & About the same & 76 & 31.4 \\
\hline & Worse & 36 & 14.9 \\
\hline & Much worse & 4 & 1.7 \\
\hline & Total & 242 & 100.0 \\
\hline
\end{tabular}

Table 14 shows the frequency distribution for the responses to items "I intend to re-enroll next year at the institution I am currently attending" and "I intend to graduate from college and obtain my bachelor's degree." The majority of respondents $(95.7 \%)$ intended to re-enroll in fall 2012 at the institution they were currently attending. Eleven 
students $(4.3 \%)$ disagreed or strongly disagreed with this same item therefore having no plans to re-enroll in the fall 2012 at the institution they were currently attending. Nearly all respondents $(97.6 \%)$ intended on graduating from college and obtaining their bachelor degree.

\section{Table 14}

Frequency Distributions for Responses to Items

"I Intend to Re-enroll Next Year At the Institution I Am Currently Attending" And

“I Intend To Graduate From College And Obtain My Bachelor's Degree"

\begin{tabular}{|c|c|c|c|}
\hline Variable & & $\mathrm{n}$ & $\%$ \\
\hline \multirow{5}{*}{$\begin{array}{l}\text { I intend to re-enroll at } \\
\text { this college next year }\end{array}$} & Strongly agree & 221 & 87.0 \\
\hline & Agree & 22 & 8.7 \\
\hline & Disagree & 2 & .8 \\
\hline & Strongly disagree & 9 & 3.5 \\
\hline & Total & 254 & 100.0 \\
\hline \multirow{5}{*}{$\begin{array}{l}\text { I intend to graduate } \\
\text { from college with a } \\
\text { bachelor's degree }\end{array}$} & Strongly agree & 232 & 91.3 \\
\hline & Agree & 16 & 6.3 \\
\hline & Disagree & 0 & 0.0 \\
\hline & Strongly disagree & 6 & 2.4 \\
\hline & Total & 254 & 1.00 .0 \\
\hline
\end{tabular}

Table 15 givens responses to the items "how many courses have you dropped or withdrawn from since beginning college at your current institution?" and "in how many courses have your received a grade below $\mathrm{C}$ since beginning college at your current 
institution?" Over half of the respondents $(68.2 \%)$ had dropped or withdrawn from at least one college course since beginning college at their current institution. Several respondents $(65.7 \%)$ had never received below a $\mathrm{C}$ in any of their coursework since beginning college and only one student $(.4 \%)$ had received six or more grades below a $\mathrm{C}$ since beginning college.

\section{Table 15}

Frequency Distributions for Responses to Items "How Many Courses Have

You Dropped or Withdrawn From Since Beginning College at Your

Current Institution?" And "In How Many Courses Have You Received a

Grade Below C Since Beginning College at Your Current Institution?"

\begin{tabular}{|c|c|c|c|}
\hline \multicolumn{2}{|l|}{ Variable } & $\mathrm{n}$ & $\%$ \\
\hline \multirow{5}{*}{$\begin{array}{l}\text { How many courses } \\
\text { have you dropped or } \\
\text { withdrawn from since } \\
\text { beginning college at } \\
\text { your current } \\
\text { institution? }\end{array}$} & None & 77 & 31.8 \\
\hline & One & 140 & 57.9 \\
\hline & $2-3$ & 25 & 10.3 \\
\hline & Total & 242 & 100.0 \\
\hline & & & \\
\hline \multirow{6}{*}{$\begin{array}{l}\text { In how many courses } \\
\text { have you received a } \\
\text { grade below C since } \\
\text { beginning college } \\
\text { at your current } \\
\text { institution? }\end{array}$} & None & 159 & 65.7 \\
\hline & One & 37 & 15.3 \\
\hline & $2-3$ & 36 & 14.9 \\
\hline & $4-5$ & 9 & 3.7 \\
\hline & 6 or more & 1 & .4 \\
\hline & Total & 242 & 100.0 \\
\hline
\end{tabular}


Scales Used in the Study and Their Reliability

Four scales were used in the study. Each of these consisted of a set of items that were designed to measure a construct relevant to the experience of second-year college students. The scales were named: (a) student thriving, (b) college involvement, (c) student-faculty interaction, and (d) student satisfaction. Levels of student thriving were determined through data collected in the Thriving Quotient. The Thriving Quotient (a five-factor model) was used as it contains the questions that have been found to be most predictive of sophomore success when these questions were compared to other questions previously used in earlier versions of the SES (L. A. Schreiner, personal communication, November 29, 2011). Ten scales created the Thriving Quotient used in this study. Questions regarding academics, social responsibility, racial identity, well-being, engaged learning, environmental mastery, optimism, positivity, and motivation are just some of the areas of content for the questions in the Thriving Quotient.

The college involvement scale consisted of eight questions regarding a student's participation in co-curricular activities from student organizations to campus events and activities. The student-faculty interaction scale consisted of six questions regarding engagement in discussions with professors regarding career goals, academic issues, as well as other academic related topics involving faculty members. The student-satisfaction scale consisted of nine questions regarding satisfaction with a student's living environment, amount a student perceived he or she was learning in the classroom, grades, as well as other satisfaction topics. All of the questions from each of these scales came from the SES. 
In order to use the scales to investigate the research questions of this study, it was required to average the items to obtain an overall score for each scale. However, to justifiably do this, it was necessary to have evidence that the items were in a scale were measuring the same construct. Cronbach's alpha internal consistency reliability coefficient provided this evidence.

Table 16 shows the alpha coefficients for the four scales. Each of the reliability coefficients exceeded the criterion of .70 that is used as the minimum acceptable value for research (Nunnally \& Bernstein, 1994). Thus, it was justified to average the items from the scales and use the averages as variables in statistical analyses.

There were eight items in the original college involvement scale. When the items were analyzed, the resulting alpha coefficient was .68; this was below the researcher's minimum criterion of .70 . Analysis of the items revealed that removal of the third item in the scale would raise the alpha coefficient above .70. This item measured students' involvement in "Music or theater performance groups on campus." Removal of the item resulted in a seven-item scale with an acceptable reliability coefficient value for research.

Table 17 shows descriptive statistics (means and standard deviations) on the four scales. Thriving items were measured on a six-step scale from $1=$ Strongly disagree to $6=$ Strongly agree. Involvement items were measured on a six-step scale from $1=$ Not at all involved to $6=$ Very involved. Interaction items were measured on a six-step scale from $1=$ Never to $6=$ Frequently. Satisfaction items were measured on a six-step scale from $1=$ Very dissatisfied to $6=$ Very satisfied . 


\section{Table 16}

Cronbach's Alpha Internal Consistency Reliability Coefficients for the Four Scales

Measuring Attitudes and Experiences of Second Year College Students

Scale $\quad$ Number of items $\quad$ Cronbach's alpha coefficient

$\begin{array}{ll}\text { Thriving } & 25 \\ \end{array}$

$\begin{array}{lll}\text { College involvement } & 7 & .72\end{array}$

Student-faculty interaction $\quad 6 \quad .78$

$\begin{array}{lll}\text { Student satisfaction } & 9 & .75\end{array}$

Table 17

Descriptive Statistics for the Four Scales Measuring

Attitudes and Experiences of Second Year College Students

\begin{tabular}{|l|l|r|r|r|r|}
\hline Scale & $n$ & Minimum & Maximum & \multicolumn{1}{c|}{$M$} & \multicolumn{1}{c|}{$S D$} \\
\hline Thriving & 239 & 2.16 & 5.88 & 4.66 & 0.59 \\
Involvement & 238 & 1.00 & 5.29 & 2.83 & 1.01 \\
Interaction & 237 & 1.50 & 6.00 & 3.59 & 1.01 \\
Satisfaction & 235 & 2.89 & 6.00 & 4.77 & 0.61 \\
\hline
\end{tabular}

Statistical Analyses Addressing Research Questions One to Seven

Research questions one through seven dealt with issues relevant to second year students. However, examination of the descriptive statistics revealed that not every 
respondent could be considered as appropriate for inclusion in analyses that addressed these seven questions. Since the researcher intended on the students to be continuously enrolled at their respective institutions, certain categories of students were removed from analysis. Specifically, three categories of respondents were problematic: (a) those who were not second year students, (b) part-time students, and (c) transfer students. Since the researcher relied on the subjects' contact information from the four institutions studied, it was impossible to ensure that the all subjects met the researcher's intended subject profile. A full year of second year experience was most ideal for this data collection as student's experiences can change dramatically over the course of a year. Noel-Levitz (2011) determined in their assessments that nearly $7 \%$ to $14 \%$ of second year students leave during their second year. For private institutions, $16.3 \%$ of students leave between census day of their second year of course work and census day of their third year of course work (Noel-Levitz, 2011).

Logistic regression analysis was to be used to answer research questions one through four, employing two logistic regression equations, one for the dependent variable intent to re-enroll and one for the dependent variable intent to graduate. Each dependent variable was to be dichotomized, with the responses Strongly agree and Agree coded 1 and the responses Strongly disagree and Disagree coded 0.

Table 18 shows frequency distributions for each dependent variable. As can be seen in the table, each variable had few cases on the disagree end of the scale. 
Table 18

Frequency Distributions for Intent to Re-enroll and Intent to Graduate

\section{$\underline{\text { Response Categories }}$}

\begin{tabular}{lcccc} 
Variable & Strongly Disagree & $\underline{\text { Disagree }}$ & $\underline{\text { Agree }}$ & $\underline{\text { Strongly Agree }}$ \\
\cline { 2 - 3 } Intent to Re-enroll & 9 & 2 & 21 & 200 \\
Intent to Graduate & 6 & 0 & 15 & 211
\end{tabular}

Note: Table 18 differs from Table 14 as those cases that did not meet the requirements for analysis (i.e. students that were not second year, were part-time and/or were transfer students) were removed from Table 18.

Given the distribution of cases, the only feasible way to use logistic regression was to classify data into two categories: (a) strongly disagree, disagree, and agree were coded 0 (zero), and (b) strongly agree was coded 1 (one). In effect, this provided a contrast between individuals who were in strong agreement with an intention (to re-enroll and to graduate) and those who were not in strong agreement with the intention. A limitation of the analysis was that it required combining cases in which the student expressed disagreement with cases in which the student expressed agreement. A strength of this analysis was that logistic regression does not require normal distribution assumption on that the dependent variable (Tabachnick \& Fidell, 2007).

However, in order to provide additional information about the research questions, the researcher decided to use ordinary least squares (OLS) regression as an alternative 
method of analysis. This allowed an employment of the full continuum of data, from strongly disagree to strongly agree without any combining of cases. It should be noted that the data on the dependent variables for the OLS regressions were skewed (i.e., most cases were at the high end of the scale), thus violating the normal distribution assumption (Tabachnick \& Fidell, 2007).

In summary, the analyses of data for research questions one through five was performed with two procedures: ordinary least squares (OLS) regression and logistic regression. Each analysis method had strengths and limitations and results were not expected to be identical with the two procedures. The researcher applied the following decision rules in the interpretation of data. If a variable was a statistically significant predictor in both types of analysis, it was identified as having strong evidence of being a significant factor. If a predictor was statistically significant in only one of the two analyses, it was described as having some evidence of being a significant factor. It was originally intended to use 13 demographic variables as predictor variables to address research questions one to five. Those demographic variables included first generation status, gender, age, college grades, enrollment status, hours worked off campus, hours worked on campus, race/ethnicity, major certainty, degree goal, dropped courses, experience compared to first year and courses compared to first year. However, one variable was dropped from the analysis_enrollment status. This was done because part-time students were screened out, making enrollment status impossible to use as a predictor. The variable first generation status was entered as a dichotomy. If a student's parent with the highest level of education stated some high school or high school graduate, the student was coded 1 (meaning they were defined as first generation). If 
some other response was made (e.g., some college or college graduate), the student was coded 0 (meaning they were defined as continuing generation).

Research Question 1: The first research question is: What pre-college characteristics contribute to the intent to re-enroll and the intent to graduate of second year college students? Ordinary least squares (OLS) regression analysis was performed with 12 demographic variables entering the regression equation with intent to re-enroll as the dependent variable. The regression model showed that the predictors were significantly associated with the dependent variable, $F(11,202)=2.93, p<.01$. The squared multiple correlation was $R^{2}=.14$, with the adjusted $R^{2}=.09$. Thus, $9 \%$ of the variance in the dependent variable could be accounted for by the predictors. The same predictors were entered into a logistic regression equation predicting the dichotomous variable of intended re-enrollment $(1=$ strongly agree; $0=$ not strongly agree). There were significant demographic predictors, $\chi(11)=37.96, p<.001$, Nagelkerke $R^{2}=.297$

Table 19 shows the statistically significant demographic predictors of intent to reenroll for OLS and logistic regression. For both statistical models, intention to re-enroll was associated with: (a) fewer courses having been dropped by the student (as indicated by the negative sign for courses dropped), and (b) positive perception of this year compared to last year. The logistic regression model identified two additional predictors: (a) first generation status (negatively associated with intention to re-enroll, and (b) being sure of one's major. 


\section{Table 19}

Statistically Significant Demographic Predictor Variables of Intent to Re-Enroll: OLS and Logistic Regression $(n=214)$

\begin{tabular}{|c|c|c|c|c|}
\hline Dependent & Predictor & & & \\
\hline Variable & Variable & $\underline{B}$ & $\underline{S E B}$ & $\beta$ \\
\hline
\end{tabular}

Intent to

Re-enroll:

OLS Regression

$\begin{array}{lllll}\text { Courses dropped } & -.164 & .068 & -.167 & -2.422 * \\ & & & & \\ \text { This year compared } & & & & \\ \text { to last year } & .199 & .052 & .273 & 3.806 * *\end{array}$

Intent to

Re-enroll:

Logistic Regression

$\underline{B} \quad \underline{S E B} \quad \underline{\operatorname{Exp}(B)} \quad \underline{p}$

\begin{tabular}{|c|c|c|c|c|}
\hline Courses dropped & -.647 & .320 & .524 & $.043 *$ \\
\hline $\begin{array}{l}\text { This year compat } \\
\text { to last year }\end{array}$ & 1.083 & .287 & 2.955 & $<.001 * *$ \\
\hline First generation & -1.446 & .674 & .235 & $.032 *$ \\
\hline Sure of major & .444 & .192 & 1.558 & $.021 *$ \\
\hline
\end{tabular}

$* p<.05, * * p<.01$

Research question one included using intent to graduate as a dependent variable.

The OLS regression model showed that the 12 demographic predictors were not significantly associated with the dependent variable, $F(11,202)=1.32, p=.216$. The same predictors were entered into a logistic regression equation predicting the dichotomous variable of intention to graduate ( $1=$ strongly agree; $0=$ not strongly agree). 
The overall statistical model was statistically significant, $\chi(11)=20.29, p<.05$, Nagelkerke $R^{2}=.201$. Table 20 shows the statistically significant demographic predictors of intent to graduate. The logistic regression model identified one predictor: being sure of one's major.

\section{Table 20}

Statistically Significant Demographic Predictor Variables of

Intent to Graduate: OLS and Logistic Regression $(n=214)$

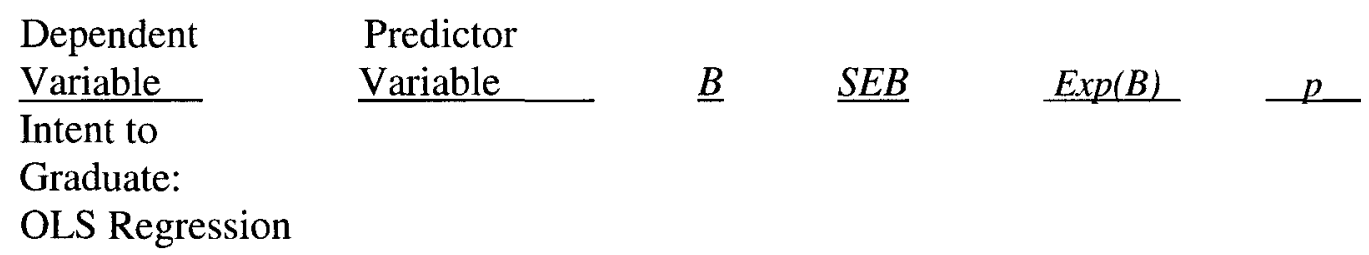

Intent to

Graduate:

Logistic Regression

$\begin{array}{lllll}\text { Sure of major } & .604 & .212 & 1.830 \quad .004 * *\end{array}$

${ }^{* *} p<.01$.

Summary of the analysis for research question one: There was strong evidence that number of courses dropped and perception of this year compared to last were significant predictors of intent to re-enroll. There was some evidence that first generation status and being sure of one's major were significant predictors of the re-enrollment intention. Regarding the dependent variable intent to graduate, there was some evidence that being sure of one's major was a significant predictor. 
Research Question 2: The second research question is: Does the thriving scale average (Block 2 of the hierarchical regression equation), as a measure of student thriving, contribute to the intent to re-enroll and intent to graduate of second year college students? This question was addressed by continuing to build the regression models that were constructed to address research question 1 . The variable thriving scale average was added to the regression equations that already contained the demographic variables.

For intent to re-enroll, addition of the thriving scale to the demographic variables did not increase the the $R^{2}$ of the OLS statistical model. The increment was not statistically significant, $F(1,201)=0.59, p=.81$. A similar outcome occurred for the logistic model, with the chi-square statistic for the addition of thriving scale being not significant, $\chi(1)=0.73, p=.39$. As shown in Table 21 , the regression coefficients for thriving scale average were not statistically significant for the dependent variable intent to re-enroll.

For intent to graduate, addition of the thriving scale to the demographic variables did not increase the $R^{2}$ of the OLS statistical model. The increment was not statistically significant, $F(1,201)=0.00, p=.99$. A similar outcome occurred for the logistic model, with the chi-square statistic for the addition of thriving scale score being not significant, $\chi$ $(1)=1.343, p=.25$. As shown in Table 21 , the regression coefficients for thriving scale average were not statistically significant for the dependent variable intent to graduate. 
Table 21

Results of Adding Thriving Scale Average To Regression Models Containing

Demographic Variables Predicting Intent to Re-enroll and Intent to Graduate $(n=214)$

$\begin{array}{lllllll}\begin{array}{l}\text { Dependent } \\ \text { Variable }\end{array} & \begin{array}{l}\text { Predictor } \\ \text { Variable }\end{array} & & \underline{B} & \underline{S E B} & \underline{\beta} & \underline{t} \\ \begin{array}{l}\text { Intent to } \\ \text { Re-enroll }\end{array} & & & & & \\ \begin{array}{l}\text { OLS regression } \\ \quad \text { Thriving scale average }\end{array} & -.020 & .083 & -.017 & -0.243\end{array}$

Intent to

Re-enroll:

Logistic Regression

$\underline{B} \quad \underline{S E B} \quad \underline{\operatorname{Exp}(B)} \quad \underline{p}$

$\begin{array}{lllll}\text { Thriving scale average } & .334 & .391 & 1.397 & .393\end{array}$

Intent to

Graduate

OLS regression

$\underline{B} \quad \underline{S E B} \quad \underline{B} \quad \underline{t}$

$\begin{array}{lllll}\text { Thriving scale average } & .000 & .069 & .000 & 0.002\end{array}$

Intent to

Graduate:

Logistic Regression

$\underline{B} \quad \underline{S E B} \quad \underline{\operatorname{Exp}(B)} \quad \underline{p}$

$\begin{array}{lllll}\text { Thriving scale average } & .519 & .448 & 1.681 & .246\end{array}$

Summary of the analysis for research question two: After demographic variables were controlled, there was no evidence that the thriving scale average significantly predicted intent to re-enroll or intent to graduate. 
Research Question 3: The third research question is: What campus experiences and perceptions (Block 3 of the hierarchical regression equation) contribute to the intent to re-enroll and intent to graduate of second year college students? This question was addressed by continuing to build the regression models that were constructed to address research questions 1 and 2. The variables involvement scale average, interaction scale average, and satisfaction scale average were added to the regression equations that already contained the demographic variables and the thriving scale average.

Summary statistics for intent to re-enroll are presented in Table 22. Addition of the campus experience and perceptions scales to the thriving scale and demographic variables increased the OLS $R^{2}$ from .138 to .169 . The increment of .032 was statistically significant, $F(3,198)=2.508, p<.065$. As shown in Table 22 , the regression coefficient for the satisfaction scale average was .242 , which was statistically significant. A similar outcome occurred for the logistic model, with the chi-square statistic for the addition of the campus experience and perceptions scales score being significant, $\chi(3)=9.24, p<$ .05 . As shown in Table 22, the regression coefficient for the satisfaction scale average was statistically significant for the dependent variable intent to re-enroll.

For intent to graduate, addition of the campus experience and perceptions scales to the thriving scale and demographic variables increased the OLS $R^{2}$ from .067 to .072 . The increment of .005 was not statistically significant, $F(3,198)=0.37, p=.77$. A similar outcome occurred for the logistic model, with the chi-square statistic for the addition of the campus experience and perceptions scales score being significant, $\chi(3)=$ 4.68, $p=.20$. As shown in Table 23 , the regression coefficient for the involvement scale average was .700 , which met the criterion of statistical significance, $.049<.050$. 
However, as previously stated, the increment in variance for the logistic regression was not statistically significant.

\section{Table 22}

Results of Campus Experience and Perception Variables Predicting Intent to Re-enroll:

Controlling For Demographic Variables And Thriving Coefficient

$(n=214)$

\begin{tabular}{|c|c|c|c|c|}
\hline $\begin{array}{l}\text { Dependent } \\
\text { Variable } \\
\end{array}$ & $\underline{B}$ & $\underline{S E B}$ & $\underline{\beta}$ & $t$ \\
\hline \multicolumn{5}{|l|}{$\begin{array}{l}\text { Intent to } \\
\text { Re-enroll: } \\
\text { OLS Regression }\end{array}$} \\
\hline Involvement scale average & .034 & .052 & .051 & 0.650 \\
\hline Interaction scale average & -.053 & .052 & -.078 & -1.015 \\
\hline Satisfaction scale average & .242 & .094 & .225 & $2.580^{*}$ \\
\hline \multicolumn{5}{|l|}{$\begin{array}{l}\text { Intent to } \\
\text { Re-enroll: }\end{array}$} \\
\hline Logistic Regression & $\underline{B}$ & $\underline{S E B}$ & $\operatorname{Exp}(B)$ & $\underline{p}$ \\
\hline Involvement scale average & .241 & .316 & 1.273 & .444 \\
\hline Interaction scale average & -.193 & .279 & .825 & .489 \\
\hline Satisfaction scale average & 1.303 & .478 & 3.679 & $.006 * *$ \\
\hline
\end{tabular}




\section{Table 23}

Results of Campus Experience and Perception Variables Predicting Intent to Graduate:

Controlling For Demographic Variables And Thriving Coefficient $(n=214)$

$\begin{array}{llllllll}\begin{array}{l}\text { Dependent } \\ \text { Variable }\end{array} & \begin{array}{l}\text { Predictor } \\ \text { Variable }\end{array} & \underline{B} & \underline{S E B} & \underline{\beta} & & \underline{t} \\ \begin{array}{l}\text { Intent to } \\ \text { Graduate: }\end{array} & & & & & & & \\ \text { OLS Regression } & \text { Involvement scale average } & .044 & .044 & .083 & 0.993 \\ & \text { Interaction scale average } & -.019 & .044 & -.035 & -0.435 \\ & \text { Satisfaction scale average } & .025 & .080 & .029 & 0.312\end{array}$

Intent to

Graduate:

Logistic Regression $\quad \underline{B} \quad \underline{S E B} \quad \underline{\operatorname{Exp}(B)} \quad \underline{p}$

$\begin{array}{lllll}\text { Involvement scale average } & .700 & .356 & 2.013 \quad .049 *\end{array}$

$\begin{array}{lllll}\text { Interaction scale average } & -.312 & .333 & .732 & .348\end{array}$

$\begin{array}{lllll}\text { Satisfaction scale average } & .352 & .577 & 1.421 & .543\end{array}$

$$
* p<.05
$$

Summary of the analysis for research question three: After demographic variables and thriving scale score were controlled, there was strong evidence that satisfaction scale average was a significant predictor of intent to re-enroll.

Research Question 4: The fourth research question is: What are the significant predictor variables that distinguish between first generation and continuing generation second year college students in their intent to re-enroll at private institutions in 
Kentucky? The planned analysis was logistic regression, but as was previously stated this was replaced with a combination of both OLS regression and logistic regression due to several factors. The plan was to produce separate regression equations for firstgeneration college students and for continuing generation college students.

The number of students in the category first generation college student was small $(n=24)$. If all of the predictor variables had been entered into a regression equation, the process would have resulted in 16 variables being entered into an equation with only 24 subjects, meaning that there would be less than 2 subjects per predictor. This would have resulted in an equation with a low amount of replicability and high sampling error. Rather than used hierarchical entry of variables, it was decided to use the forward entry method of creating regression models. This would allow only significant predictors to enter a regression equation and not require entry of all variables. This method of forming regression equations was used for both first-generation and continuing generation students.

Table 24 summarizes the results of the two OLS regression equations. For the dependent variable intent to re-enroll, first generation students had one significant predictor: number of courses dropped, $F(1,22)=5.90, p<.05$, adjusted $R^{2}=.176$. This was a negative relationship $(\beta=-.553)$ meaning that the fewer the courses that the student reported dropping since beginning college, the greater the intent to re-enroll. Students who were continuing generation had two significant predictors of intent to re-enroll: overall satisfaction and perception of this year compared to last, $F(2,187)=13.02, p<$ .01, adjusted $R^{2}=.113$. 
Table 25 summarizes the results of the two logistic regression equations. For the dependent variable intent to re-enroll, first generation students had two significant predictors: number of courses dropped and this year compared to last, $\chi(2)=15.575, p<$ .001 , Nagelkerke $R^{2}=.707$. As with the OLS, regression the number of courses dropped predictor for the logistic regression had a negative relationship with intent to enroll $(B=$ 22.30). Students who were continuing generation had two significant predictors of intent to re-enroll: overall satisfaction and perception of this year compared to last, $\chi(2)=$ $26.892, p<.001$, Nagelkerke $R^{2}=.253$.

Table 24

Statistically Significant Predictors of Intent to Re-enroll for First Generation and Continuing Generation Students: Ordinary Least Squares Regression

\begin{tabular}{|c|c|c|c|c|c|}
\hline $\begin{array}{l}\text { Dependent } \\
\text { Variable } \\
\end{array}$ & $\begin{array}{l}\text { Predictor } \\
\text { Variable } \\
\end{array}$ & $\underline{B}$ & $\underline{S E B}$ & $\underline{\beta}$ & $t$ \\
\hline $\begin{array}{l}\text { Intent to } \\
\text { Re-enroll } \\
\text { First Gen } \\
(n=24) \\
\end{array}$ & & & & & \\
\hline $\begin{array}{l}\text { Intent to } \\
\text { Re-enroll } \\
\text { Continuing } \\
\text { Gen } \\
(n=190) \\
\end{array}$ & Courses dropped & -.553 & .228 & -.460 & $-2.429 *$ \\
\hline
\end{tabular}
Satisfaction
$.240 \quad .079$
.219
$3.036^{* *}$

This year compared to last $.155 \quad .053$

.212

$2.934 * *$

$$
{ }^{*} p<.05,{ }^{* *} p<.01 \text {. }
$$




\section{Table 25}

Statistically Significant Predictors of Intent to Re-enroll First Generation and Continuing Generation Students: Logistic Regression

Dependent Predictor

Variable Variable

$\underline{B} \quad \underline{S E B} \quad \underline{\operatorname{Exp}(B)} \quad \underline{p}$

Intent to

Re-enroll

First Gen

$(n=24)$

$\begin{array}{llll}\text { Courses dropped } \quad-22.30 & 10383.17 & .000 \quad .001 * *\end{array}$

$\begin{array}{lllll}\text { This year compared to last } & 2.13 & 1.21 & 8.439 & .027^{*}\end{array}$

Intent to

Re-enroll

Continuing

Gen

$(n=190)$

\begin{tabular}{ccccc} 
Satisfaction & 1.296 & .422 & 3.653 & $<.001^{* *}$ \\
This year compared to last & .713 & .279 & 2.040 & $.009^{* *}$ \\
\hline
\end{tabular}

${ }^{*} p<.05,{ }^{* *} p<.01$

Note. Values of $p$ mean the obtained probability for the entry of the variable into the regression model.

Summary of the analysis for research question four: For first generation college students there was strong evidence that number of courses dropped predicted intent to reenroll. There was some evidence that the perception of this year compared to last was a significant predictor. For continuing generation college students, there was strong evidence that the perception of this year compared to last and satisfaction scale average significantly predicted intent to re-enroll. 
Research Question 5: The fifth research question is: What are the significant predictor variables that distinguish between first generation and continuing generation second year college students in their intent to graduate at private institutions in Kentucky? As stated in research questions four, the planned analysis was logistic regression, but this was replaced with a combination of both OLS regression and logistic regression due to several factors. The plan was to produce separate regression equations for first-generation college students and for continuing generation college students.

As explained in research question four, the number of students in the category first generation college student was small $(n=24)$. Rather than used hierarchical entry of variables, it was decided to use the forward entry method of creating regression models. This approach would allow only significant predictors to enter a regression equation and not require entry of all variables. This method of forming regression equations was used for both first-generation and continuing generation students.

Table 26 summarizes the results of the two OLS regression equations. For the dependent variable intent to graduate, there was no statistically significant predictor variable for first generation students. Students who were continuing generation had one significant predictor of intent to graduate: how sure the student was of his or her major, $F(1,188)=5.18, p<.05$, adjusted $R^{2}=.022$.

Table 27 summarizes the results of the two logistic regression equations. For the dependent variable intent to graduate, first generation students had one significant predictor: score on the Thriving scale: $\chi(1)=6.962, p<.01$, Nagelkerke $R^{2}=.424$. Students who were continuing generation had two significant predictors of intent to 
graduate: how sure the student was of his or her major and score on the Involvement scale, $\chi(2)=10.251, p<.01$, Nagelkerke $R^{2}=.124$.

\section{Table 26}

Statistically Significant Predictors of Intent to Graduate for First Generation and Continuing Generation Students: Ordinary Least Squares Regression

\section{Dependent \\ Variable \\ Intent to \\ Graduate \\ First Gen \\ $\underline{(n=24)}$}

Predictor

Variable

$\underline{B} \quad \underline{S E B}$

$\underline{\beta}$

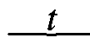

None

Intent to

Graduate

Continuing

Gen

$\underline{(n=190)}$

$\begin{array}{lllll}\text { Sure of major } & .091 & .040 & .164 & 2.276^{*}\end{array}$

$$
{ }^{*} p<.05,{ }^{* *} p<.01 .
$$




\section{Table 27}

Statistically Significant Predictors of Intent to Graduate for First Generation and Continuing Generation Students: Logistic Regression

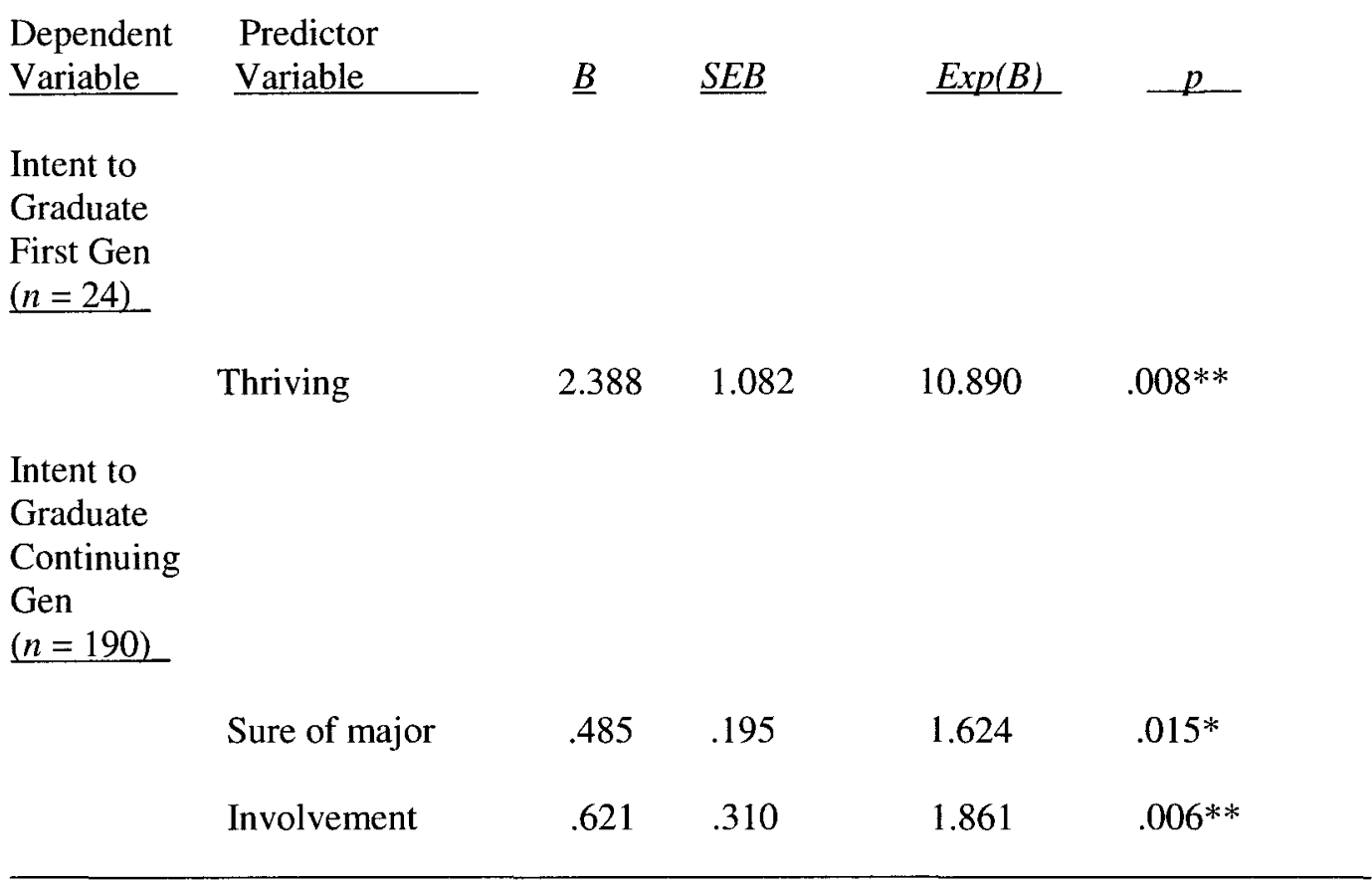

$$
{ }^{*} p<.05, * * p<.01
$$

Note. Values of $p$ mean the obtained probability for the entry of the variable into the regression model.

Summary of the analysis for research question five: Regarding the dependent variable intent to graduate, there was some evidence that the Thriving Scale was a significant predictor for first generation students. For continuing generation college students, there was strong evidence that how sure a student was of his or her major significantly predicted intent to graduate. For these same students, there was some evidence that involvement scale average significantly predicted intent to graduate. 
Research Question 6: The sixth research question was: Are first generation second year college students less likely to intend on re-enrolling for the following semester of college as compared to continuing generation college students? A chi-square test of association was performed to address this question, which involved crosstabulating first generation status with intent to re-enroll. Table 28 shows the results of the cross-tabulation. There was no significant relationship between first generation status and intent to re-enroll, $\chi(1)=0.034, p=.853$. The percentages of students expressing the intention to re-enroll were about the same for the two groups of students.

\section{Table 28}

Cross-tabulation of Intent to Re-enroll with First-Generation in College Status

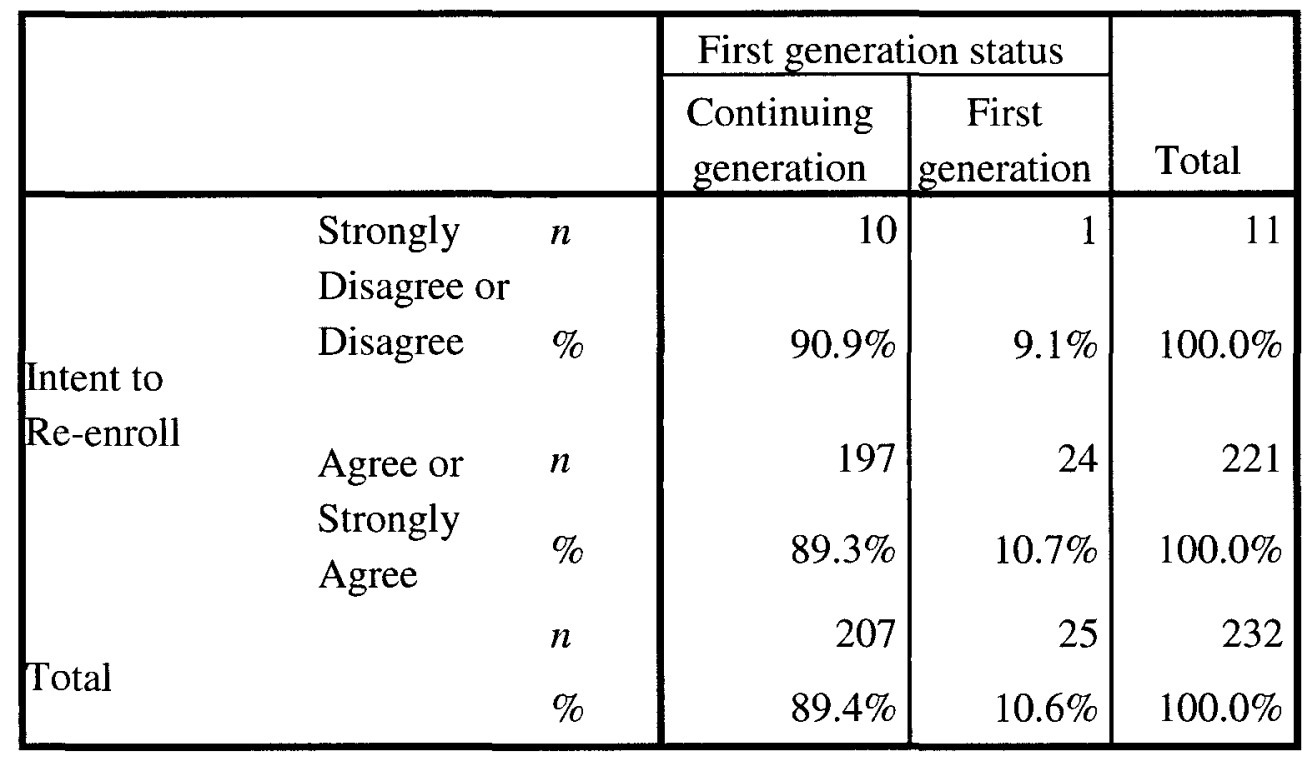

Research Question 7: The seventh research question was: Are first generation second year college students less likely to intend on graduating from college as compared to continuing generation college students? A chi-square test of association was performed 
to address this question, which involved cross-tabulating first generation status with intent to graduate. There were very few students who expressed disagreement with the statement: Do you intend to graduate?" Only six students stated strongly disagree and none stated disagree. A chi-square test with so few students in a category would have not been advisable. As a consequence, data were re-coded so that the variable intend to graduate had two categories: (a) strongly disagree or agree, and (b) strongly agree. The rationale was that there would still be a contrast between subjects in terms of the strength of their belief that they would graduate. Table 29 shows the results of the crosstabulation. There was no significant relationship between first generation status and intent to graduate $, \chi(1)=1.643, p=.200$.

\section{Table 29}

Cross-tabulation of Intent to Graduate with First-Generation in College Status

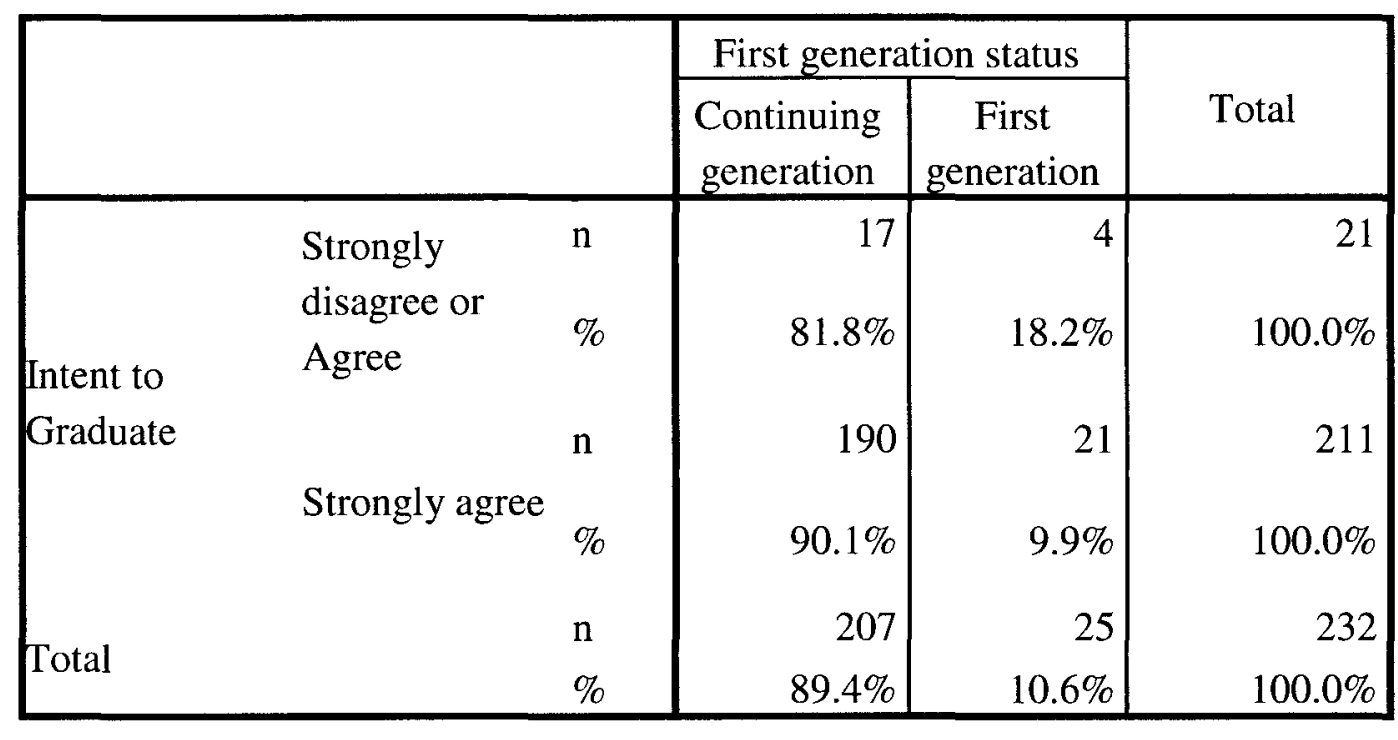


Summary of Statistical Analyses Addressing Research Questions One to Seven

Table 30 provides a summary of the results of the statistical analyses that were performed to address the six research questions of the study. The implications of these results will be explored in Chapter 5 .

\section{Table 30}

Research Questions, Analyses, and Key Results Pertaining to Variables Associated with the Intention to Re-enroll in College and the Intention to Graduate

\begin{tabular}{|l|l|l|}
\hline Research Question & Analyses & Results \\
\hline $\begin{array}{l}\text { 1. What pre-college } \\
\text { characteristics contribute } \\
\text { to the intent to re-enroll } \\
\text { and the intent to } \\
\text { graduate of second year } \\
\text { college students? }\end{array}$ & $\begin{array}{l}\text { Two ordinary least } \\
\text { squares (OLS) regression } \\
\text { equations were created, } \\
\text { one with intent to re- } \\
\text { enroll as the dependent } \\
\text { variable and one with } \\
\text { intent to graduate as the } \\
\text { dependent variable. Each } \\
\text { had 11 demographic } \\
\text { variables entered in step } \\
\text { of a hierarchical entry } \\
\text { process. The same } \\
\text { process was repeated } \\
\text { using logistic regression } \\
\text { equations. }\end{array}$ & $\begin{array}{l}\text { Thence that number of } \\
\text { perception of } \text { this year } \\
\text { compared to last were } \\
\text { significant predictors of } \\
\text { intent to re-enroll. } \text { There } \\
\text { was some evidence that } \\
\text { first generation status } \\
\text { and being sure of one's } \\
\text { major were significant } \\
\text { predictors of the re- } \\
\text { enrollment intention. }\end{array}$ \\
& $\begin{array}{l}\text { Regarding the dependent } \\
\text { variable intent to } \\
\text { graduate, there was } \\
\text { some evidence that being } \\
\text { sure of one's major was } \\
\text { a significant predictor. }\end{array}$ \\
\hline
\end{tabular}




\begin{tabular}{|c|c|c|}
\hline $\begin{array}{l}\text { 2. Does the thriving } \\
\text { scale (Block } 2 \text { of the } \\
\text { hierarchical regression } \\
\text { equation), as a measure } \\
\text { of student thriving, } \\
\text { contribute to the intent } \\
\text { to re-enroll and intent to } \\
\text { graduate of second year } \\
\text { college students? }\end{array}$ & $\begin{array}{l}\text { Building on the two } \\
\text { ordinary least squares } \\
\text { (OLS) regression } \\
\text { equations from research } \\
\text { question } 1 \text {, one with } \\
\text { intent to re-enroll as the } \\
\text { dependent and one with } \\
\text { intent to graduate as the } \\
\text { dependent, the variable } \\
\text { thriving scale average } \\
\text { was added into step } 2 \text { of a } \\
\text { hierarchical entry } \\
\text { process. The same } \\
\text { process was repeated } \\
\text { using logistic regression } \\
\text { equations. }\end{array}$ & $\begin{array}{l}\text { With the addition of the } \\
\text { thriving scale average to } \\
\text { the demographic } \\
\text { variables, there was not a } \\
\text { statistically significant } \\
\text { predictive relationship } \\
\text { between the thriving } \\
\text { scale average and the } \\
\text { dependent variable, intent } \\
\text { to re-enroll or intent to } \\
\text { graduate after controlling } \\
\text { for the demographic } \\
\text { variables. }\end{array}$ \\
\hline $\begin{array}{l}\text { 3. What campus } \\
\text { experiences and } \\
\text { perceptions (Block } 3 \text { of } \\
\text { the hierarchical } \\
\text { regression equation) } \\
\text { contribute to the intent } \\
\text { to re-enroll and intent to } \\
\text { graduate of second year } \\
\text { college students? }\end{array}$ & $\begin{array}{l}\text { Building on the two } \\
\text { ordinary least squares } \\
\text { (OLS) regression } \\
\text { equations from research } \\
\text { question } 1 \text { and } 2 \text {, one } \\
\text { with intent to re-enroll as } \\
\text { the dependent and one } \\
\text { with intent to graduate as } \\
\text { the dependent, the } \\
\text { involvement scale } \\
\text { average, interaction scale } \\
\text { average, and satisfaction } \\
\text { scale average were added } \\
\text { to step } 3 \text { of the } \\
\text { hierarchical entry. The } \\
\text { same process was } \\
\text { repeated using logistic } \\
\text { regression equations. }\end{array}$ & $\begin{array}{l}\text { After demographic } \\
\text { variables and thriving } \\
\text { scale average were } \\
\text { controlled, there was } \\
\text { strong evidence that the } \\
\text { satisfaction scale } \\
\text { average did significantly } \\
\text { predict intent to enroll. } \\
\text { After demographic } \\
\text { variables and thriving } \\
\text { scale average were } \\
\text { controlled, the } \\
\text { involvement scale } \\
\text { average, interaction } \\
\text { scale average, and } \\
\text { satisfaction scale } \\
\text { average did not } \\
\text { significantly predict } \\
\text { intent to graduate. }\end{array}$ \\
\hline
\end{tabular}




\begin{tabular}{|c|c|c|}
\hline $\begin{array}{l}\text { 4. What are the } \\
\text { significant predictor } \\
\text { variables that } \\
\text { distinguish between first } \\
\text { generation and } \\
\text { continuing generation } \\
\text { second year college } \\
\text { students in their intent } \\
\text { to re-enroll at private } \\
\text { institutions in } \\
\text { Kentucky? }\end{array}$ & $\begin{array}{l}\text { Two ordinary least } \\
\text { squares (OLS) regression } \\
\text { equations were created } \\
\text { with intent to re-enroll as } \\
\text { the dependent variable. } \\
\text { Using the forward entry } \\
\text { method to create the } \\
\text { regression equations, only } \\
\text { significant predictors } \\
\text { entered the regression } \\
\text { equations. This } \\
\text { construction of regression } \\
\text { equations was used for } \\
\text { both first-generation and } \\
\text { continuing generation } \\
\text { students. The same } \\
\text { process was repeated } \\
\text { using logistic regression } \\
\text { equations. }\end{array}$ & $\begin{array}{l}\text { For first generation } \\
\text { college students, there } \\
\text { was strong evidence that } \\
\text { the number of courses } \\
\text { dropped predicted intent } \\
\text { to re-enroll. For first } \\
\text { generation college } \\
\text { students, there was some } \\
\text { evidence that perception } \\
\text { of this year compared to } \\
\text { last year predicted intent } \\
\text { to re-enroll. } \\
\text { For continuing } \\
\text { generation college } \\
\text { students, there was strong } \\
\text { evidence that the } \\
\text { perception of this year } \\
\text { compared to last and the } \\
\text { satisfaction scale } \\
\text { average predicated intent } \\
\text { to re-enroll. }\end{array}$ \\
\hline $\begin{array}{l}\text { 5. What are the } \\
\text { significant predictor } \\
\text { variables that } \\
\text { distinguish between first } \\
\text { generation and } \\
\text { continuing generation } \\
\text { second year college } \\
\text { students in their intent } \\
\text { to graduate at private } \\
\text { institutions in } \\
\text { Kentucky? }\end{array}$ & $\begin{array}{l}\text { Two ordinary least } \\
\text { squares (OLS) regression } \\
\text { equations were created } \\
\text { with intent to graduate as } \\
\text { the dependent variable. } \\
\text { Using the forward entry } \\
\text { method to create the } \\
\text { regression equations, only } \\
\text { significant predictors } \\
\text { entered the regression } \\
\text { equations. This } \\
\text { construction of regression } \\
\text { equations was used for } \\
\text { both first-generation and } \\
\text { continuing generation } \\
\text { students. The same } \\
\text { process was repeated } \\
\text { using logistic regression } \\
\text { equations. }\end{array}$ & $\begin{array}{l}\text { For first generation } \\
\text { college students, there } \\
\text { was some evidence that } \\
\text { the thriving scale } \\
\text { average predicted intent } \\
\text { to graduate. } \\
\text { For continuing } \\
\text { generation college } \\
\text { students, there was strong } \\
\text { evidence that how sure a } \\
\text { student was of his or her } \\
\text { major significantly } \\
\text { predicted intent to } \\
\text { graduate. For continuing } \\
\text { generation college } \\
\text { students, there was some } \\
\text { evidence that the } \\
\text { involvement scale } \\
\text { average significantly } \\
\text { predicted intent to } \\
\text { graduate. }\end{array}$ \\
\hline
\end{tabular}




\begin{tabular}{|c|c|c|}
\hline $\begin{array}{l}\text { 6. Are first generation } \\
\text { second year college } \\
\text { students less likely to } \\
\text { intend on re-enrolling } \\
\text { for the following } \\
\text { semester of college as } \\
\text { compared to continuing } \\
\text { generation college } \\
\text { students? }\end{array}$ & $\begin{array}{l}\text { A chi-square test of } \\
\text { association was } \\
\text { performed to address this } \\
\text { question, which involved } \\
\text { cross-tabulating first } \\
\text { generation status with } \\
\text { intent to re-enroll. }\end{array}$ & $\begin{array}{l}\text { There was no significant } \\
\text { relationship between } \\
\text { first-generation status } \\
\text { and intent to re-enroll. }\end{array}$ \\
\hline $\begin{array}{l}\text { 7. Are first generation } \\
\text { second year college } \\
\text { students less likely to } \\
\text { intend on graduating } \\
\text { from college as } \\
\text { compared to continuing } \\
\text { generation college } \\
\text { students? }\end{array}$ & $\begin{array}{l}\text { A chi-square test of } \\
\text { association was } \\
\text { performed to address this } \\
\text { question, which involved } \\
\text { cross-tabulating first } \\
\text { generation status with } \\
\text { intent to graduate. Since } \\
\text { very few students } \\
\text { expressed disagreement } \\
\text { with the statement "Do } \\
\text { you intent to graduate?," } \\
\text { data were re-coded so that } \\
\text { the variable intend to } \\
\text { graduate had two } \\
\text { categories: (a) strongly } \\
\text { disagree or agree, and (b) } \\
\text { strongly agree. }\end{array}$ & $\begin{array}{l}\text { There was no significant } \\
\text { relationship between first- } \\
\text { generation status and } \\
\text { intent to graduate. }\end{array}$ \\
\hline
\end{tabular}




\section{CHAPTER V}

\section{DISCUSSION, IMPLICATIONS, AND LIMITATIONS}

\section{Overview}

This dissertation examined pre-entry variables that predicted persistence beyond the second year at four private institutions in Kentucky. Data were collected through quantitative analysis of the Sophomore Experiences Survey (SES). Students were surveyed during the end of their fourth semester in college. This chapter will discuss the conclusions and implications of the results, recommendations for practitioners, recommendations for future research and limitations of this study.

The persistence and attrition of second year college students is a growing concern of colleges and universities because second year college students face some of the greatest challenges among members of the college student population (Gahagan \& Hunter, 2006; Lemons \& Richmond, 1987; Morgan \& Davis, 1981; Wilder, 1993). Schaller (2005) found that students in their second year felt alone and isolated. These students felt overwhelmed with plans for their future and unsure as to their fit in the career world. Many of the students Schaller (2005) studied felt as though they were operating in periods of crisis both in relationships and academics. The stress and the worry in these students' lives were impacting their academic success. Spady's (1970) model of student dropout and Tinto's (1975) model of student departure served as the 
theoretical foundation for this study. Schreiner's (2010b) understanding of student thriving also helped develop the conceptual framework for this study.

Spady's (1970) model of student dropout is constructed from two variables: sense of integration and social and academic rewards. Social rewards are those that a subject receives from participation in out of the classroom experiences. Examples of social rewards include participation in a sport, college involvement, and campus work. Tinto's (1975) model of student departure proposes that successful social and academic integration in the college community leads to an institutional commitment. Without successfully integrating into the social and academic realms of the college community, a student is likely to dropout. Schreiner's (2010b) understanding of student thriving suggests that students need to develop successfully in college through a positive outlook, interactions with faculty and an overall sense of well-being.

This study revealed that there was some evidence that the involvement scale average of the Sophomore Experiences Survey significantly predicted intent to graduate. The results of these regression models also revealed that there was strong evidence that the satisfaction scale average of the Sophomore Experiences Survey was a significant predictor of intent to re-enroll. These findings correlate well with both Spady's (1970) and Tinto's (1975) models as involvement and satisfaction play a critical role in both of these theorists' understanding of student dropout decisions. Therefore, it makes sense that the data analysis from this dissertation would discover that the involvement scale average significantly predicted intent to graduate and that the satisfaction scale average was a significant predictor of intent to re-enroll. 
The sample for this study consisted of full-time, second year students who were completing their fourth semester of academic work. This predictive study examined the relationship between predictor variables including pre-college characteristics, scores on the Thriving Quotient, and campus experiences and perceptions and the criterion variables of the student's intent to re-enroll after their fourth semester of their second year and intent to graduate from college. For the first five research questions, ordinary least squares regression and logistic regression were used to measure the predictive nature and magnitude of the relationship between the variables. The sixth and seventh research questions constituted a comparative study. Cross tabulations and chi-square statistics were used to address each of these questions.

\section{Discussion of Results}

\section{Demographic and Background Data}

This study provided a glance at the lives of full-time, second year college students during the spring 2012 semester at four private institutions in the state of Kentucky. The sample consisted of traditional age college students ( $94.5 \%$ were age $19-20)$, mostly female (73.1\%), and Caucasian (89.3\%). The demographics (age, gender and race/ethnicity) of this sample were representative of the overall population of students at the four institutions studied. Table 1 provides an overall of the four institutions studied. A small number (10.6\%) of the participants in the study were considered first generation college students. These students had at least one parent with the highest level of education as high school graduate, GED, or some high school. A large majority of the students (89.7\%) aspired to obtain a doctoral or master's degree at some point in their 
lifetime. Many of these students (64\%) did not work any hours off campus while over half of the students $(55.8 \%)$ worked a minimum of five hours or less at an on-campus job.

After examination of descriptive statistics in preparation for data analysis, the researcher discovered that not every respondent could be considered appropriate for inclusion in the analyses that addressed the seven research questions. Three categories of students were removed (a) those who were not second year students, (b) part-time students, and (c) transfer students. These categories of students were removed because they did not fit the "type" of study intended to be studied. Students included in this study were intended to be full-time, second year students that had not transferred to their current institution. The University of South Carolina's taskforce on second year college students defines second year college students as any 'first-time, full-time students who have persisted into their second year of academic work' (Gahagan \& Hunter, 2006, p. 18).

Research question one of this study asked: "what pre-college characteristics contribute to the intent to re-enroll and intent to graduate of second year college students?" The researcher hypothesized that there would be a significant predictive relationship between college grades and major certainty and the dependent variables, intent to re-enroll and intent to graduate, of second year students at private institutions in Kentucky as measured by the Sophomore Experiences Survey. Analysis of the data revealed that four of the demographic variables were statistically significant predictors of intent to re-enroll using ordinary least squares regression and logistic regression. The two demographic variables that had strong evidence of being significant predictor variables were fewer courses having been dropped by the student and positive perception of this 
year compared to last year. The two demographic variables that had some evidence of being significant predictors of intention to re-enroll were first generation status (negatively associated with intention to re-enroll) and being sure of one's major. In agreement with these results, Thayer (2000) suggested that first generation college students were less likely to persistent through graduation.

There was a positive relationship between intent to re-enroll and two of the demographic variables: positive perception of this year compared to last year and being sure of one's major. Having a positive perception of this year compared to last year can only encourage students to believe that their third year will only be better than their two previous years. It then makes sense that a positive perception of this year compared to last year would have a positive relationship with intent to re-enroll. Being sure of one's major allows a student to feel more confident about their college experience; they recognize what they are working toward because they understand which classes are needed for their major. Having this confidence can certainly lead a student to feel more stable about their coursework and the reasons why they are taking specific classes. Using logistic regression, there was some evidence that one demographic variable was a statistically significant predictor of intent to graduate. There was a positive relationship between intent to graduate and being sure of one's major. This suggests that second year students who were sure of their major also intended on graduating from college for the reasons mentioned above

These results are suggested in previous research as Graunke and Woosley (2005) discovered that sophomores who had chosen a major had higher grades and more satisfaction with their academic courses. These researchers found that students who 
decided on a major had increased motivation and focus which lead to greater dedication and integration in courses. The research from this study seems to indicate that second year students may also have had increased motivation and focus because they had decided on a major. Also, the majority of the students that participated in this study had high educational aspirations for their future. Graunke and Woosley (2005) also discovered that students perceived their interaction with faculty members to be motivating because they were taking many courses that were required for this major. It can be assumed that many students in this dissertation study may have had similar feelings about their faculty interactions in major courses. Newlon and Gaither (1980) discovered that declaring a major did assist students in their persistence through college. This research differs a bit from Newlon and Gaither's (1980) study as they found that students had higher persistence rates in professional programs because a student attempting to receive a professional program degree believed that a better job would result from such a degree. While specific questions about professional programs and job placement were not asked in this study, it can be concluded that second year students in this study may have believed that declaring a major lead to a better understanding of future job opportunities.

\section{The Thriving Quotient}

As part of the Sophomore Experiences Survey, students were asked 25 questions that constituted the Thriving Quotient. The Thriving Quotient (a five-factor model) includes the Engaged Learning Index, Diverse Citizenship, Academic Determination, Positive Perspective, and Social Connectedness (L. A. Schreiner, personal communication, November 29, 2011). The first version of the Sophomore Experiences 
Survey was administered in spring 2007. This instrument was “... designed to measure various aspects of the sophomore experience, in additions to levels of student thriving, which was conceptualized as academic self-efficacy, hope, mindset, engaged learning, and meaning of life" (Schreiner, 2010, p. 45). A follow-up study of the 2007 version of the Sophomore Experiences Survey was administered in 2010 (L. A. Schreiner, personal communication, April 26, 2011).

Using only items predictive of second year success, scales from various instruments that had been tested and found to be reliable were used to study second year students. The 2010 administration of the Sophomore Experiences Survey yielded a total reliability of .94 (L. A. Schreiner, personal communication, April 26, 2011). Schreiner then performed a follow-up study in 2011 and developed the Thriving Quotient (a fivefactor model) from 10 of the 18 original independent scales from the 2010 version of the SES. Schreiner (2012) studied 14,067 students from 53 public and private institutions and found that the Thriving Quotient accounted for $11-23 \%$ of the variation in outcomes for students such as college grades and intent to graduate.

Research question two for this study asked: does the Thriving Quotient contribute to the intent to re-enroll and intent to graduate of second year college students? The researcher hypothesized that there would be a significant predictive relationship between the Thriving Quotient and the dependent variables, intent to re-enroll and intent to graduate, of second year students at private institutions in Kentucky as measured by the Sophomore Experiences Survey. However, this current study found that after demographic variables were controlled, the variable thriving scale average did not significantly predict intent to re-enroll or intent to graduate. This differs from previous 
studies of second year college students in regards to the Thriving Quotient. Potentially, this difference may have occurred because of the few cases that responded negatively to either the intent to re-enroll or the intent to graduate questions. Since there were so few students who disagreed with these statements, the results may be a bit skewed. It seems likely to assume that if more students have disagreements with these statements there may have been more similarities with the findings from the research as compared to previous research results.

Schreiner (2010b) found the Thriving Quotient and its five elements of thriving to explained 8 to 18 percent of the variation in such outcomes as college grades and intent to graduate. Schreiner (2010b) suggests that "[these]...finding[s] indicate that there is a significant piece of the student-success puzzle that can be understood by focusing on the concept of thriving" (p. 6). Higher levels of engagement, having a positive outlook and believing that they could make a difference were key reasons why students had a higher likelihood on intending to graduate from college. These key reasons are all questions that constitute the Thriving Quotient. Schreiner (2012) constructed a model using the Thriving Quotient as the measure of overall student thriving, to determine if the Thriving Quotient was a predictor for student's intention to graduate. Schreiner (2012) earliest findings suggested that the Thriving Quotient is predictive of a student's intent to graduate.

\section{Experiences and Perception}

After building upon the regression models in research questions one and two, research question three addressed "what campus experiences and perceptions contributed to the intent to re-enroll and intent to graduate of second year college students?" The 
variables Involvement scale average, Student-Faculty Interaction scale average, and Satisfaction scale average were added to the regression equations that already contained the demographic variables and the Thriving scale average. The researcher hypothesized that there would be a significant predictive relationship among Involvement scale average, Student-Faculty Interaction scale average, and Satisfaction scale average and the dependent variables, intent to re-enroll and intent to graduate, of second year students at private institutions in Kentucky as measured by the Sophomore Experiences Survey The results of these regression models revealed that there was strong evidence that the Satisfaction scale average was a significant predictor of intent to re-enroll. None of the campus experience and perception variables were found to be significant predictors of intent to graduate.

Schreiner (2010a) discussed her findings of the 2007 administration of the Sophomore Experiences Survey. Her findings revealed that student satisfaction was one of the strongest predictors of a student's intent to re-enroll and intent to graduate. Satisfaction is a key component of Spady's (1970b) model of student dropout. It makes sense that this dissertation would also find that overall student satisfaction was a predictor for intent to re-enroll. However, this study did not find overall student satisfaction as a predictor variable for intent to graduate. Perhaps the data are a bit skewed as $97.6 \%$ of respondents to the survey in this dissertation intended on graduating from college. Since there were so few students who expressed that they did not intent to graduate from college, analysis of the data required combining cases in which the student expressed disagreement (where the student answered strongly disagree and disagree) with cases in which the student expressed agreement (where the student answered agree). 
First Generation and Continuing Generation Second Year College Students

Thayer (2000) suggested that first generation college students are less likely to persistent through graduation. Pike and Kuh (2005) revealed that first generation college students as compared to continuing generation college students found the college environment to be less welcoming and supportive. Pike and Kuh (2005) also suggested that a first generation college student's difficulty with socialization and adjustment in the college environment may be the result of a lack of role models with knowledge of the college experiences. Pascarella et al. (1996) discovered that first generation college students will need to spend more time studying as compared to continuing generation college students in order to improve their reading comprehension scores.

The fourth research question in this study asked "what significant predictor variables distinguished between first generation and continuing generation second year college students in their intention to re-enroll?" The researcher hypothesized that the significant predictor variables that distinguish between first generation and continuing generation second year college students in their intent to re-enroll at private institutions in Kentucky as measured by the Sophomore Experiences Survey would include hours worked off campus, Involvement scale average, and Student-Faculty Interaction scale average.

For first generation college students, there was strong evidence that the number of courses dropped predicted intent to re-enroll. The fewer courses a student dropped since beginning college the higher likelihood that he or she would intend to re-enroll for a third year. Students who have more dropped courses have more courses to take which might add to the uncertainty to re-enroll or graduate from college. There was some evidence 
that the positive perception of this year compared to last year was a significant predictor of intent to re-enroll. As suggested by much of the literature review for this study, academic challenges can exist for first-generation college students because of their lack of social capital and lack of role models in regard to knowledge of the college experience (Purswell, Yazedjian, \& Toews, 2008). Pascarella et al. (2004) determined that those students engaged outside of the classroom had higher critical thinking skills, aspiration for degree attainment, and a better sense of control of their environment. Yet, first generation college students were found to be less engaged outside of the classroom. While this study discovered that number of courses dropped predicted intent to re-enroll, this suggests that second year students at these four institutions may be getting the appropriate assistance from their academic advisors in picking the right courses.

Potentially, these students had a better sense of control that Pascarella et al. (2004) were discussing in their research which led to greater engagement in the college experience. Also, it can be inferred that these first generation college students may have found role models in their outside of the classroom experiences that assisted them in their navigation of college.

A continuing-generation student for this study was any student with at least one parent who has attended some college. Purswell, Yazedjian, and Toews (2008) studied students with parents who had no college experience, some college experience, and students with at least one parent who earned a baccalaureate degree. These researchers learned that parental support was predictive of the academic behavior of students with parents with some college experience as well as students with at least one parent with a baccalaureate degree. Therefore, students with parents with some college experience and 
those with at least one parent with a baccalaureate degree had enough social capital needed for assistance to navigate the transition to college and the college environment (Purswell, Yazedjian, \& Toews, 2008). For continuing generation college students, there was strong evidence that the positive perception of this year compared to last and the Satisfaction scale average predicted intent to re-enroll. It seems appropriate that there was strong evidence that both positive perception of this year compared to last and the Satisfaction scale average would predict intent to re-enroll because Schreiner's (2012) concept of thriving is understood to be impacted by a person's positive outlook and their overall satisfaction. It can be assumed that these students were thriving students because of their positive outlook and satisfaction, thus impacting their decisions to re-enroll.

The fifth research question in this study asked "what significant predictor variables distinguished between first generation and continuing generation second year college students in their intention to graduate?" The researcher hypothesized that the significant predictor variables that distinguish between first generation and continuing generation second year college students in their intent to graduate at private institutions in Kentucky as measured by the Sophomore Experiences Survey would include hours worked off campus, Involvement scale average, and Student-Faculty Interaction scale average. There was some evidence that the Thriving scale average was a significant predictor for first generation college students. The Thriving scale average suggests that students have higher levels of engagement, have a positive outlook, and believe that they could make a difference which leads to a higher likelihood on intending to graduate from college (Schreiner, 2010). While some research suggests that first generation college students are less likely to be engaged on campus and have a more negative attitude as 
compared to continuing generation college students because of lack of family encouragement or worry about failing out of school, potentially the first generation second year college students in this study had higher levels of engagement inside and outside of the classroom (Bui, 2002; Terenzini, Springer, Yaeger, Pascarella, \& Nora, 1996).

For continuing generation college students, there was strong evidence that being sure of one's major significantly predicted intent to graduate. For continuing generation college students, there was some evidence that the Involvement scale average significantly predicted intent to graduate. Tinto's (1975) model of student dropout suggests that social integration plays a key role in a student's dropout decision. In accordance with Tinto's model, it makes sense that this study would find that continuing generation college student's involvement scale average significantly predicts their intention to graduate.

The sixth research question asked "Are first generation second year college students less likely to intend on re-enrolling from college as compared to continuing generation college students?" The researcher hypothesized that first generation college students would be less likely to intend to re-enroll for the following semester of college as measured by the response to the question "I intend to re-enroll next year at the institution I am currently attending" as measured by the Sophomore Experiences Survey. The seventh research question asked "Are first generation second year college students less likely to intend on graduating from as compared to continuing generation college students?" The researcher hypothesized that first generation college students would be less likely to intend to graduate from college as compared to continuing generation 
college students as measured by the response to the question "I intend to graduate from college and obtain a bachelor's degree" as measured by the Sophomore Experiences Survey. For both of these questions, there was no statistically significant relationship between first generation status and the students' intention (either to re-enroll or graduate). Longwell-Grice and Longwell-Grice (2008), interviewed four first generation college students. They found that it was important for a student to feel as if he or she belonged on campus in order to be retained at that institution. This dissertation study can reassure the four institutions studied that they are doing a successful job at helping their first generation college students feel a sense of belonging on campus as there was found to be no difference between first generation and continuing generation second year college students' intentions on re-enrolling or graduating from college in this study.

Implications and Recommendations for Practitioners

\section{Second Year College Student Attrition}

Research shows that the second year in college life can be one of the greatest challenges for many students (Gahagan \& Hunter, 2006; Lemons \& Richmond, 1987; Morgan \& Davis, 1981; Wilder, 1993). Second year students experience stress in determining their major, struggle with balancing their time devoted to social activities rather than to academic success, and need faculty support outside of the classroom to succeed in the classroom (Gardner, 2000; Graunke \& Woosley, 2005; Schaller, 2005) Continuing to understand how demographic variables predict second year college student attrition is important. Much of the second year studies that have been constructed are qualitative research studies rather than quantitative research studies. Gahagan and Hunter (2006) remind researchers that it is important that concentrated investigation of the 
second year experience occur in order for institutions to understand how to retain second year students. Schreiner et al. (2012) found that student-faculty interaction played a pivotal role in the academic success of college students. These important relationships helped the students develop connections at their institutions. While this study did not find a significant relationship between student-faculty interaction and intent to re-enroll or intent to graduate, this study did discover that deciding a major did significantly impact a student's intent to graduate. Student-faculty interactions may help a student determine his/her major specifically if they are engaged inside the classroom.

\section{Second Year College Student Advising}

As found in this study, students who had decided a major had a greater likelihood of intending to re-enroll for their third year. Schaller (2005) found in her research that second year students had an easier college experience their second year if they had decided on their major as compared to their counterparts that had not yet decided a major. Through an understanding of Schaller's (2005) research and the knowledge provided from the research of this current study, mandatory major selection may be beneficial for students especially during their second year in college. This discovery reminds practitioners and educators at colleges and universities that it is imperative for second year students to be provided strong and solid advising for their coursework and their career paths. Advisors must be well trained to assist students in determining coursework that fits their educational desires and provides them with a strong foundation for choosing a major that the second year student enjoys.

For first generation second year college students, the number of courses dropped was a significant predictor variable for a student's intent to re-enroll. Advisors must be 
successful in assisting students in their course selections. Without assistance from advisors, students may take courses that are not necessary for their degree or do not match their academic capabilities resulting in more courses to take in the latter half of their college enrollment. These courses will eventually be dropped. Collier and Morgan (2008) found that first generation college students had little help outside of the classroom with assignments and struggled to get assignments completed because of outside commitments (i.e., family obligations). Collier and Morgan (2008) also discovered that first generation college students struggled to understand faculty jargon and faculty expectations for assignments. Because of these challenges, Collier and Morgan (2008) reported that first generation college students would often drop a course. The research of this dissertation only emphasized how important good advising is for first generation second year college students.

\section{Partnering with Career Centers}

As noted above, choosing a major is critical for second year students. Since a decision of a major is important, partnerships with career centers are essential for the programming needs of second year students. Stockenberg (2007) stated that colleges and universities having strong partnerships with career centers and second year programs can provide second year students with the tools to make solid decisions about their college major. This current study supported programming initiatives that include career centers and their educated staff members.

\section{Examination and Assessment of Existing Campus Programs}

This study found that a second year student's satisfaction with their second year was a strong indicator of the students' intent to re-enroll. This study also discovered that 
for continuing generation second year college students their involvement on campus provided some evidence for those students' intent to graduate from college. In understanding this information, educators and practitioners must survey their existing programs to make sure they are meeting the needs of their second year students. It can be inferred that programming initiatives lead to satisfaction, as they give second year students an opportunity to be engaged and involved in the campus community. Tobolowsky and Cox (2007) remind institutions that without performing a campus audit of existing programs and services an institution may not be meeting the needs of their students. Stockenberg (2007) calls for an examination and assessment of existing programs so that opportunities for engagement and involvement are met by students.

\section{Recommendations for Future Research}

It is important that researchers continue to study the second year because of the challenges students face and the potential impact those challenges have on college student persistence and attrition. When studying the second year of college, it is important to know the difference between public and private institutions. While Schreiner (2010a) did survey both private and public second year college students, she did not pay particular attention to the differences between those students. Future research on the differences between private and public second year college students would help educators understand the variations in these students' college experiences and how to positively impact those experiences. As noted in Chapter II, the definition for first generation college student differs from institution to institution. The United States Department of Education defines first generation students "... as a student whose parents [neither of which] have [any] postsecondary education" (U.S. Department of Education, 1998, p. 1). 
In some cases,..."first generation students are defined as students whose parents [neither of which] earned a bachelor's degree" (U.S. Department of Education, 1998, p. 1). Variations in the definition for first generation can impact the number of subjects that are placed into the first generation category when data analysis is performed. Future researchers must be aware of the multiple definitions for first generation and take that into consideration when comparing research studies of first generation students. While this study uses a quantitative research approach, other studies of its kind must continue to be performed. Many previous second year college student studies have been qualitative in nature. While the data are rich from those studies, a quantitative approach is also useful. A commitment to surveying second year students will offer institutions a better glance at the lives of these students.

This study found that for continuing generation college students, there was some evidence that the Involvement scale average significantly predicted intent to graduate. Future research must be done to determine what involvement opportunities are provided for second year students and if they are appropriately meeting the needs of those students. Potentially, there could be social barriers that prevent some of the second year students from getting involved. It would also be interesting to know which second year students are getting involved or not getting involved; determining demographic and background information that may impact involvement. Also, since overall satisfaction played a role in predicting a student's intent to re-enroll it becomes imperative for institutions to learn what avenues of the college lead to student satisfaction. Many institutions administer the Student Satisfaction Inventory to their students. A better understanding of the responses 
from second year students on that survey would allow institutions to make changes to their existing operations in hopes of positively impacting a student's experience.

\section{Limitations}

This dissertation only studied second year students at four private institutions in the state of Kentucky. These results will be difficult to generalize to other types of institutions (public, community, for-profit). The data from this study can educate researchers about the second year students at the four private institutions that were studied and can potentially educate researchers about similar populations of second year students at comparable institutions. Self-reported data is another limitation of this study. Dillman (2007) tells us that often times when subjects complete self-reported data they hurry through the survey responses and often spend little time on the answers. This does pose a limitation for this study. Dillman (2007) also suggests that subjects from selfreported data want to provide what they perceive as desirable results. One can assume this too can be a limitation for this study as several of the questions were Likert scale format. Most people can easily identify the socially desirable answers to Likert scale questions.

Since the survey instrument was given out to students during the latter part of the fourth semester of college courses, the sample size was the number of students that completed the survey instrument. McMillian and Schumacher (2001), in their discussion of sample size, suggest that "the general rule in determining sample size is to obtain a sufficient number to provide a credible result" (p. 177). Stevens (2002) tells us that for social science research for each predictor variable there needs to be around 15 subjects in order for the equation to cross-validate producing a reliable regression equation. For this 
study, there were 16 predictor variables therefore around 240 subjects were needed for the equation to cross-validate producing reliable regression equations. There were 242 students who completed the survey however after those students who did not fit the criteria for the study (those students were either part time students, transfer students, or not second year students) there were only 214 subjects used in the analysis of data for the research questions. While this is not the recommended 240 subjects needed, it is fairly close. Stevens (2002) recommends around 15 subjects per variable. The response rate needed to be met the power threshold was $19 \%$. However, with the removal of the subjects that did not fit the criteria of the study, a $17 \%$ response rate was achieved. Since 240 subjects and a power threshold of $19 \%$ were not met, this does pose a limitation for the study and must be noted for readers as they review this research. However, the demographics of the sample size for this study were representative of the overall population for all four institutions studied. Table 1 provides an overview of the population for all four institutions.

For the research questions addressed in this study, there were two dependent variables: intent to re-enroll and intent to graduate. Each was scaled in four steps, ranging from strongly disagree (1) to strongly agree (4). Responses to both of these items were almost all on the agree side of the scale: $95 \%$ of the respondents agreed or strongly agreed they intended to re-enroll and $97 \%$ of the respondents agreed or strongly agreed they intended to graduate. This skewness limited the variability of the dependent variables, making is more difficult to detect relationships with predictors. It might be that the students in the private institutions that were surveyed had relatively strong levels of commitment to both the institution they attended and to the concept of college 
completion. Future researchers who survey students at private colleges and universities might consider using scaling techniques that result in a wider range of responses for intent to re-enroll and intent to graduate. A final limitation for this study pertained to the demographic characteristics of the subjects. The majority of the subjects were female (73.1\%), Caucasian (89.3\%) and continuing generation college students (89.4\%). Understanding these demographics should inform readers that this research is most appropriately generalized to populations similar to those in the study.

\section{Conclusion}

This study examined pre-entry variables that predicted persistence beyond the second year at four private institutions in Kentucky. Data were collected through quantitative analysis of the Sophomore Experiences Survey (SES). Students were surveyed during the end of their fourth semester in college. This study affirms previous research that the persistence and attrition of second year college students is a growing concern for institutions as second year college students experience some of their greatest challenges in college during their second year (Gahagan \& Hunter, 2006; Lemons \& Richmond, 1987; Morgan \& Davis, 1981; Wilder, 1993).

This dissertation explored reasons why second year college students intend to reenroll and/or intend to graduate from college. For first generation college students, there was strong evidence that the number of courses dropped predicted a student's intent to re-enroll. There was some evidence that the Thriving Scale predicted intent to graduate. For continuing generation college students, there was strong evidence that the perception of last year to compared to their second year and the student's overall satisfaction predicted intent to re-enroll. There was also strong evidence that having decided a major 
predicted intent to graduate and some evidence that the scores on the involvement scale predicted intent to graduate. These findings must call institutions to think about their practices, policies and programs. For first generation college students, it seems that strong advisors will play a pivotal role in the life of a these second year college students. Also, the relationship the student has with their faculty members will assist them in their coursework, hopefully leading those students to stay in their courses rather than drop them.

For continuing generation college students, institutions must be concerned with these students' overall satisfaction and these students' involvement outside of the classroom. Increasing the institutions data collection by consistently surveying students to make sure their needs are met will help increase a student's overall satisfaction. Campus audits and reviews of existing programs will help colleges and universities understand if they are offering the right programs for their students that encourage the students to get involved on campus. Overall, this dissertation calls for colleges and universities to continue to study the second year in hope of increasing knowledge about the lives of second year colleges students and how to successfully impact those lives to increase intention for re-enrollment into the third year and intention for graduating from college. 


\section{REFERENCES}

Association of Independent Kentucky College and Universities. (2012). Retrieved on April 11, 2012 from http://www.aikcu.org/data-and-reports/.

Astin, A. W., Korn, W., \& Green, K. (1987). Retaining and satisfying students. Educational Record, 68, 36-42.

Barry, L. M. (2009). Differences in self-reported disclosure of college experiences by first- generation college student status. Adolescence, 44, 55-68.

Baxter Magolda, M. B. (2001). Finding their own way: Narratives for transforming higher education to promote self-authorship. Sterling, VA: Stylus.

Billson, J. M., \& Terry, B. T. (1982). In search of the silken purse: Factors in attrition among first generation students. College and University, 58, 57-75.

Braxton, J. M. (Ed.). (2000). Reworking the student departure puzzle. Nashville, TN: Vanderbilt University Press.

Bui, V. T. K. (2002). First generation college students at a four-year university: Background characteristics, reasons for pursuing higher education, and first year experiences. College Student Journal, 36(1), 3-11.

Caison, A. L. (2005). Determinants of systemic retention: Implications for improving retention practices in higher education. Journal of College Student Retention: Research, Theory \& Practice, 6, 425-441. 
Chen, R., \& DesJardins, S. L. (2008). Exploring the effects of financial aid on the gap of student dropout risks by income level. Research in Higher Education, 49, 1-18.

Choy, S. (2001). Students whose parents did not go to college: Postsecondary access, persistence, and attainment (NCES 2001-126). Washington, DC: U.S.

Department of Education, National Center for Education Statistics.

Collier, P. J., \& Morgan, D. L. (2008). “Is that paper really due today?'”: Differences in first-generation and traditional college students' understandings of faculty expectations. Higher Education, 55, 425-446.

Coleman, J. S. (1988). Social capital in the creation of human capital. The American Journal of Sociology, 94, 95-120.

Daly, B. E., \& Breegle, G. (1989). Retention in higher education: A statewide perspective. Paper presented at the meeting of the Association for Institutional Research, Baltimore, MD.

DesJardins, S. L., Ahlburg, D. A., \& McCall, B. P. (2002). A temporal investigation of factors related to timely degree completion. Journal of Higher Education, 73(5), 555-581.

Diener, E., Emmons, R. A., Larsen, R. J., \& Griffin, S. (1985). The satisfaction with life scale. Journal of Personality Assessment, 49(1), 71-75.

Dillman, D. A. (2007). Mail and internet surveys: The tailored design method ( $2^{\text {nd }}$ ed.). Hobken, NJ: John Wiley \& Sons.

Durkheim, E. (1897/1951). Suicide: A study in sociology. (J. A. Spaulding, \& G. Simpson, Trans.) New York: The Free Press. 
Eggens, L., Van der Werf, M. P. C., \& Bosker, R. J. (2008). The influence of personal networks and social support on study attainment of students in university education. Higher Education, 55, 553-573.

Engle, J., \& Tinto, V. (2008). Moving beyond access: College success for low-income, first generation students. Washington, DC: The Pell Institute for the Study of Opportunity in Higher Education.

Feldman, K. A., \& Newcomb, T. M. (1969). The impact of colleges upon their students. San Francisco: Jossey-Bass.

Flanagan, W., \& Black, R. (1991). Beating the sophomore slump. Recruitment and Retention, 5(11), 1-3.

Fredrickson, B. L. (2002). Positive emotions. In C. R. Snyder \& S. J. Lopez (Eds.), Handbook of positive psychology ( pp. 120-134). New York: Oxford University Press.

Freedman, M. B. (1956). The passage through college. Journal of Social Issues, 12, $13-27$.

Fuertes, J. N., Miville, M. L., Mohr, J. J., Sedlacek, W. E., \& Gretchen, D. (2000). Factor structure and short form of the Miville-Guzman Universality-Diversity Scale. Measurement and Evaluation in Counseling and Development, 33(3), 157-170.

Furr, S., \& Gannaway, L. (1982). Easing the sophomore slump: A student development approach. Journal of College Student Personnel, 23, 340-341.

Gahagan, J., \& Hunter, M. S. (2006). The second year experience: Turning attention to the academy's middle children. About Campus, 17-22. 
Gardner, E. D. (2000). From the drift to engagement: Finding purpose and making career connections in the sophomore year. In L. A. Schreiner \& Pattengale. (Eds.), Visible solutions for invisible students: Helping sophomores succeed. (Monograph 31). (pp. 19-29). Columbia, SC: University of South Carolina, National Resource Center for the First-Year Experience and Students in Transition.

Gohn, L., Swartz, J., \& Donnelly, S. (2001). A case study of second year student persistence. Journal of College Student Retention, 2(4), 271-294.

Graunke, S. S., \& Woosley, S. A. (2005). An exploration of the factors that affect the academic success of college sophomores. College Student Journal, 39, 367-376.

Horn, L. (1998). Stopouts or stayouts? Undergraduates who leave college in their first year (NCES 1999-087). Washington, DC: U.S. Government Printing Office.

Hunter, M. S., Tobolowsky, B. F., \& Gardner, J. N. (2010). Helping sophomores succeed: Understanding and improving the second year experience. San Francisco: Jossey-Bass.

Inkelas, K. K., Daver, Z. E., Vogt, K. E., \& Leonard, J. B. (2007). Living learning programs and first generation college students' academic and social transition to college. Research in Higher Education, 48(4), 403-434.

Janasiewicz, B. A. (1987). Campus leaving behavior. NACADA Journal, 7(2), 23-30.

Jehangir, R. R. (2010a). Higher education and first generation students: Cultivating community, voice, and place for a new minority. Palgrave Macmillan: New York.

Jehangir, R. R. (2010b). Stories as knowledge: Bringing the lived experience of first generation college students into the academy. Urban Education, 45, 533-553. 
Jones, G., \& Dennison, J. D. (1972). A comparative study of persister and non-persister college students. Vancouver City, British Columbia: Vancouver City College.

Juillerat, S. (2000). Assessing the expectations and satisfaction levels of sophomores: How are they unique? In L. A. Schreiner \& J. Pattengale (Eds.).Visible solutions for invisible students: Helping students succeed. (Monograph No. 31). (pp. 1929). Columbia, SC: University of South Carolina, National Resource Center for The First-Year Experience and Students in Transition.

Karp, R., \& Logue, R. (2002). Retention initiative for unscheduled sophomores and unscheduled readmits. Journal of College Student Retention, 4(2), 147-172.

Kentucky Council on Postsecondary Education. (2010). http://cpe.ky.gov/info/retention/. Retrieved on November 1, 2010.

Kentucky Council on Postsecondary Education. (2011). http://dataportal.cpe.ky.gov/enrollment.shtm. Retrieved on November 2, 2011.

Kentucky Council on Postsecondary Education. (2012). http://cpe.ky.gov/info/retention/. Retrieved on February 21, 2012.

Kentucky employment. (2005, March). Economic Trends, 15-16.

Keyes, C. L. M., \& Haidt, J. (Eds.) (2003). Flourishing: Positive psychology and the life well lived. Washington DC: American Psychological Association.

King, L. A., \& Napa, C. K. (1998). What makes a life good? Journal of Personality and Social Psychology, 75, 156-165.

Lemons, L. J., \& Richmond, D. R. (1987, Winter). A developmental perspective of the sophomore slump. NASPA Journal, 24(3), 15-19. 
Lipka, S. (2006, September 8). After the freshman bubble pops. The Chronicle of Higher Education, 53, A34, retrieved September 3, 2011 from www.beloit.edu/syi/assets/freshman_bubble.pdf.

Loeb, R. C., \& Magee, P. M. (1992). Changes in attitudes and self-perceptions during the first two years of college. Journal of College Student Development, 33, 348355.

Lohfink, M., \& Paulsen, H. (2005). Comparing the determinants of persistence for firstgeneration and continuing-generation students. Journal of College Student Development, $46,409-428$.

London, H. B. (1989). Breaking away: A study of first generation college students and their families. The American Journal of Sociology, 97, 144-170.

Longwell-Grice, R., \& Longwell-Grice, H. (2008). Testing Tinto: How do retention theories work for first generation, working-class students? Journal of College Student Retention, 9(4), 407-420.

Lorenzetti, J. P. (2006). Two major steps to addressing the sophomore experience. Recruitment \& Retention in Higher Education, 20(11), 3-8.

Mallette, B. I., \& Cabrera, A. F. (1991). Determinants of withdrawal behavior: An exploratory study. Research in Higher Education, 32(2), 179-194.

Margolis, G. (1976). Unslumping our sophomores: Some clinical observations and strategies. American College Health Association, 25, 133-136.

Masburn, A. J. (2000/2001). A psychological process of college student dropout. Journal of College Student Retention, 2(3), 219-238. 
McMillan, J .H., \& Schumacher, S. (2001). Research in education: A conceptual introduction (5th ed.). New York: Longman.

Measuring up. (2012). Retrieved on March 1, 2012 from www.highereducation.org.

Milem, J. F., \& Berger, J. B. (1997). A modified model of college student persistence: Exploring the relationship between Astin's theory of involvement and Tinto's theory of student departure. Journal of College Student Development, 38, $387-400$.

Morgan, J. D., \& Davis, D. A. (1981). Sophomore students: They are special too. Journal of College Student Personnel, 22, 170-171.

Murtaugh, P. A., Burns, L. D., \& Schuster, J. (1999). Predicting the retention of university students. Research in Higher Education, 40, 355-371.

Nelson, D. D., \& Vetter, D. (2012) Thriving in the first year of college. In L. A. Schreiner, M. C. Louis, \& D. N. Nelson (Eds.), Thriving in transitions. Columbia, SC: University of South Carolina Press.

Newlon, L., \& Gaither, G. (1980). Factors contributing to attrition: An analysis of program impact on persistence patterns. College and University, 55, 237-251.

Noel-Levitz. (2011). The attitudes of second year college students. Retrieved April 20, 2011 from, https://www.noellevitz.com/papers-research-highereducation/2011/attitudes-second year-college-students.

Nunez, A., \& Guccaro-Alamin, S. (1998). First generation students: Undergraduates whose parents never enrolled in postsecondary education (NCES Report 98-082). Washington, DC: U.S. Department of Education, National Center for Education Statistics. 
Nunnally, J. C., \& Bernstein, I. H. (1994). Psychometric theory (3rd ed.). New York: McGraw-Hill.

Pantages, T. J. \& Creedon, C. F. (1978). Studies of college attrition: 1950-1975. Review ofEdcuational Research, 48, 49-101..

Parades-Collins, K. (2012). Thriving in students of color on predominately White campuses: A divergent path? In L. A. Schreiner, M. C. Louis, \& D. N. Nelson (Eds.), Thriving in transitions. Columbia, SC: University of South Carolina Press.

Pascarella, E. T. (1985). The influence of on campus living versus commuting to college on intellectual and interpersonal self-concept. Journal of College Student Personnel, 26(4), 292-299.

Pascarella, E. T., et al. (1996). What have we learned from the first year of the national study of student learning? Journal of College Student Development, 37, 182-192.

Pascarella, E. T., Pierson, C. T., Wolniak, G. C., \& Terenzini, P. T. (2004). First generation college students: Additional evidence on college experiences and outcomes. The Journal of Higher Education, 75(3): 249-284.

Pascarella, E. T., \& Terenzini, P. T. (2005). How college affects students, Vol. 2. A third decade of research. San Francisco: Jossey-Bass.

Pattengale, J., \& Schreiner, L. A. (2000). What is the sophomore slump and why should we care? In L. A. Schreiner \& J. Pattengale. (Eds.), Visible solutions for invisible students: Helping sophomores succeed (Monograph 31). Columbia, SC:

University of South Carolina, National Resource Center for the First-Year Experience and Students in Transition. 
Peltier, G. L., Laden, R., \& Matranga, M. (1999). Student persistence in college: A review of research. Journal of College Student Retention, 1, 357-375.

Perry, W. G., Jr. (1970). Forms of intellectual and ethical development in the college years: A scheme. New York: Holt, Rinehart, and Winston.

Peterson, C. (2006). A primer in positive psychology. Oxford, UK: Oxford University Press.

Peterson, S. L. \& delMas, R.C. (1996, April). Effects of career decision-making selfefficacy on the retention of underprepared adults: A path analytic study of student persistence. Paper presented at the Annual Meeting of the American Educational Research Association, New York, NY.

Pintrich, P. R., Smith, D., A. F., Garcia, T., \& McKeachie, W. J (1993). Reliability and predictive validity of the Motivated Strategies for Learning Questionnaire (MSLQ). Educational and Psychological Measurement, 53, 801-813.

Pike, G. R., \& Kuh, G. D. (2005). First- and second-generation college students: A comparison of their engagement and intellectual development. Journal of Higher Education, 76: 276-300.

Pope, W. (1976). Durkheim's suicide: A classic analyzed. University of Chicago Press: Chicago, IL.

Purswell, K. E., Yazedjian, A., \& Toews, M. L. (2008). Students' intentions and social support as predictors of self-reported academic behaviors: A comparison of firstand continuing-generation college students. Journal of College Student Retention: Research, Theory and Practice, 10(2), 191-206. 
Reason, R. D. (2003). Student variables that predict retention: Recent research and new developments. NASPA Journal, 40, 172-191.

Reason, R. D. (2004). Using an ACT-based merit-index to predict between-year retention. Journal of College Student Retention, 5(1), 71-87.

Rendon, R. (1996). Life on the border. About Campus, 1(5), 14-20.

Richardson, R. C., \& Skinner, E. F. (1992). Helping first generation minority students achieve degrees. In L. S. Zwerling \& H. B. London (Eds.), First generation students: Confronting the cultural issues (New Directions for Community Colleges Series, No.80, pp. 29-43). San Francisco: Jossey-Bass.

Richmond, D. R., \& Lemons, L. J. (1985). Sophomore slump: An individual approach to recognition and response. Journal of College Student Personnel, 26, 176-177.

Riehl, R. J. (1994). The academic preparation, aspirations, and first-year performance of first generation students. College and University, 70(1), 14-19.

Rodriguez, R. (1982). Hunger of memory: The education of Richard Rodriguez-An autobiography. Boston: Godine.

Rootman, I. (1972). Voluntary withdrawal from a total adult socializing organization: A model. Sociology of Education, 45, 258-270.

Ryff, C. D., \& Keyes, C. L. M. (1995). The structure of psychological well-being revisited. Journal of Personality \& Social Psychology, 69(4), 719-727.

Sanchez-Leguelinel, C. (2008). Supporting 'slumping' sophomores: Programmatic peer initiatives designed to enhance retention in the crucial second year of college. College Student Journal, 42(2), 637-646. 
Sandler, M. E. (1998, April). Career decision-making self-efficacy and an integrated model of student persistence. Paper presented at the Annual Meeting of the American Educational Research Association, San Diego, CA.

Schaller, M. A. (2005). Wandering and wondering: Traversing the uneven terrain of the second college year. About Campus, 10(3), 17-24.

Scheier, M. F., Carver, C. S., \& Bridges, M. W. (1994). Distinguishing optimism from neuroticism (and trait anxiety, self-mastery, and self-esteem): A reevaluation of the Life Orientation Test. Journal of Personality and Social Psychology, 67, 1063-1078.

Schreiner, L. A. (2010a). Factors that contribute to sophomore success and satisfaction. In M. S. Hunter, B.F. Tobolowsky, \& J. N. Gardner (Eds.), Helping sophomores succeed: Understanding and improving the second year experience. San Francisco: Jossey-Bass.

Schreiner, L. A. (2010b). The thriving quotient: A new vision for student success. About Campus, 15(2), 2-10.

Schreiner, L. A. (2012). From surviving to thriving during transitions. In L. A. Schreiner, M. C. Louis, \& D. N. Nelson (Eds.), Thriving in transitions. Columbia, SC: University of South Carolina Press.

Schreiner, L. A., Edens, D., \& McIntosh, E. J. (2011). The Thriving Quotient: A new vision for student success. Presentation at NASPA, Philadelphia, PA.

Schreiner, L. A., \& Louis, M. C. (2011). The Engaged Learning Index: Implications for faculty development. Journal on Excellence in College Teaching, 22(1), 5-28. 
Schreiner, L. A., \& Pattengale, J. (Eds.). (2000). Visible solutions for invisible students: Helping sophomores succeed (Monograph 31). Columbia, SC: University of South Carolina, National Resource Center for The First-Year Experience and Students in Transition.

Schreiner, L. A., Slavin Miller, S., Pullins, T., \& Seppelt, T. (2012). Beyond sophomore survival. In L. A. Schreiner, M. C. Louis, \& D. N. Nelson (Eds.), Thriving in transitions. Columbia, SC: University of South Carolina Press.

Schuh, J. H., Triponey, V. L., Heim, L. L., \& Nishimura, K. (1992). Student invovlement in historically Black Greek letter organization. NASPA Journal, 29(4), 274-281.

Spady, W. G. (1970a). Lament for the letterman: The effects of peer status and activities on goals and attainments. American Journal of Sociology, 75, 680-702.

Spady, W. G. (1970b). Dropouts from higher education: An interdisciplinary review and synthesis. Interchange, $1(1), 64-85$.

Seligman, M. E. P. (2002). Authentic happiness: Using the new positive psychology to realize your potential for lasting fulfillment. New York, NY: Free Press.

Sriram, R., \& Vetter, D. (2012) Thriving in high-risk students. In L. A. Schreiner, M. C. Louis, \& D. N. Nelson (Eds.), Thriving in transitions. Columbia, SC: University of South Carolina Press.

Stevens, J. P. (2002). Applied multivariate statistics for the social sciences. ( $\left.4^{\text {th }} \mathrm{ed}.\right)$. Mahwah, New Jersey: Lawrence Erlbaum Associates.

Stieha, V. (2010). Expectations and experiences: The voice of a first generation, first-year college student and the question of student persistence. International Journal of Qualitative Studies in Education, 23, 237-249. 
Stockenberg, J. (2007). The "sophomore jump" program at Colorado College. In B. G. Tobolowsky \& B. E. Cox (Eds.), Shedding light on sophomores: An exploration of the second college year (Monograph No. 47) (pp. 63-74). Columbia, SC: University of South Carolina, National Resource Center for The First-Year Experience ${ }^{\circledR}$ and Students in Transition.

Tabachnick, B.G., \& Fidell, L.S. (2007). Using multivariate statistics (5th ed.). New York: Allyn and Bacon.

Terenzini, P. T., Rendon, L. I., Upcraft, M. L., Millar, S. B., Allison, K. A., Gregg, P. L., \& Jalomo, R. (1994). The transition to college: Diverse students, diverse stories. Research in Higher Education, 35, 57-73.

Terenzini, P. T., Springer, L., Yaeger, P. M., Pascarella, E. T., \& Nora, A. (1996). Firstgeneration college students: Characteristics, experiences and cognitive development. Research in Higher Education, 37, 1-22.

Terenzini, P. T., \& Wright, T. M. (1987). Students' personal growth during the first two years of college. The Review of Higher Education, 10(3), 259-271.

Thayer, P. B. (2000). Retention of students from first generation and low income backgrounds. Opportunity Outlook, 2-8.

The condition of education. (2012). Retrieved on April 11, 2012 from http://nces.ed.gov/pubs2012/2012045.pdf.

Tinto, V. (1975). Dropout from college: A theoretical synthesis of recent research. Review of Educational Research, 45(1), 89-125.

Tinto, V. (1982). Limits of theory and practice in student attrition. The Journal Higher Education, 6, 687-700. 
Tinto, V. (1988). Stages of student departure: Reflections on the longitudinal character of student leaving. Journal of Higher Education, 59, 438-455.

Tinto, V. (1993). Leaving college: Rethinking the causes and cures of student leaving ( $2^{\text {nd }}$ ed.). Chicago: The University of Chicago Press.

Tinto, V. (1999). Taking retention seriously: Rethinking the first year of college. NACADA Journal, 19, 5-9.

Tinto, V. (2006). Research and practice of student retention: What's next? Journal of College Student Retention: Research, Theory, and Practice, 8, 1-19.

Tobolowsky B. F., \& Cox, B. E. (Eds.). (2007). Shedding light on sophomores: A exploration of the second college year (monograph No. 47). Columbia, SC: University of South Carolina, National Resource Center for The First-Year Experience ${ }^{\circledR}$ and Students in Transition.

Tross, S. A., Harper, J. P., Osher, L. W., \& Kneidinger, L. M. (2000). Not just the usual cast of characteristics: Using personality to predict college performance and retention. Journal of College Student Development, 41, 323-334.

Tyree, T. M. (1998). Designing an instrument to measure the socially responsible leadership using the social change model of leadership development. Dissertation Abstracts International, 59 (06), 1945. (UMI No. 9836493).

United States Department of Education, National Center for Education Statistics. (1998). First-generation students: Undergraduates whose parents never enrolled in postsecondary education (NCES 98-082). Retrieved from http://www.atu.edu/ir/docs/retention-info/retentionother/First_Gen_College_Students_98082.pdf. 
University of Louisville Sustainability. (2012). Retrieved on March 1, 2012 from http://louisville.edu/sustainability/finance-outreach/diversity-affordability.html.

Wells, R. S. (2008). Social and cultural capital, race and ethnicity, and college student retention Journal of College Student Retention: Research, Theory and Practice, $10(2), 103-128$.

Whalen, D., Saunders, K., \& Shelley, M. (2009). Leveraging what we know to enhance short-term and long-term retention of university students. Journal of College Student Retention: Research, Theory and Practice, 11(3), 407-430.

Wilder, J. S. (1993). The sophomore slump: A complex developmental period that contributes to attrition. College Student Affairs Joumal, 12(2), 18-27.

Winslow, R. (2006). Sophomore program begins where first-year program ends. Recruitment and Retention in Higher Education, 20(7), 3-4.

Woosley, S. (2003/2004). Stop-out or drop-out? An examination of college withdrawals and re-enrollments. Journal of College Student Retention, 5, 293-303.

Zeitlin-Ophir, I., Melitz, O., Miller, R., Podoshin, P., \& Mesh, G. (2004). Variables affecting the academic and social integration of nursing students. Journal of Nursing Education, 43(7), 326-329. 


\section{Appendix A}

Thriving Quotient (Five-Factor Model)

Schreiner, Edens, \& McIntosh (2011)

\section{Engage Learning Index}

Engaged Learning Index. (Schreiner \& Louis, 2011).

1. I feel as though I am learning things in my classes that are worthwhile to me as a person.

2. I can usually find ways of applying what I'm learning in class to something else in my life.

3. I find myself thinking about what I'm learning in class even when I'm not in class.

4. I feel energized by the ideas I'm learning in most of my classes.

5. I am bored in class a lot of the time.

\section{Academic Determination}

Self-Regulation. (Pintrich, Smith, Garcia, \& McKeachie, 1993).

6. When I become confused about something I'm reading for class, I go back and try to figure it out.

Academic Hope Scale. (Lopez, unpublished as cited in L. A. Schreiner, personal communication, April 26, 2011).

7. I actively pursue my educational goals.

8. I am motivated to do well in school.

Effort Regulation. (Ryff \& Keyes, 1995).

9. Even when course materials are dull and boring, I manage to keep working until I finish.

Environmental Mastery. (Ryff \& Keyes, 1995).

10. I am good at managing the many responsibilities of my daily life.

11. I am good at managing my time so that I can fit everything in that needs to be done. 


\section{Social Connectedness}

Positive Relations. (Ryff \& Keyes, 1995).

12. Other people seem to have more friends than I do.

13. I often feel lonely because I have few close friends with whom to share my concerns.

14. I don't have many people who want to listen when I need to talk.

\section{Diverse Citizenship}

Citizenship Scale. (Tyree, 1998).

15. I give time to making a difference for someone else.

16. I have the power to make a difference in my community.

17. I value opportunities that allow me to contribute to my community.

18. I am willing to act for the rights of others.

Diversity. (Fuertes, et al., 2000).

19. Knowing how a person differs from me greatly enhances our friendship.

20. I can best understand someone after I get to know how he/she is both similar and different from me.

\section{Positive Perspective}

Optimism. (Scheier, Carver, \& Bridges, 1994).

21 . When things are uncertain for me, I usually expect the best.

22. I always look on the bright side of things.

23. I'm optimistic about what will happen to me in the future.

Subjective Well-Being. (Diener et al, 1985).

24. I am satisfied with my life.

25. The conditions of my life are excellent. 


\section{Appendix B}

\section{SOPHOMORE EXPERIENCES SURVEY}

In order to better understand the experiences of students in their second year of college, we would like for you to please respond to each of the sections below. No individual identifying information is requested of you and all responses will be grouped with other students before being reported. Thank you for taking the time to complete the survey - it should only take you 15-20 minutes or so.

Is this your second year attending college? Yes

No

How many college credits/units do you have, including this semester's courses?

How many credits are you taking this semester?

Did you transfer to this institution from another college? Yes __ No

Think about the classes you are taking RIGHT NOW - this semester - as you answer the following questions.

Please rate your agreement with each of the items by using a 1 to 6 scale, with 1 indicating "strongly disagree" and 6 indicating "strongly agree."

I feel as though I am learning things in my classes that are worthwhile to me as a person.

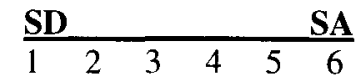

I can usually find ways of applying what I'm learning in class to $\begin{array}{llllll}1 & 2 & 3 & 4 & 5 & 6\end{array}$

something else in my life.

I find myself thinking about what I'm learning in class $\ldots \begin{array}{llllll} & 1 & 3 & 4 & 5 & 6\end{array}$

even when I'm not in class.

I feel energized by the ideas that I am learning in most of $\quad 1 \quad 2 \quad 3 \quad 4 \quad 5 \quad 6$

my classes.

I am bored in class a lot of the time. $\quad \begin{array}{llllll}1 & 2 & 3 & 4 & 5 & 6\end{array}$

When I become confused about something I'm reading $\quad \begin{array}{lllllll}1 & 3 & 4 & 5 & 6\end{array}$

for class, I go back and try to figure it out.

I actively pursue my educational goals.

I am motivated to do well in school.

Even when course materials are dull and boring,

I manage to keep working until I finish.

I am good at managing the many responsibilities of my daily life.

I am good at managing my time so that I can fit

everything in that needs to be done.

Other people seem to have more friends than I do.

I often feel lonely because I have few close friends with whom to share my concerns.

I don't have many people who want to listen when I need to talk.

I give time to making a difference for someone else.

$\begin{array}{llllll}1 & 2 & 3 & 4 & 5 & 6\end{array}$

$\begin{array}{llllll}1 & 2 & 3 & 4 & 5 & 6\end{array}$

$\begin{array}{llllll}1 & 2 & 3 & 4 & 5 & 6\end{array}$

$\begin{array}{llllll}1 & 2 & 3 & 4 & 5 & 6\end{array}$

$\begin{array}{llllll}1 & 2 & 3 & 4 & 5 & 6\end{array}$

$\begin{array}{llllll}1 & 2 & 3 & 4 & 5 & 6\end{array}$

$\begin{array}{llllll}1 & 2 & 3 & 4 & 5 & 6\end{array}$

$\begin{array}{llllll}1 & 2 & 3 & 4 & 5 & 6\end{array}$

$\begin{array}{llllll}1 & 2 & 3 & 4 & 5 & 6\end{array}$ 
I have the power to make a difference in my community.

I value opportunities that allow me to contribute to my community.

I am willing to act for the rights of others.

Knowing how a person differs from me greatly enhances our friendship.

I can best understand someone after I get to know

how he/she is both similar and different from me.

When things are uncertain for me, I usually expect the best.

I always look on the bright side of things.

I'm optimistic about what will happen to me in the future.

I am satisfied with my life.

The conditions of my life right now are excellent.

$\begin{array}{llllll}1 & 2 & 3 & 4 & 5 & 6 \\ 1 & 2 & 3 & 4 & 5 & 6 \\ 1 & 2 & 3 & 4 & 5 & 6 \\ 1 & 2 & 3 & 4 & 5 & 6 \\ 1 & 2 & 3 & 4 & 5 & 6 \\ & & & & & \\ 1 & 2 & 3 & 4 & 5 & 6 \\ 1 & 2 & 3 & 4 & 5 & 6 \\ 1 & 2 & 3 & 4 & 5 & 6 \\ & & & & & \\ 1 & 2 & 3 & 4 & 5 & 6 \\ 1 & 2 & 3 & 4 & 5 & 6\end{array}$

Please respond to the following questions about activities on campus. How involved are you in any of the following THIS YEAR?

Student organizations on campus

Fraternity or Sorority

Music or theatre performance groups on campus

Community Service

Campus events and activities

Student government

Peer mentoring or leadership programs

Religious activities

\begin{tabular}{cccccc}
$\begin{array}{c}\text { Not at all } \\
\text { Involved }\end{array}$ & \multicolumn{3}{c}{$\begin{array}{c}\text { Very } \\
\text { Involved }\end{array}$} \\
\hline $\mathbf{1}$ & 2 & $\mathbf{3}$ & 4 & 5 & 6 \\
1 & 2 & 3 & 4 & 5 & 6 \\
1 & 2 & 3 & 4 & 5 & 6 \\
1 & 2 & 3 & 4 & 5 & 6 \\
1 & 2 & 3 & 4 & 5 & 6 \\
1 & 2 & 3 & 4 & 5 & 6 \\
1 & 2 & 3 & 4 & 5 & 6 \\
1 & 2 & 3 & 4 & 5 & 6
\end{tabular}

\section{How often have you engaged in each of the following THIS YEAR?}

Met with a professor during office hours.

Discussed career plans or goals with a professor.

Met informally or socially with a faculty member outside of class or office hours.

Discussed academic iśsues with a faculty member outside of class or office hours.

Met with your academic advisor.

Attended any programs geared specifically to sophomores.

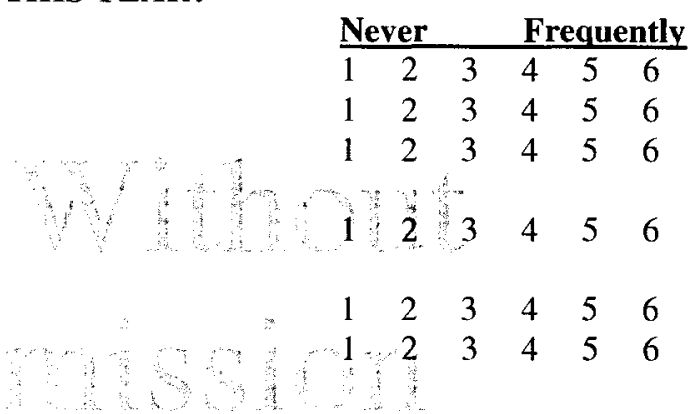

Rate your satisfaction with each of the following aspects of your college experience THIS YEAR using a 1 to 6 scale, with 1 indicating "very dissatisfied" and 6 indicating "very satisfied".

The amount you are learning in college.

\begin{tabular}{cccccc} 
VD & & & & & VS \\
\hline 1 & 2 & 3 & 4 & 5 & 6 \\
1 & 2 & 3 & 4 & 5 & 6 \\
1 & 2 & 3 & 4 & 5 & 6 \\
1 & 2 & 3 & 4 & 5 & 6 \\
1 & 2 & 3 & 4 & 5 & 6 \\
1 & 2 & 3 & 4 & 5 & 6 \\
1 & 2 & 3 & 4 & 5 & 6 \\
1 & 2 & 3 & 4 & 5 & 6 \\
1 & 2 & 3 & 4 & 5 & 6
\end{tabular}




\section{Please tell us a little about yourself.}

Highest level of education achieved by at least one parent

Elementary school or less

Some high school/secondary school but did not graduate

GED

Completed high school/secondary school

Some college but no degree

Associate degree

Bachelor's degree (4-5 year degree)

Master's degree or equivalent

First-professional degree

Other advanced professional degree

Doctorate (Ph.D., Ed.D.)

What is your sex? Female _ _ Male __ Other

What is your age?

Enrollment Status: Full-time _ Part-time _

Please respond to the following question on your intention for re-enrollment next year from "strongly disagree" to "strongly agree."

I intend to re-enroll next year at the institution I am currently attending. \begin{tabular}{rlrr} 
SD & SA \\
\hline
\end{tabular}

Please respond to the following question on your intention for graduating from college from "strongly disagree" to "strongly agree."

I intend to graduate from college and obtain my bachelor's degree. \begin{tabular}{llllr} 
SD & & & SA \\
\cline { 3 - 4 } & & 2 & 3 & 4
\end{tabular}

What is the highest degree you see yourself obtaining at some point in your life?

Bachelor's Degree

Teaching Credential

Master's Degree

Doctorate

Medical or Law Degree

Other (Please specify)

How would you describe your grades in your firșt year of college?

Mostly A's

$A$ 's and B's

Mostly B's

$B$ 's and C's'

Mostly C's

C's and D's

D's and F's

How would you describe your grades THIS YEAR?

Mostly A's

A's and B's

Mostly B's

B's and C's

Mostly C's

C's and D's

D's and F's 
When you chose to attend this institution, was it your first choice? Yes _

Where do you live?

_ On Campus _ Off Campus

Are you a student athlete? Yes _ $\quad$ No

What is your race/ethnicity? (All that apply)

African-American/Black
American Indian/Alaskan Native
Asian-American/Asian
Native Hawaiian/Pacific Islander
Caucasian/White
Mexican-American/Chicano
Puerto Rican
Other Latino
Multiracial
Other (Please specify)

How many hours per week do you work OFF campus?

None

5 or less

6-10 hours

11-15 hours

16-20 hours

$21-25$ hours

26-30 hours

More than 30 hours

How many hours per week do you work ON campus?

None

5 or less

6-10 hours
$11-15$ hours

16-20 hours

21-25 hours

26-30 hours

More than 30 hours

What is your major? (Leave blank if you have not declared a major yet)

How sure are you of your major?

Very Unsure

Unsure

Somewhat sure

Sure

Very Sure

How many courses have you dropped or withdrawn from since beginning college? (count all courses at your current institution)

None

One

$2-3$

$4-5$

6 or more 
In how many courses have you received a grade below $\mathrm{C}$ since beginning college at your current institution?

None

One

2-3

4-5

6 or more

Compared to your first year of college, my experiences this year has been:

Much Worse

Worse

About the Same

Better

Much Better

Compared to the courses you took in your first year of college, have your courses this year been:

Much Worse

Worse

About the Same

Better

Much Better

Please add anything else you think is important for us to know about your experiences in your second year of college. For instance, if there was one thing you could change about this year, what would it be or what are the best or worse things about this year?

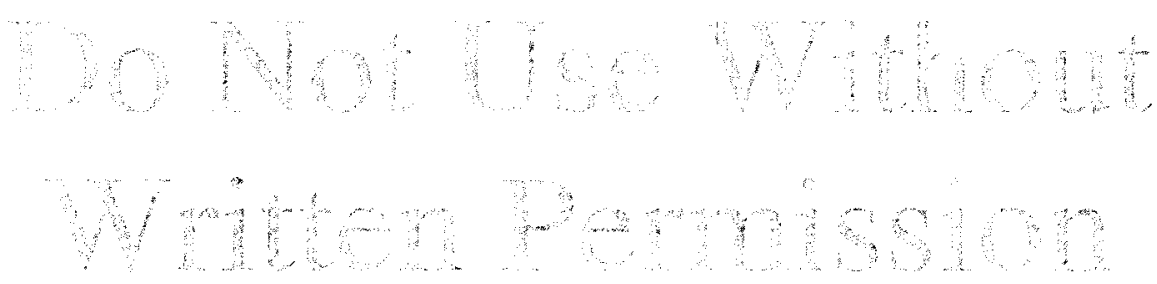

Please enter the institution you attend

Please enter your student ID below, so that this research project can track your enrollment and GPA to help us better understand the elements of student success at this college or university. Your ID will never be released to anyone other than the researchers involved in the project and the university office that holds the GPA and enrollment data.

Thank you for taking the time to give us your perspective. When combined with the responses of other students from around the state, they will provide important feedback to colleges and universities about how to meet the needs of students in the second year of college. Thank you! 


\section{CURRICULUM VITAE}

\section{ANGELA B. TAYLOR}

130 Hawthorne Drive

Georgetown, KY 40324
Office \& Fax: (502) 863-8368

angela_taylor@georgetowncollege.edu

\section{EDUCATION}

Ph.D., Counseling and Personnel Services

Concentration: College Student Personnel

Graduation: December 2012

University of Louisville, Louisville, KY

M.Ed., Counseling and Personnel Services

Concentration: College Student Personnel

May 2006

University of Louisville, Louisville, KY

B.A., Communication Arts \& Psychology

Georgetown College, Georgetown, KY

May 2003

\section{EMPLOYMENT}

Associate Dean of Students

July 2011 - Present

Director of Greek Life \& Student Accountability

Georgetown College

Responsible for the areas of Greek Life, student accountability, new student orientation, family association, family weekend, outstanding student leader recognition celebration, higher education seminar, and the commuter student club. Oversee the Graves Center for Calling and Career while supervising the Director of the Center. Serve as a resource to departments outside of student life through committee involvements and ongoing institutional projects. Supervise the Executive Director of the Global Scholars Program. Oversee the Area Coordinator for Student Accountability.

\section{Director of Greek Life \& Judicial Affairs}

January 2010 - June 2011 Georgetown College

Provide leadership to the division of student life. Responsible for the areas of Greek life, judicial affairs, new student orientation, family association, family weekend, outstanding student leader recognition celebration, higher education seminar, and commuter student club. Created opportunities for collaboration among members in the department while communicating effective with professionals outside of the student life office. 
Ass't. Dir. of Student Activities \& Greek Affairs July 2008 - December 2009 Georgetown College

Responsible for the student life areas of student activities, new student orientation, Greek affairs, campus judicial board, family association, family weekend, outstanding student leader recognition celebration, and the higher education seminar. Supervised the Area Coordinator for Student Activities. Served as the first advisor to the newly created Georgetown Activities Council and assisted with the development of that organization.

Area Coordinator for Greek Life

July 2006 - June 2008

Georgetown College

Responsible for Greek affairs on campus including advising Panhellenic Council, InterFraternity Council, coordinated Greek life programs, and created the Greek Athletic Spirit committee. Served as a committee member on the Regional Conference Planning Committee for the Southeastern Panhellenic Association. Mentored 4 student resident directors and worked directly with 7 resident assistants.

\section{Graduate Assistant, Housing and Residence Life July 2004 - June 2006 Resident Director University of Louisville}

Established and developed community through regular interactions with residents, organized programming efforts, and established recognition efforts of outstanding members of the residence hall community. Enhanced skills of working with a diverse residence hall student population of approximately 220 students including first year students, Greek students, and upperclassmen in five residence halls.

\section{Leadership Consultant}

Alpha Gamma Delta International Fraternity

July 2003 - June 2004

Observed the internal workings of 25 collegiate chapters and provided complete evaluations to Volunteer Service Team members, International Headquarters, and university officials. Met with individual collegiate chapter officers to determine chapter's strengths and areas of improvements while providing guidance and assistance in helping to create a financially responsible, organized, and bonded Alpha Gamma Delta collegiate chapter.

\section{INTERNSHIPS}

Graduate Intern, Academic Enhancement Office $\quad$ May 2008 - June 2009 Georgetown College

Researched diversity programs throughout various benchmark institutions. Reviewed over 80 institutions for information regarding recent programs and initiatives in relationship to their endowment and fundraising efforts. Compiled information regarding first-year common reading programs and assisted with collaborative efforts to enhance the first year experience at Georgetown College. 
Graduate Intern, Student Activities

Aug. 2005 - December 2005

Bellarmine University

Created and implemented a signature Bellarmine University program called

"Louisville Connections." Assessed first- year student involvement at Bellarmine University through the use of an assessment survey and questionnaire. Presented at various Student Affairs Division meetings.

Graduate Intern, Student Activities Office Bellarmine University

May 2005 - August 2005

Organized, coordinated, and enhanced an existing all-campus involvement program at Bellarmine University called "Knightfest." Created and customized Knightfest 2005 posters and flyers to publicize events. Designed a new portion of Knightfest 2005 called "Knightfest KnightPasses." Initiated and composed a student information section on the Student Government Association website called the "Weekend Spotlight."

\section{PRESENTATIONS}

Taylor, A., Brown, M., \& Farley, J. Students' Use of Social Media (Roundtable). Invited co-presenter, College Personnel Association of Kentucky, November 2012, Frankfort, KY.

Taylor, A. Ethical Leadership. Invited presenter, Georgetown College Leadership Course, October, 2011, Georgetown, KY.

Taylor, A. Judicial Affairs Presentation. Invited presenter, University of Kentucky Legal Issues Course, February 2011, Lexington, KY.

Taylor, A. Working in Greek Affairs. Invited panelist, Phi Kappa Tau Volunteer Development Institute, November 2010, Lexington, KY.

Taylor, A. Student Development Theory. Invited presenter, Rising Stars Program, October 2012, Georgetown, KY.

Taylor, A. First Generation College Students and the Sophomore Orientation Program. Invited presenter, Georgetown College Board of Trustees Meeting, April 2010, Georgetown KY.

Taylor, A., \& Mardis, M. ACPA \& NAPSA: Exploring a Common Voice. Invited copresenter, College Personnel Association of Kentucky Annual Conference, March 2010, Louisville, KY.

Taylor, A. The Secrets to GREAT Recruiting. Invited presenter, Pi Kappa Alpha Chapter Meeting, October 2010, Georgetown, KY.

Taylor, A. How to be a GREAT Recruiter. Invited presenter, Phi Mu Chapter Meeting, October 2010, Georgetown, KY. 
Taylor, A. How to Manage Your Time. Invited presenter, Academic Success Series, September 2009, Georgetown, KY.

Taylor, A. Student Personality Types: Extrovert vs. Introvert. Invited presenter, Alpha Gamma Delta Chapter Meeting, April 2009, Georgetown, KY.

Taylor, A. Preparation for Finals. Invited presenter, Academic Success Series, September 2009, Georgetown, KY.

Taylor, A., \& Banter, J. Georgetown College Policies. Invited co-presenter, Residence Life Training, August 2007, Georgetown, KY.

Taylor, A., \& Banter, J. Residence Life Expectations. Invited co-presenter, Residence Life Training, August 2007, Georgetown, KY.

Taylor, A. Goal Setting and Organization. Invited presenter, Academic Success Series, September 2007, Georgetown, KY.

Taylor, A. Stress Management 101. Invited presenter, Harper Gatton Leadership Program, March 2007, Georgetown, KY.

Taylor, A. Risk Management 101. Invited presenter, Phi Kappa Tau Chapter Meeting, November 2006, Georgetown, KY.

Taylor, A. Myths and Facts about Hazing. Invited presenter, Phi Mu Chapter Meeting, October 2006, Georgetown, KY.

Taylor, A. A Guide to Greek Life at Georgetown College. Invited presenter, Residence Life Training, August 2006, Georgetown, KY.

Taylor, A. Facebook. Invited co-presenter, Residence Life Training, August 2006, Georgetown College.

Taylor, A. Stress Management-How to Deal. Invited presenter, Apartment Manager Training, May 2006, Louisville, KY.

Taylor, A., \& Knox, M. Establishing Expectations for Campus Life through Frontloading. Invited co-presenter, College Personnel Association of Kentucky Annual Conference, March 2006, Lexington, KY.

Taylor, A. Program Planning 101. Invited co-presenter, Residence Life Training, January 2006, Louisville, KY.

Taylor, A. Something of Value. Invited facilitator, Miami University Conference, October 2005, Miami, OH. 
Taylor, A. Program Planning 101. Invited presenter, Leadership Bellarmine, September 2005, Louisville, KY.

Taylor, A., \& Hardaway, K. Case Study Competition. Co-presenter, College Personnel Association of Kentucky, March 2005, Louisville, KY.

Taylor, A. Online Case Student Competition, Co-Developer, Student Affairs.com., March 2005.

\section{PROFESSIONAL MEMBERSHIPS}

Association of Fraternity and Sorority Advisors

ACPA, College Student Educators International

College Personnel Association of Kentucky

Southeastern Association of Housing Officers

Graduate Association for Professionals in Student Affairs
September 2006 - Present

August 2005 - Present

January 2005 - Present

January 2007 - July 2008

January 2005 - May 2006

PROFESSIONAL DEVELOPMENT AND INVOLVEMENT

\section{ACPA, College Student Educators International}

- Local Arrangements Chair, ACPA Conference October 2010 - March 2012

\section{College Personnel Association of Kentucky}

- Past President

- President

- President-Elect

- Membership Coordinator

- Member-at-Large for Public Institutions
March 2011 - Nov. 2012

March 2010 - March 2011

March 2009 - March 2010

March 2007 - March 2009

March 2005 - March 2006

\section{Graduate Association for Professionals in Student Affairs}

- Co-Dir. for Programming, University of Louisville May 2005 - May 2006

\section{Alpha Gamma Delta International Fraternity}

- Special Development Coordinator

August 2005 - June 2006 Alpha Gamma Delta Chapter at Miami University

\section{LEADERSHIP}

Institutional Effectiveness Committee, Georgetown College

Marching Band Committee, Georgetown College

Freshmen Seminar Instructor, Georgetown College

Hiring Committee Chair, Georgetown College

Family Campaign Committee, Georgetown College

SCAN Committee, Georgetown College

Senior Leadership Academy, Council of Independent Colleges

Christian Identity Taskforce, Georgetown College

Student Life Flight Team, Georgetown College

President's Creative Team, Georgetown College

Retention Taskforce, Georgetown College
Spring 2012

Fall 2011

Fall 2011

Spring 2011 - Sum. 2011

Spring 2011 - Sum. 2011

Spring 2011 - Sum. 2011

Fall 2010 - Sum. 2011

Spring 2010 - Fall 2011

Spring 2010 - Sum. 2011

Summer 2009

Fall 2007 - Spring 2008 
CSP Orientation Committee, University of Louisville CSP Assessment Committee, University of Louisville RD Selection Committee, University of Louisville HRL Check-in/out Committee, University of Louisville
Fall 2005 - Spring 2006

Fall 2005 - Spring 2006

Spring 2005

Spring 2005

AWARDS \& HONORS

2011 Top Tiger Supporter Award

Graduate Dean's Citation

Outstanding Student in College Student Personnel

National Residence Hall Honorary Advisor of the Year

CPAK Outstanding Graduate Student

University of Louisville Hall Advisor of the Month

KAHO Outstanding Graduate Student

Outstanding Student Leader of the Year

Outstanding Senior in Communication Arts

Resident Assistant of the Year

Sorority Woman of the Year
May 2011

May 2006

May 2006

April 2006

March 2006

November 2005

October 2005

April 2003

April 2003

April 2003

March 2003

\section{COMMUNITY INVOLVEMENT}

\section{Scott County Salvation Army}

- Chairperson

July 2009 - Present

- City of Georgetown, KY received a $\$ 500,000$ grant that was used to renovate a new facility for the Scott County Salvation Army.

Fall 2010-met with several perspective donors for the Salvation Army campaign to assist in these renovation initiatives.

- Secretary

August 2006 - July 2009

\section{REFERENCES}

Available upon request. 